Universidade de São Paulo

Instituto de Astronomia, Geofísica e Ciências Atmosféricas

Departamento de Geofísica

Rafael Monteiro da Silva

Modelagem numérica do padrão de esforços na litosfera e implicações na formação do Rifte Continental do Sudeste do Brasil

São Paulo 



\section{Modelagem numérica do padrão de esforços na litosfera e implicações na formação do Rifte Continental do Sudeste do Brasil}

Dissertação apresentada ao Departamento de

Geofísica do Instituto de Astronomia, Geofísica e Ciências Atmosféricas da Universidade de São Paulo como requisito parcial para a obtenção do título de Mestre em Ciências.

Versão Corrigida. O original encontra-se disponível na Unidade.

Área de Concentração: Geofísica

Orientador: Prof. Dr. Victor Sacek

São Paulo 



\section{Agradecimentos}

Gostaria de agradecer ao Prof. Dr. Victor Sacek pela orientação, atenção e dedicação que me ofereceu durante esse projeto.

Aos meus pais, Alexandre e Vera Lúcia, que apesar da distância, não deixaram de me apoiar e incentivar para prosseguir.

À minha namorada, Kathia, pelo seu amor e companheirismo, e que sem dúvida me deu forças para suportar os momentos difíceis ao longo dessa jornada.

Ao Programa de Recursos Humanos da Agência Nacional de Petróleo e Gás Natural pela oportunidade da bolsa de estudos para o Mestrado.

Aos Professores do IAG, por todo o conhecimento passado durante o curso e ao próprio IAG por proporcionar essa oportunidade. À Profa. Dr. Yara pelo acompanhamento deste trabalho.

À todos os colegas do IAG, entre eles, Plínio, Wilbor, Aruã, Giovanni, Dani, Grasiane, Janine, Karine, pela amizade e momentos de estudos ou compartilhando o café.

Esta tese/dissertação foi escrita em ATEX com a classe IAGTESE, para teses e dissertações do IAG. 

"If we knew what we were doing, it wouldn't be called research, would it?" Unsourced attribution to Albert Einstein 



\section{Resumo}

O Rifte Continental do Sudeste do Brasil é uma das feições geotectônicas mais expressivas da margem continental brasileira e sua formação influenciou significativamente o padrão de transporte de sedimentos para as bacias marginais de Santos e Campos. Diferentes modelos foram propostos para a origem deste rifte e envolvem a reativação, como falhas normais, de zonas de cisalhamento pré-cambrianas. Não obstante, esses modelos são qualitativos e não existem experimentos numéricos que avaliaram a viabilidade dos mecanismos propostos para a origem do rifte. O presente trabalho teve como objetivo estudar a gênese deste rifte e analisar quantitativamente como diferentes fatores geológicos podem ter influenciado sua formação. Essa análise foi realizada numericamente a partir da simulação da evolução de uma margem divergente representativa do sudeste do Brasil. Foi utilizado um modelo numérico bidimensional que descreve a reologia da litosfera como um material viscoelástico de Maxwell na condição de deformação plana, permitindo analisar o estado de esforços na litosfera ao longo do tempo. Os fatores geológicos considerados nos testes numéricos incluíram erosão do continente, sedimentação ao longo da margem estirada, soerguimento regional induzido por uma anomalia térmica mantélica e esforço tectônico intraplaca relacionado ao empurrão pela expansão da cadeia meso-oceânica e orogenia andina. Esses fatores foram considerados separadamente e conjuntamente nos testes. Para avaliar o limite de ruptura das rochas foi considerado o critério de ruptura de Mohr-Coulomb para diferentes valores de coesão interna da rocha. Foi observado que, quando considerados separadamente, tanto a erosão como a sedimentação produziram um estado de esforços compatível com falhamento normal na região continental próxima à margem estirada. No entanto, o soerguimento regional induzido pela passagem de uma anomalia térmica na base da litosfera produz inexpressiva mudança da tensão deviatórica 
na crosta superior. O efeito sobreposto da erosão e da sedimentação no balanço de cargas sobre a litosfera produziu uma maior magnitude dos esforços resultando em uma condição suscetível à formação de falhas normais profundas, até o limite da crosta superior, na margem emersa. De modo semelhante, a sobreposição de uma compressão regional resultou em uma ligeira diminuição da profundidade do limite de ruptura para as rochas da crosta superior. Os resultados deste trabalho mostraram que o balanço de cargas devido à erosão da porção emersa do sudeste do Brasil e à sedimentação nas bacias marginais juntamente com baixos valores de coesão interna das rochas durante a evolução da margem divergente foram responsáveis por produzirem um estado de esforços na litosfera compatível com falhas normais profundas, e o efeito de um soerguimento regional causado por uma anomalia térmica assim como o efeito de uma compressão horizontal regional, não afetaram significativamente o estado de esforços de modo a alterar expressivamente a condição de ruptura das rochas ao longo da margem continental. 


\section{Abstract}

The Continental Rift of Southeastern Brazil is a remarkable feature at the Brazilian continental margin and its formation significantly influenced the sediment transport pattern to the Santos and Campos marginal basins. Several models were proposed to explain the genesis of the rift and involve the reactivation of Precambrian shear zones as normal faults. However, these models are qualitative and there is a lack of numerical experiments regarding the validity of the proposed mechanisms for the rift genesis. The aim of this work is to study the genesis of the rift and analyze quantitatively how different geological factors can affect its formation. The analysis were conducted through numerical simulations of the evolution of a divergent margin which represents the southeastern Brazil. The two-dimensional numerical model used to represent the lithospheric rheology by a Maxwell viscoelastic material in a state of plane strain and permits the analysis of the lithospheric state of stress throughout time. The geological factors considered in the numerical tests included the continental erosion, sedimentation, regional uplift induced by thermal mantle anomaly and the wide-plate tectonic stress due the ridge-push. These factors were considered separately and superimposed in the numerical tests. The Mohr-Coulomb criterion was adopted to calculate the failure condition, taking into account different values for the cohesion factor. Both erosion and sedimentation, when considered separately, produced a tectonic setting compatible with normal faulting near the stretched continental margin. However, the regional uplift due to the passage of a thermal anomaly on the base of the lithosphere didn't expressively affected the change of deviatoric stresses in the upper crust. The superimposed effect of erosion and sedimentation in the load balance on the lithosphere produced greater stresses magnitudes resulting in a favorable condition for the formation of deep normal faulting, up to the base of upper crust, under the onshore margin 
area. Similarly, the superimposed effect of compressive stresses resulted in the shallowing of the rupture limit of the upper crust. The results of this work showed that the load on the lithosphere due to erosion of the onshore continental area in the southeastern Brazil and the sedimentation on the marginal basins during the evolution of the margin were responsible to produce a state of stress in the lithosphere favorable to the formation of deep normal faulting and either the effect of regional uplift caused by a thermal anomaly or the compressive horizontal stresses didn't significantly influenced the state of stress to change the rupture condition of rocks along the continental margin. 


\section{Lista de Figuras}

1.1 Características geológicas na região sudeste do Brasil. 1) Embasamento precambriano; 2) sedimentos paleozóicos da Bacia do Paraná; 3) Formação Serra Geral (rochas vulcânicas); 4) rochas magmáticas (Cretáceo-Paleogeno); 5) bacias cenozóicas do RCSB (1- Bacia de Itaboraí, 2- Gráben de Barra de São João, 3- Bacia do Macacu, 4- Bacia de Volta Redonda, 5- Bacia de Resende, 6- Bacia de Taubaté, 7- Bacia de São Paulo, 8- Gráben de Sete Barras, 9- Formação Pariquera-Açu, 10- Formação Alexandra e Gráben de Guaraqueçaba, 11- Bacia de Curitiba, 12- Gráben de Cananéia); 6) zonas de fraquezas cisalhantes do precambriano. Extraído de Riccomini et al. (2004).

1.2 Cronoestratigrafia das Bacias de Campos e Santos ao longo da costa sudeste do Brasil. Extraído de Milani (2004) . . . . . . . . . . . . . . . . . .

2.1 Topografia e batimetria da região sudeste do Brasil . . . . . . . . . . . . .

2.2 Região norte do segmento central do RCSB e perfil topográfico ao longo da Bacia de Taubaté ilustrando as principais feições morfoestruturais da região sudeste do Brasil. Extraído de Zalán e Oliveira (2005) . . . . . . . . . . . .

2.3 Litoestratigrafia e evolução tectono-sedimentar da região central do RCSB. Simbologia: (a) depósitos aluviais; (c) depósitos coluviais; (ca) depósitos colúvio-aluviais; (t) depósitos de tálus; (p) leques aluviais proximais; (md) leques aluviais medianos a distais associados a planície aluvial de rios entrelaçados. Modificado de Riccomini et al. (2004) . . . . . . . . . . . . .

3.1 Modelos físicos esquemáticos ilustrando o comportamento reológico para diferentes escalas de tempo. Modificado de Watts et al. (2013). . . . . . . . 
3.2 Componentes do tensor de esforços sobre um corpo. Extraído de Turcotte e Schubert $(2002) \ldots \ldots \ldots \ldots \ldots \ldots$

3.3 Modelo de Maxwell (representação esquemática) . . . . . . . . . . . . . 36

3.4 Representação do domínio $\Omega$ e dos contornos $\Gamma_{q}$ e $\Gamma_{h} \ldots \ldots$. . . . . . 38

3.5 Representação esquemática do modelo numérico utilizado na comparação com uma solução analítica. T é o esforço aplicado no modelo. . . . . . . 4 44

3.6 Esforço horizontal e diferença entre a solução analítica e o resultado numérico na camada superior (gráficos à esquerda) e inferior (gráficos à direita) do modelo. ................................ 44

3.7 Esforço horizontal e diferença entre a solução analítica e o resultado numérico na camada superior (gráficos à esquerda) e inferior (gráficos à direita) do modelo. Para este resultado foi assumido valor nulo para o coeficiente de Poisson no modelo numérico. . . . . . . . . . . . . . . . .

4.1 Mapa do sudeste do Brasil e perfil topográfico/batimétrico. Os triângulos indicam as posições das amostras utilizadas para obter o vínculo de denudação (Gallagher et al., 1994; Cogné et al., 2011). O perfil representa a topografia e as barras verticais indicam a denudação máxima para cada amostra projetada ao longo do perfil. Estão indicadas as áreas que correspondem à Serra da Mantiqueira (S. Mant.), às bacias cenozóicas do Rifte Continental do Sudeste do Brasil (RCSB), e à Serra do Mar (S. Mar). A seção estratigráfica da bacia de Santos foi digitalizada de Contreras et al. (2010). O números (à direita) referem-se às idades (Ma) aproximadas para os horizontes estratigráficos em traços espessos. emb.: embasamento; s.f.: fundo do oceano. . . . . . . . . . . . . . . . . . . . 49

4.2 Colunas litosféricas em equilíbrio isostático (Airy-Heiskanen). (A) Coluna continental de referência com espessura da crosta $H_{c}$ e (B) coluna com crosta afinada de espessura $h$ e lâmina d'água de espessura $h_{w}$. $h_{m}$ é a espessura do manto litosférico original. . . . . . . . . . . . . . . . . 50

4.3 Configuração do modelo numérico. A crosta tem espessura variável entre $H_{c}$ e $h_{a}$. Sob a crosta não estirada, o manto litosférico tem espessura de 110 $\mathrm{km}$. A espessura da lâmina d'água é indicada por $h_{w} \ldots \ldots \ldots$. . . . 51 
4.4 Malha triangular do modelo. A malha é composta por $201 \times 61$ nós. A linha vermelha indica a profundidade da Moho. Apenas uma parte da malha é representada na figura. . . . . . . . . . . . . . . . . .

5.1 Esforços não litostáticos deviatóricos e envelope de ruptura para o modelo de referência (padrão). São representados os instantes inicial e final da simulação. A curva preta indica o envelope de ruptura considerando coesão nula e $\phi=30^{\circ}$. As cores azul e vermelha dos traços representam compressão e tensão, respectivamente, e a orientação corresponde à direção dos esforços principais

5.2 Esforços não litostáticos deviatóricos e envelope de ruptura para o modelo com efeito do soerguimento causado por uma anomalia térmica de comprimento de onda de $600 \mathrm{~km}$ (soerg 600, cf. Tabela 4.3). Ver posição do centro do soerguimento regional nas Figuras B.2 $\mathrm{B}$ B.3, indicado por uma seta preta na base do modelo. Conferir Figura 5.1 para demais parâmetros. . . . . . .

5.3 Esforços não litostáticos deviatóricos e envelope de ruptura para o modelo com erosão continua (ero cont, cf. Tabela 4.3). Conferir Figura 5.1 para demais parâmetros. . . . . . . . . . . . . . . . .

5.4 Esforços não litostáticos deviatóricos e envelope de ruptura para o modelo com erosão variável (ero var, cf. Tabela 4.3). Conferir Figura 5.1 para demais parâmetros. . . . . . . . . . . . . . . . . .

5.5 Esforços não litostáticos deviatóricos e envelope de ruptura para o modelo com denudação e sedimentação variáveis (ero/sed var, cf. Tabela 4.3). Conferir Figura 5.1 para demais parâmetros. . . . . . . . . . . . . . .

5.6 Esforços não litostáticos deviatóricos e envelope de ruptura para o modelo com denudação e sedimentação variáveis e efeito do soerguimento causado por uma anomalia térmica de comprimento de onda de $200 \mathrm{~km}$ (ero/sed var + soerg 200, cf. Tabela 4.3). Ver posição do centro do soerguimento regional nas Figuras B.10 e B.11, indicado por uma seta preta na base do modelo. Conferir Figura 5.1 para demais parâmetros. . . . . . . . . . . 
5.7 Esforços não litostáticos deviatóricos e envelope de ruptura para o modelo com denudação e sedimentação variáveis e efeito do soerguimento causado por uma anomalia térmica de comprimento de onda de $600 \mathrm{~km}$ (ero/sed var + soerg 600, cf. Tabela 4.3). Ver posição do centro do soerguimento regional nas Figuras B.12 e B.13, indicado por uma seta preta na base do modelo. Conferir Figura 5.1 para demais parâmetros. . . . . . . . . . . .

5.8 Esforços não litostáticos deviatóricos e envelope de ruptura para o modelo com denudação e sedimentação variáveis e e compressão regional (ero/sed var + comp, cf. Tabela 4.3). Conferir Figura 5.1 para demais parâmetros. .

5.9 Esforços não litostáticos deviatóricos e envelope de ruptura para o modelo com denudação e sedimentação variáveis, compressão regional e compressão adicional a partir de $45 \mathrm{Ma}$ (ero/sed var + comp + Andes, cf. Tabela 4.3). Conferir Figura 5.1 para demais parâmetros. . . . . . . . . . . . . .

5.10 Esforços não litostáticos deviatóricos e envelope de ruptura, em $80 \mathrm{Ma}$, para 6 modelos: a) padrão, b) soerg 600, c) ero/sed var, d) ero/sed var + soerg 200, e) ero/sed var + soerg 600, f) ero/sed var + comp. Conferir Figura 5.1 para demais parâmetros. . . . . . . . . . . . . . . .

5.11 Profundidade máxima do envelope do limite de ruptura das rochas ao longo do tempo. ............................ 74

B.1 Esforços não litostáticos deviatóricos e envelope de ruptura para o modelo padrão em a) 130 Ma e b) 0 Ma. . . . . . . . . . . . . . . . .

B.2 Esforços não litostáticos deviatóricos e envelope de ruptura para o modelo soerg $600 \mathrm{em} \mathrm{a)} 110 \mathrm{Ma} \mathrm{e} \mathrm{b)} 80 \mathrm{Ma}$. . . . . . . . . . . . . . .

B.3 Esforços não litostáticos deviatóricos e envelope de ruptura para o modelo soerg 600 em a) $50 \mathrm{Ma} \mathrm{e} \mathrm{b)} 20 \mathrm{Ma}$. . . . . . . . . . . . . .

B.4 Esforços não litostáticos deviatóricos e envelope de ruptura para o modelo ero cont em a) $110 \mathrm{Ma} \mathrm{e} \mathrm{b)} 80 \mathrm{Ma}$. . . . . . . . . . . . . . .

B.5 Esforços não litostáticos deviatóricos e envelope de ruptura para o modelo

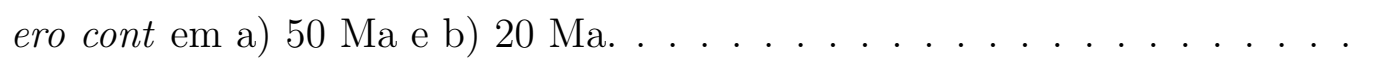

B.6 Esforços não litostáticos deviatóricos e envelope de ruptura para o modelo ero var em a) 110 Ma e b) 80 Ma. . . . . . . . . . . . . 97 
B.7 Esforços não litostáticos deviatóricos e envelope de ruptura para o modelo ero var em a) 50 Ma e b) 20 Ma. . . . . . . . . . . . . . . 98

B.8 Esforços não litostáticos deviatóricos e envelope de ruptura para o modelo ero sed/var em a) $110 \mathrm{Ma} \mathrm{e} \mathrm{b)} 80 \mathrm{Ma}$. . . . . . . . . . . . . . . .

B.9 Esforços não litostáticos deviatóricos e envelope de ruptura para o modelo ero sed/var em a) $50 \mathrm{Ma} \mathrm{e} \mathrm{b)} 20 \mathrm{Ma}$. . . . . . . . . . . . . . . 100

B.10 Esforços não litostáticos deviatóricos e envelope de ruptura para o modelo ero sed/var + soerg 200 em a) $110 \mathrm{Ma}$ e b) 80 Ma. . . . . . . . . . . . . . 101

B.11 Esforços não litostáticos deviatóricos e envelope de ruptura para o modelo ero sed/var + soerg 200 em a) 50 Ma e b) $20 \mathrm{Ma}$.

B.12 Esforços não litostáticos deviatóricos e envelope de ruptura para o modelo ero sed/var $+\operatorname{soerg} 600$ em a) $110 \mathrm{Ma} \mathrm{e} \mathrm{b)} 80$ Ma. . . . . . . . . . . . 103

B.13 Esforços não litostáticos deviatóricos e envelope de ruptura para o modelo ero sed/var + soerg 600 em a) $50 \mathrm{Ma} \mathrm{e} \mathrm{b)} 20 \mathrm{Ma}$. . . . . . . . . . . 104

B.14 Esforços não litostáticos deviatóricos e envelope de ruptura para o modelo ero sed/var + comp em a) 110 Ma e b) 80 Ma. . . . . . . . . . . . . . 105

B.15 Esforços não litostáticos deviatóricos e envelope de ruptura para o modelo ero sed/var + comp em a) $50 \mathrm{Ma} \mathrm{e} \mathrm{b)} 20 \mathrm{Ma}$. . . . . . . . . . . . 106

B.16 Esforços não litostáticos deviatóricos e envelope de ruptura para o modelo ero sed/var + comp + Andes em a) $110 \mathrm{Ma} \mathrm{e} \mathrm{b)} 80$ Ma. . . . . . . . . . 107

B.17 Esforços não litostáticos deviatóricos e envelope de ruptura para o modelo ero sed/var + comp + Andes em a) $50 \mathrm{Ma} \mathrm{e} \mathrm{b)} 20 \mathrm{Ma}$. . . . . . . . . . 108 



\section{Lista de Tabelas}

4.1 Parâmetros do modelo numérico. . . . . . . . . . . . . . 52

4.2 Parâmetros reológicos. . . . . . . . . . . . . . . . . . 52

4.3 Nomenclatura dos testes numéricos. . . . . . . . . . . . . 57 



\section{Sumário}

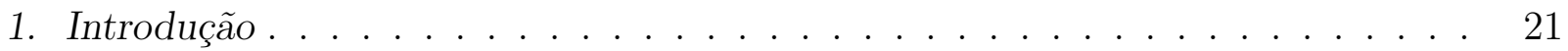

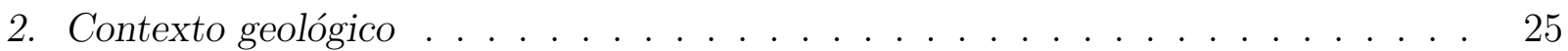

3. Equações constitutivas e método numérico . . . . . . . . . . . . . . . . . 31

3.1 Modelo viscoelástico . . . . . . . . . . . . . . . . . . . . . . 32

3.1 .1 Comportamento elástico . . . . . . . . . . . . . 33

3.1 .2 Comportamento fluido . . . . . . . . . . . . . . 35

3.1.3 Viscoelasticidade . . . . . . . . . . . . . . . . . 36

3.2 Formulação numérica . . . . . . . . . . . . . . . . . . . . . . 37

3.3 Validação do modelo numérico . . . . . . . . . . . . . . . . . . . . 42

3.4 Envelope de ruptura . . . . . . . . . . . . . . . . . . . . 45

4. Configuração numérica . . . . . . . . . . . . . . . . . . . 47

4.1 Vínculos de erosão e sedimentação . . . . . . . . . . . . . . . . . . . . 47

4.2 Configuração do modelo . . . . . . . . . . . . . . . . . . . . . 50

5. Resultados e discussão . . . . . . . . . . . . . . . . . . . . . 59

6. Conclusões ................................. 77

Referências .............................. 79

Apêndice

A. Modelo viscoelástico de Maxwell . . . . . . . . . . . . . . . . . . . . . . 87 
B. Esforços e envelope de ruptura (figuras) . . . . . . . . . . . . . . . . 91 
Capítulo 1

\section{Introdução}

A feição tectônica mais importante do sudeste do Brasil originada no Cenozoico é o Rifte円 Continental do Sudeste do Brasil (RCSB) (Riccomini et al., 2004), presente na porção emersa do continente próximo à costa. O RCSB estende-se por aproximadamente $900 \mathrm{~km}$ paralelamente à costa, resultando na formação de diversas bacias cenozoicas, indicadas pelos números de 1 a 12 na Figura 1.1. A maior das bacias ao longo do RCSB é a Bacia de Taubaté, contendo um pacote sedimentar que atinge até $800 \mathrm{~m}$ de profundidade (Riccomini et al., 2004).

Através da análise de estruturas tectônicas e suas relações com dados estratigráficos, Riccomini (1989) concluiu que a formação do RCSB e preenchimento sedimentar e vulcânico das bacias formadas ocorreu no Paleógeno, sob a ação de esforços distensivos, que resultou na reativação como falhas normais de antigas zonas de cisalhamento.

A criação do RCSB resultou em uma mudança significativa do padrão de drenagem e consequente transporte de sedimentos para as bacias marginais de Santos e Campos. Karner e Driscoll (1999) mostraram que a cronoestratigrafia das Bacias de Campos e Santos diferem ao longo do tempo, sendo que no final do Cretáceo e início do Terciário há uma contínua diminuição do fornecimento de sedimentos para a Bacia de Santos e um aumento de sedimentos clásticos para a Bacia de Campos, a nordeste da Bacia de Santos (Figura 1.2). Essa mudança é interpretada como uma consequência da formação do RCSB, resultando na captura de drenagem no interior do continente para o Rio Paraíba do Sul, transportando sedimentos para a Bacia de Campos, resultando na diminuição no fornecimento de sedimentos para a Bacia de Santos. Assim a compreensão do mecanismo formador deste rifte é fundamental para o entendimento da evolução geológica do sudeste

\footnotetext{
${ }^{1}$ Optou-se por utilizar a termo rifte ao invés do termo em inglês rift.
} 


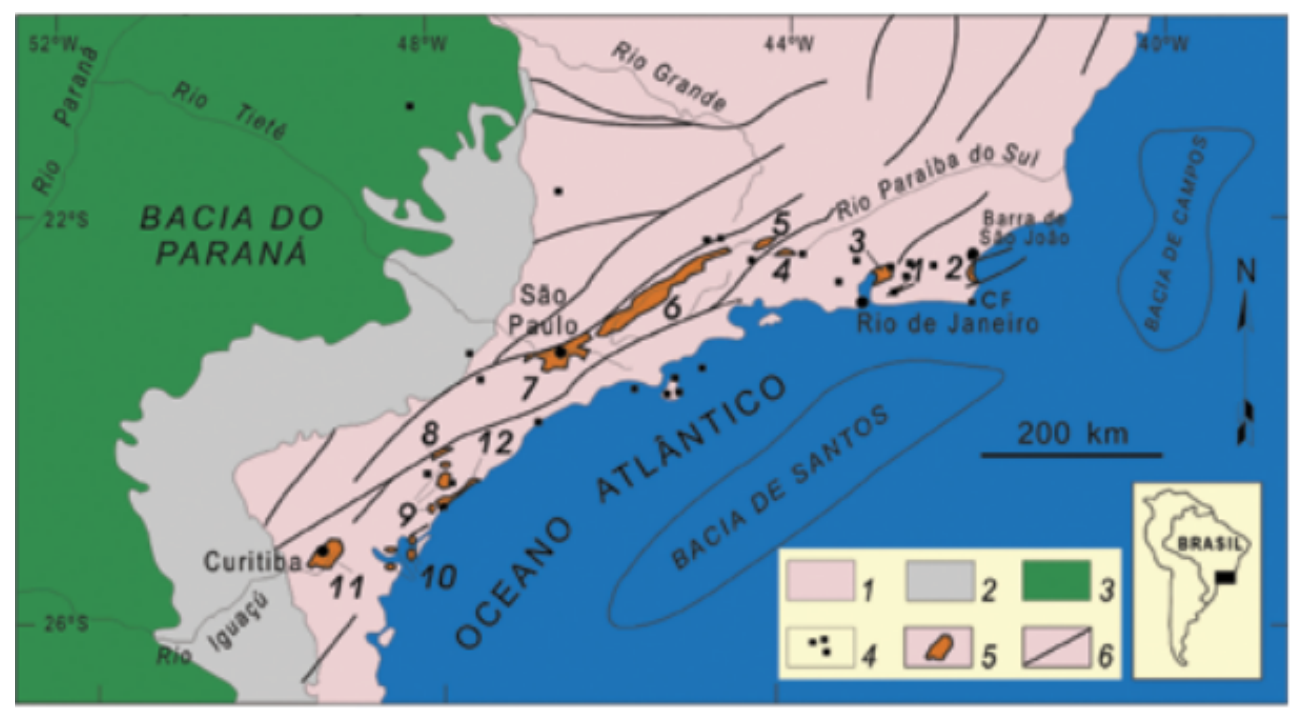

Figura 1.1: Características geológicas na região sudeste do Brasil. 1) Embasamento precambriano; 2) sedimentos paleozóicos da Bacia do Paraná; 3) Formação Serra Geral (rochas vulcânicas); 4) rochas magmáticas (Cretáceo-Paleogeno); 5) bacias cenozóicas do RCSB (1- Bacia de Itaboraí, 2- Gráben de Barra de São João, 3- Bacia do Macacu, 4- Bacia de Volta Redonda, 5- Bacia de Resende, 6- Bacia de Taubaté, 7- Bacia de São Paulo, 8- Gráben de Sete Barras, 9- Formação Pariquera-Açu, 10- Formação Alexandra e Gráben de Guaraqueçaba, 11- Bacia de Curitiba, 12- Gráben de Cananéia); 6) zonas de fraquezas cisalhantes do precambriano. Extraído de Riccomini et al. (2004).

do Brasil desde a abertura do Atlântico Sul, sendo de grande importância para a análise de risco exploratório na indústria de petróleo.

Diversos modelos foram propostos para explicar a formação do RCSB (e.g. Almeida, 1976; Riccomini, 1989; Cobbold et al., 2001; Cogné et al., 2011). Até o presente momento, no entanto, não há na literatura trabalhos que descrevam experimentos numéricos para avaliar se os mecanismos propostos por esses autores são fisicamente viáveis para a geração e formação do RCSB.

O presente trabalho tem como principal objetivo simular numericamente a evolução da margem sudeste do Brasil e a formação do RCSB e testar como diferentes fatores geológicos afetaram esse processo. Os fatores geológicos incluem denudação do continente, sedimentação na bacia oceânica adjacente, soerguimento regional causado por uma anomalia térmica na base da litosfera e esforços regionais horizontais compressivos.

No presente trabalho, a simulação numérica da evolução da margem foi feita utilizando um modelo numérico adaptado de Assumpção e Sacek (2013). Esse modelo simula o comportamento reológico da litosfera assumindo o modelo de Maxwell para um material viscoelástico em estado de deformação plana. O código, em 2D, utiliza o método 


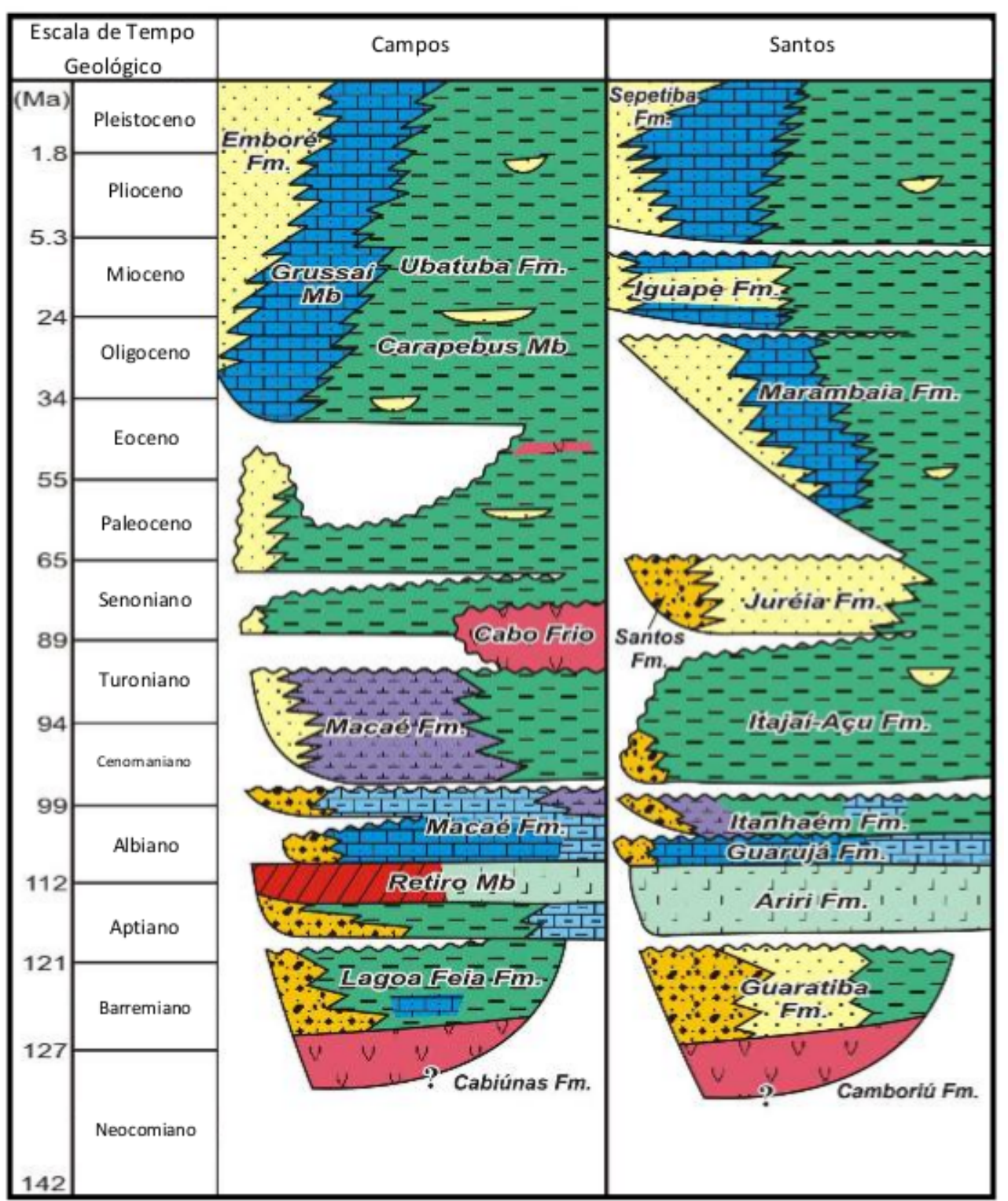

Figura 1.2: Cronoestratigrafia das Bacias de Campos e Santos ao longo da costa sudeste do Brasil. Extraído de Milani (2004).

dos elementos finitos para resolver numericamente o problema. A componente de comportamento viscoso da litosfera é descrita por um fluido não Newtoniano. As adaptações efetuadas no código permitiram incluir variações temporais de cargas topográficas, relacionadas à erosão e sedimentação, e do esforço regional. Também, adaptou-se o código para permitir a representação geométrica da margem sudeste do Brasil.

Para avaliar o efeito da variação de carga no modelo, utilizou-se como vínculos (input) para o modelo numérico, dados de termocronologia e de cronoestratigrafia da Bacias de Santos, que permitiram estimar a erosão e a sedimentação ao longo do tempo no modelo. 
Adicionalmente, analisou-se os efeitos da variação da tensão regional causada por variações nas taxas de espalhamento na dorsal meso-oceânica (ridge-push) e na subducção da placa de Nazca (slab-pull).

\section{Estrutura da dissertação}

Neste manuscrito, inicialmente é apresentado o contexto geológico do RCSB juntamente com os modelos propostos na literatura para a gênese do rifte (Capítulo 2). No Capítulo 3 é apresentado o formalismo matemático de um material viscoelástico e método dos elementos finitos utilizado para resolver numericamente as equações. Ainda, apresenta-se nesse capítulo os testes de validação do modelo numérico. Os vínculos, a configuração do modelo e os experimentos numéricos são descritos no Capítulo 4. O Capítulo 5 aborda os resultados dos diferentes experimentos numéricos e discute as implicações dos resultados para a origem do RCSB. O Capítulo 6 apresenta as conclusões deste trabalho. 
Capítulo 2

\section{Contexto geológico}

Em um contexto regional, o sudeste do Brasil abrange as províncias tectônicas do Paraná, São Francisco, Mantiqueira, a província Costeira e a Margem Continental Almeida et al., 1981). As feições topográficas com grandes escarpamentos e altitudes que superam $1500 \mathrm{~m}$, e tectônicas, relacionadas ao vales e bacias menores que ocorrem na área, são reconhecidas como característica notável da margem Atlântica brasileira (e.g. Almeida, 1976; Almeida e Carneiro, 1998; Riccomini et al., 2004).

Dentre essas províncias, a Província Mantiqueira se estende ao longo da costa desde a fronteira com o Uruguai, ao sul, até a latitude $15^{\circ} \mathrm{S}$, ao norte (Almeida et al., 1981), na qual se enquadra o Cinturão Ribeira (Trouw et al., 2000) (1.1). Esta região apresenta zonas de fraquezas de direções entre ENE a E-W e que registram movimentação cisalhante, resquício da evolução do cinturão durante o Ciclo Brasiliano (Trouw et al., 2000). As rochas que compõe o cinturão têm idades precambrianas (arqueanas à neoproterozóicas) e incluem gnaisses, migmatitos e rochas metamórficas de baixo a alto grau (Riccomini et al., 2004).

O Rifte Continental do Sudeste do Brasil (RCSB) Riccomini, 1989; Riccomini et al., 2004) é caracterizado pela feição tectônica associada à depressão que existe no Cinturão Ribeira e que abriga diversas bacias cenozóicas (Figura 1.1). O RCSB estende-se desde a Bacia de Curitiba, ao sul, até o Gráben de Barra de São João, ao norte (Figura 1.1), por uma distância de c. $900 \mathrm{~km}$, e é caracterizado morfologicamente por uma depressão alongada segundo a direção NE (Riccomini, 1989, Riccomini et al., 2004) e regiões adjacentes de topografia elevada, chegando a superar $1000 \mathrm{~m}$ de altitude (Figura 2.1). Cabe ressaltar que a denominação utilizada, RCSB, de Riccomini (1989), não é única. Almeida (1976) utilizou Sistemas de Riftes da Serra do Mar, enquanto Melo et al. (1985) empregaram Sistema de bacias tafrogênicas continentais do Sudeste do Brasil e Zalán e Oliveira (2005) 
denominaram de Sistema de Riftes Cenozóicos do Sudeste do Brasil.

O RCSB é subdividido em três segmentos (Riccomini et al., 2004): o segmento sul, que inclui a Bacia de Curitiba e ocorrências sedimentares isoladas, representada pelas formações Alexandra e Pariquera-Açu, além dos grábens de Cananéia, Guaraqueçaba e Sete Barras; o seguimento central, com as bacias de São Paulo, Taubaté, Resende e Volta Redonda e também os locais de ocorrência dos depósitos de Bonfim e de Cafundó; e o segmento norte, no qual integram o gráben de Barra de São João e as bacias de Itaboraí e Macacu (Figura 1.1).

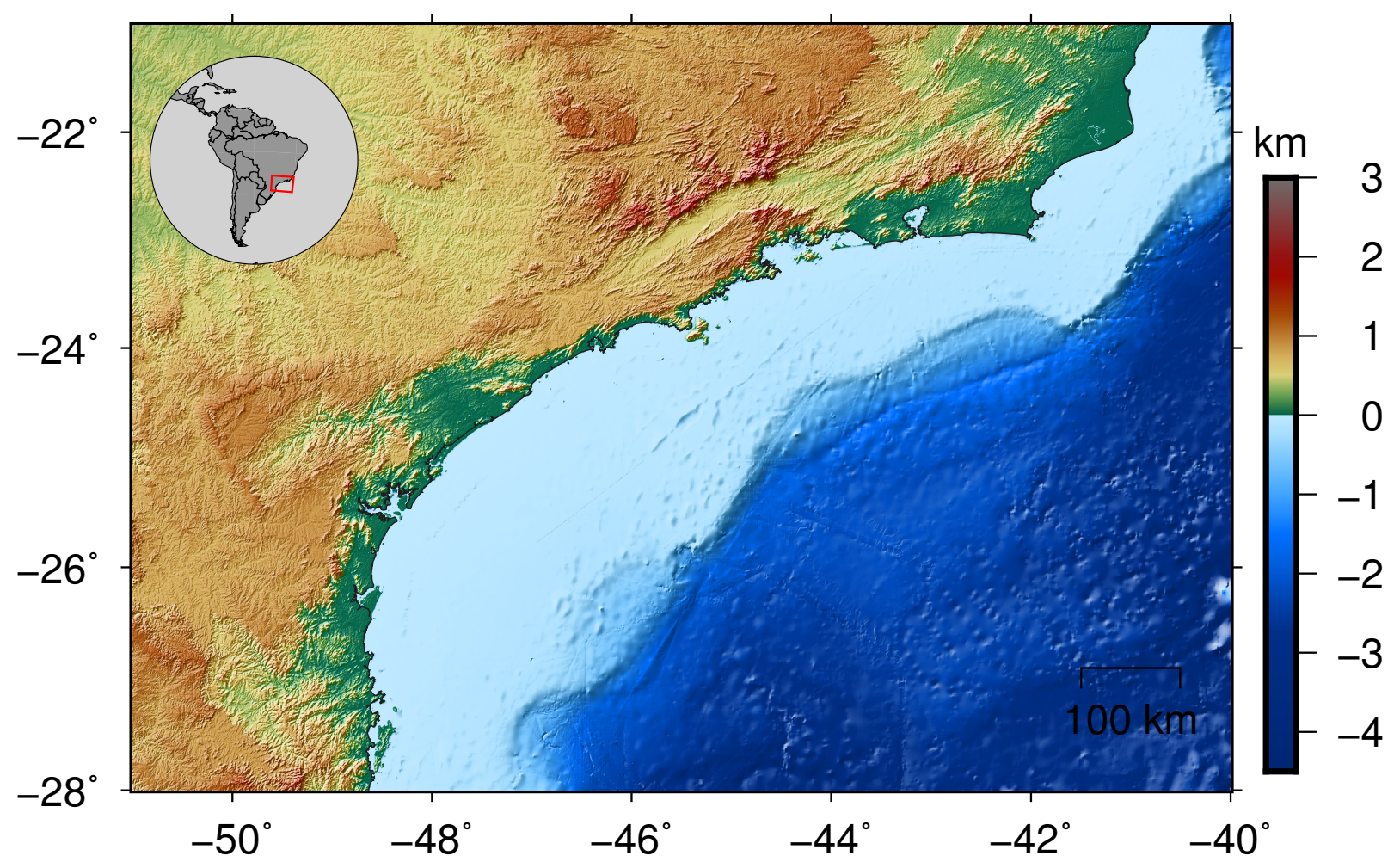

Figura 2.1: Topografia e batimetria da região sudeste do Brasil

$\mathrm{Na}$ região central, existem quatro feições morfoestruturais, da costa ao interior do continente (Hiruma et al., 2010; Cogné et al., 2011): (1) a planície costeira; (2) a Serra do Mar; (3) o vale do Rio Paraíba do Sul; e (4) a Serra da Mantiqueira. As duas serras, que formam um escarpamento duplo, constitui uma feição característica da costa leste brasileira, bem exemplificado ao longo da Bacia de Taubaté (Figura 2.2.

A Serra do Mar é uma cadeia montanhosa, assimétrica, que contorna a costa desde o Rio de Janeiro até Florianópolis (Cobbold et al., 2001) (Figura 2.1), com altitude nivelada em c. $1200 \mathrm{~m}$, porém as regiões com maiores altitudes ocorrem ao longo do vale do rio 


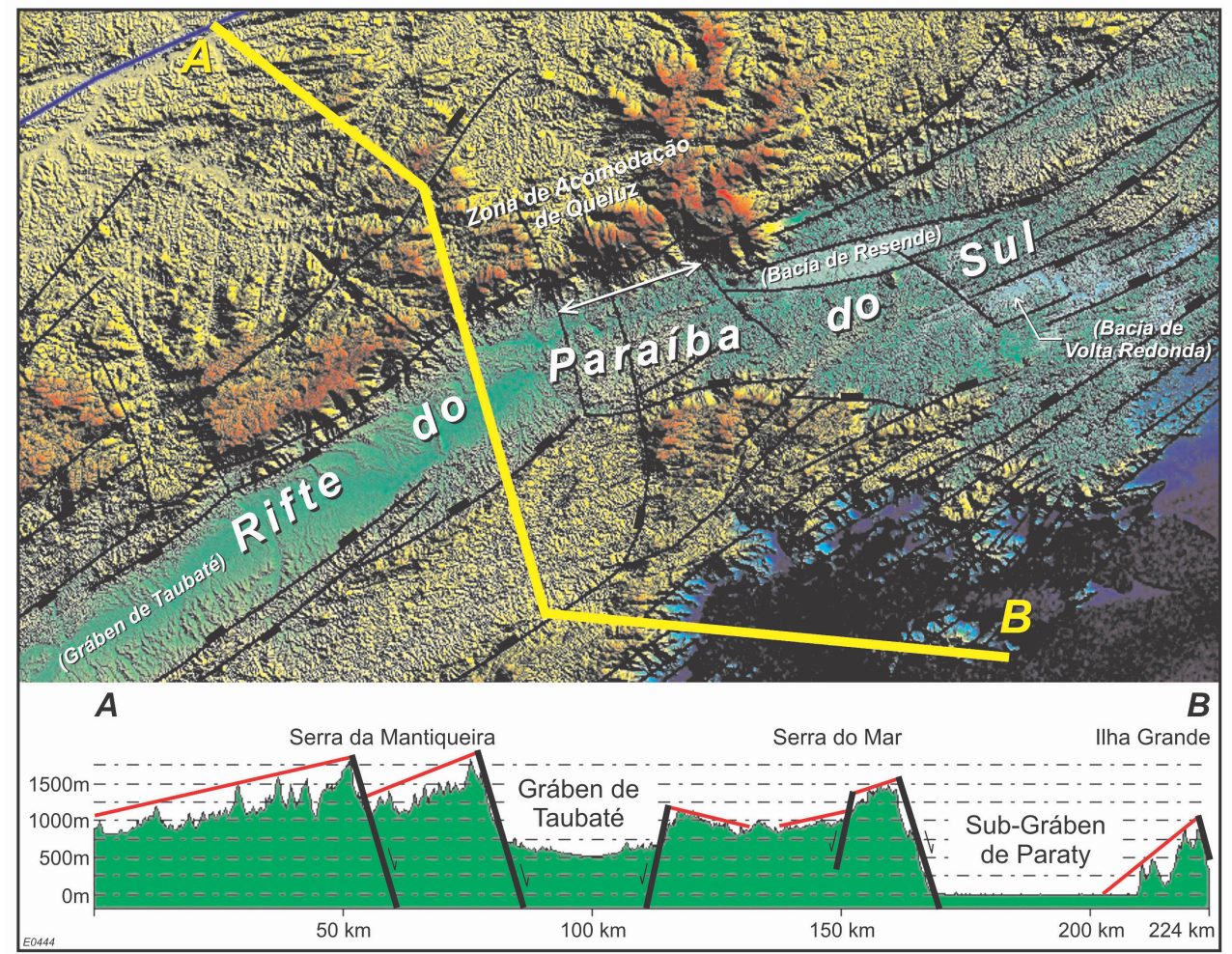

Figura 2.2: Região norte do segmento central do RCSB e perfil topográfico ao longo da Bacia de Taubaté ilustrando as principais feições morfoestruturais da região sudeste do Brasil. Extraído de Zalán e Oliveira (2005).

Paraíba do Sul, atingindo mais de 2000 m no planalto da Bocaina (Riccomini et al., 2004; Hiruma et al., 2010). A Serra da Mantiqueira, a oeste da Bacia de Taubaté, têm altitudes ainda maiores, com planaltos entre 2000 e $2800 \mathrm{~m}$ de altitude (Zalán e Oliveira, 2005; Cobbold et al., 2001) (Figuras 2.1 e 2.2). Entre essas serras, na região central do RCSB, ocorre a Bacia do Taubaté, a maior das bacias que compõe o RCSB, com c. $20 \mathrm{~km}$ de largura e c. $170 \mathrm{~km}$ de comprimento, e espessura de sedimentos de até $c .850 \mathrm{~m}$ (Padilha et al., 1991). As escarpas, ao longo da Bacia de Taubaté, são assimétricas e atingem 10001500 m na Serra da Mantiqueira, a oeste, e 400-500 m a leste, na Serra do Mar (Zalán e Oliveira, 2005).

O posicionamento temporal dos sedimentos das bacias inseridas ao logo do RCSB é dado pela ocorrência de rochas igneas efusivas. O vínculo absoluto de idade das camadas sedimentares é dado pela identificação da ocorrência de derrames de lavas ankaramíticas intercalados aos sedimentos na base da Bacia de Volta Redonda (Figura 1.1) e ilustrado como o pacote intercalado na base da Formação Resende (na Figura 2.3). A datação desse pacote de lavas forneceu idades de 43,8 \pm 6,2 e 41,7 \pm 5,7 Ma pelo método K/Ar e 48,3 


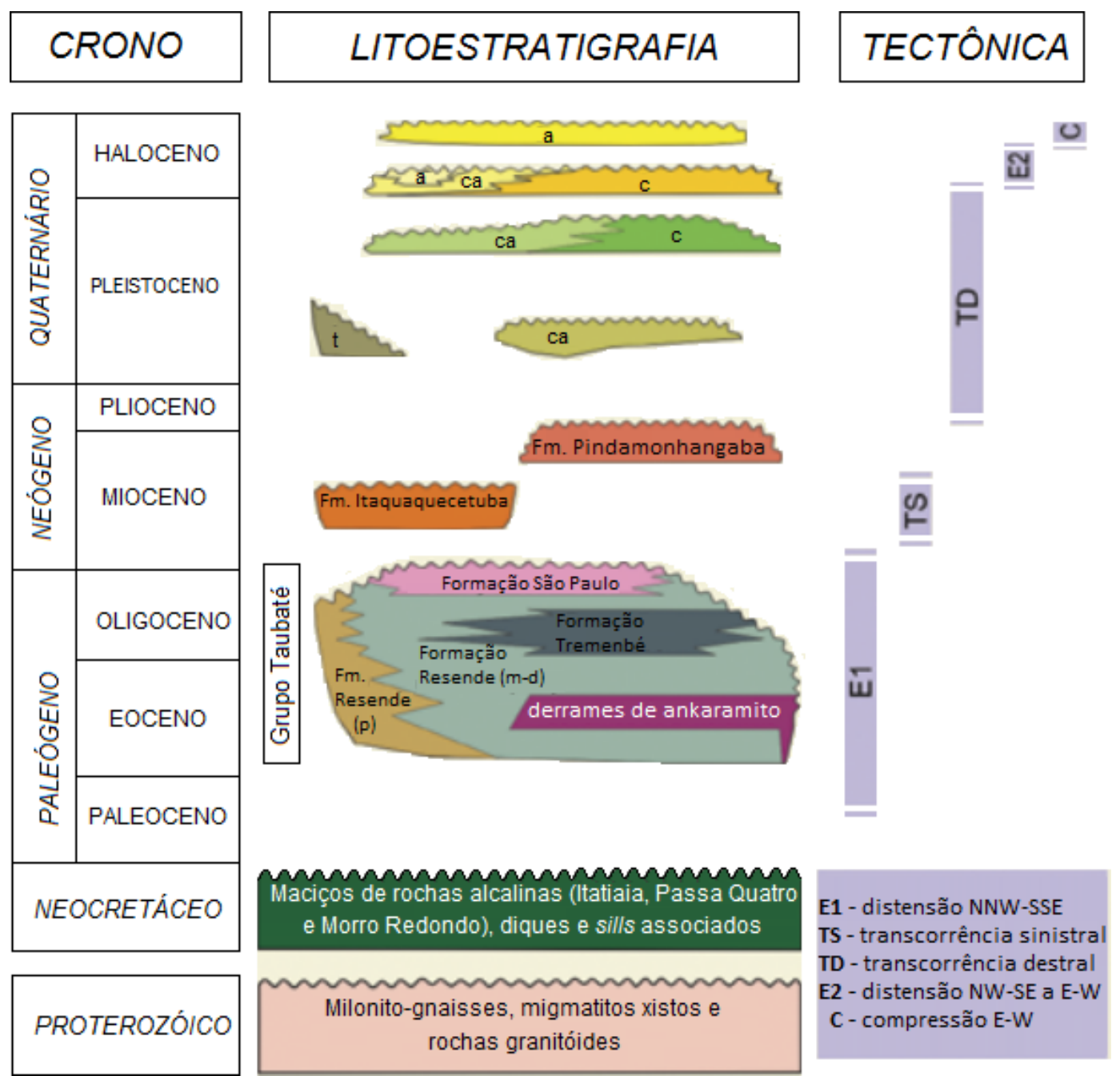

Figura 2.3: Litoestratigrafia e evolução tectono-sedimentar da região central do RCSB. Simbologia: (a) depósitos aluviais; (c) depósitos coluviais; (ca) depósitos colúvio-aluviais; (t) depósitos de tálus; (p) leques aluviais proximais; (m-d) leques aluviais medianos a distais associados a planície aluvial de rios entrelaçados. Modificado de Riccomini et al. (2004).

$\pm 0,5$ e 47,6 $\pm 0,7$ por $\operatorname{Ar} / \operatorname{Ar}($ Riccomini et al. 2004).

Diversos estudos analisaram a formação do RCSB, porém ainda existe debate sobre o tema (e.g. Cogné et al., 2013). Trabalhos anteriores à década de 1970 concentraram-se na geomorfologia e consideraram a origem do RCSB como tectônica ou erosiva Martonne 1943; Ruellan, 1947; Freitas, 1956; Birot, 1959; King, 1956). Entre os modelos de geração do RCSB posteriores a essa época, existem propostas que consideram reativações normais das zonas de fraquezas precambrianas associadas ao colapso gravitacional vinculado ao movimento vertical entre a região continental e a Bacia de Santos Almeida (1976); Riccomini et al. (2004); Asmus e Ferrari (1978) com a hipótese de um desequilíbrio isostático 
entre o continente e a bacia marginal que desencadeou movimentos verticais, os quais, seguidos por deslizamentos gravitacionais e basculamento de blocos crustais configurou as Serras do Mar e Mantiqueira; e Riccomini (1989) ao atribuir a gênese do RCSB aos esforços extensionais de direção NW-SE no Paleógeno (Figura 2.3, coluna Tectônica), devido ao basculamento termomecânico ocorrido na Bacia de Santos.

Outras propostas consideram a origem das bacias cenozóicas associadas à reativação com movimentação transcorrente das falhas preexistentes (Zalán, 1986). Padilha et al. (1991), através de métodos geofísicos (magnetotelúrico, modelagem gravimétrica e fluxo térmico), associaram a origem do rifte com esforços de longo alcance relacionados à taxa de espalhamento do assoalho oceânico do Atlântico Sul. Cobbold et al. (2001) analisaram diferentes dados (sismicidade, topografia digital, idades por traços de fissão em apatita, gravimétricos e de poços) relacionando a gênese à esforços de longo alcance e atividade térmica anômala. Zalán e Oliveira (2005) consideraram o colapso gravitacional, no Cenozóico, como gênese dos grábens que fazem parte do RCSB, após o soerguimento causado por uma anomalia térmica no Neocretáceo.

Através da interpretação de dados de termocronologia Cogné et al. (2011) sugeriram que a origem do RCSB, no Paleogeno, estaria ligada à concentração de deformação na zona cisalhante preexistente, devido a um estado de compressão regional, associado com fases de evolução da orogenia andina, modelo reiterado por Cogné et al. (2012) com base em novos dados termocronológicos das Bacias de Taubaté e Resende e regiões adjacentes. Com foco na Bacia de Taubaté (Figura 1.1), Cogné et al. (2013) propuseram que a bacia se formou em um regime de esforços transtensional, na qual a direção do maior esforço horizontal foi NE-SW. 
Capítulo 3

\section{Equações constitutivas e método numérico}

A camada superior da Terra, em termos do comportamento físico, é composta pela litosfera, que se comporta como um bloco rígido para grandes intervalos de tempo. Já a astenosfera, camada do manto logo abaixo da litosfera, apresenta um comportamento fluido nas longas escalas do tempo geológico devido à maior temperatura. Além do mais, mesmo a litosfera pode apresentar, parcialmente, um comportamento fluido para intervalos longos de tempo. Desse modo, para realizar a modelagem dos esforços na litosfera é necessário uma descrição do comportamento reológico dessas camadas ao longo do tempo que incorpore tanto as propriedades elásticas quanto as de fluido.

A Figura 3.1 ilustra as principais características do comportamento reológico do planeta para diferentes escalas de tempo. Para intervalos de até uma centena de segundos, a resposta dos materiais que compõem o interior terrestre aos esforços aplicados é essencialmente elástica, ou seja, as rochas deformam-se em resposta às forças aplicadas, mas ao cessar a aplicação das forças, retornam à sua forma inicial, sem adquirir deformação permanente. Esse comportamento reológico é caracterizado por um modelo de semiespaço elástico.

Na escala temporal a partir da ordem dezenas de milhares de anos, a litosfera e a astenosfera diferenciam-se em relação à resposta aos esforços aplicados. A litosfera mantém o comportamento elástico, mas a astenosfera apresenta um comportamento misto, deformando-se elasticamente, porém mantém uma quantidade de deformação permanente. Esse tipo de deformação dos materiais é definido como viscoelasticidade. Esse modelo é caracterizado por uma placa elástica sobre um meio viscoelástico.

Para intervalos de tempo maiores que um milhão de anos, a litosfera ainda apresenta comportamento elástico, porém, o manto deixa de apresentar elasticidade, exibindo um 


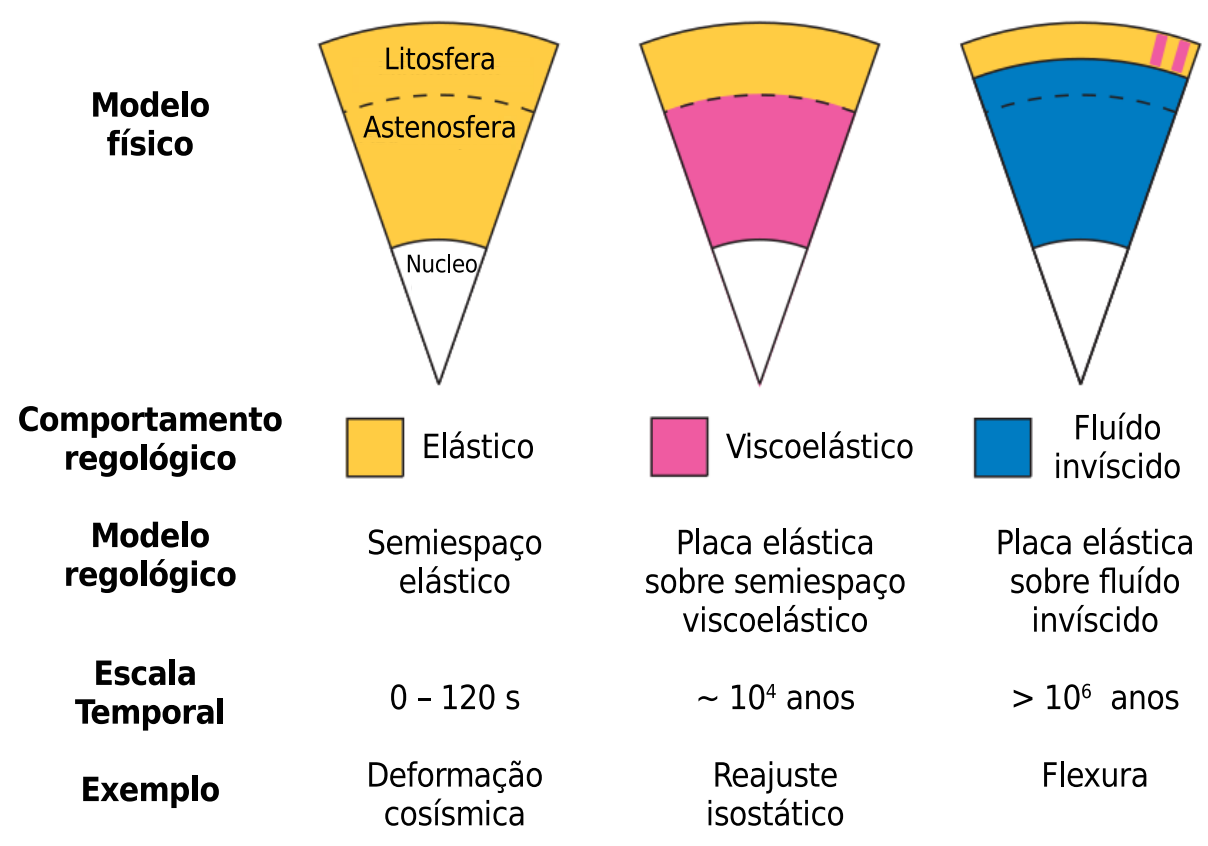

Figura 3.1: Modelos físicos esquemáticos ilustrando o comportamento reológico para diferentes escalas de tempo. Modificado de Watts et al. (2013).

comportamento de um fluido, mesmo possuindo valores altos de viscosidade. É interessante notar que mesmo a base da litosfera passa a ter esse comportamento reológico e ainda partes da litosfera comportam-se de modo viscoelástico. O modelo reológico que caracteriza esse cenário é uma placa elástica sobre um fluido viscoso.

O presente trabalho analisa as tensões na litosfera durante dezenas de milhões de anos, correspondendo à ordem do intervalo de tempo de evolução da margem divergente da costa leste do Brasil. Desse modo, assume-se a descrição viscoelástica para o comportamento reológico da litosfera. A seguir, serão detalhados o formalismo matemático que descreve um material elástico e o comportamento fluido, e como a junção desses elementos fornece a descrição do comportamento de um material viscoelástico.

\subsection{Modelo viscoelástico}

O detalhamento do comportamento viscoelástico será feito por partes, detalhando o comportamento elástico e o comportamento fluido. A composição dessas duas formulações é feita para criar o modelo viscoelástico. 


\subsubsection{Comportamento elástico}

Os esforços que atuam sobre um corpo (Figura 3.2) são dados por um tensor de esforços, $\sigma_{i j}^{e}$, que representa as componentes normais e cisalhantes dos esforços, isto é, as componentes aplicadas na direção perpendicular às faces do elemento cúbico (da figura) ou tangente a estas, respectivamente. De maneira análoga, a deformação do corpo é representada por um tensor de deformação, $\epsilon_{i j}^{e}$, nos quais as componentes normais estão relacionadas com a variação de volume, e as componentes cisalhantes estão associadas com a alteração da forma do elemento.

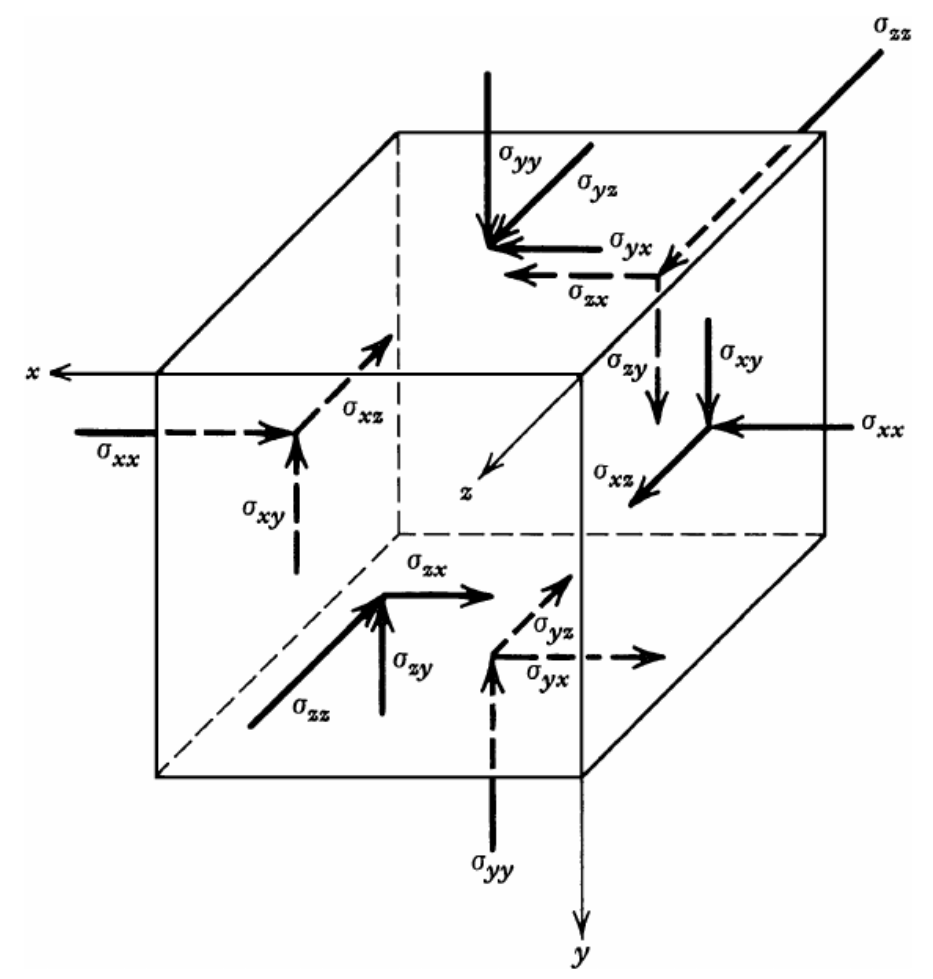

Figura 3.2: Componentes do tensor de esforços sobre um corpo. Extraído de Turcotte e Schubert (2002).

A relação entre os esforços $\left(\sigma_{i j}^{e}\right)$ e a deformação $\left(\epsilon_{i j}^{e}\right)$ para o comportamento elástico é dada pela relação linear (Ricard, 2007):

$$
\sigma_{i j}^{e}=A_{i j k l}^{e} \epsilon_{k l}^{e}
$$

na qual $A_{i j k l}^{e}$ é um tensor de quarta ordem ${ }^{1}$ relacionado com as propriedades do material.

A Equação 3.1 representa um caso geral, onde o tensor $A_{i j k l}^{e}$ têm 81 componentes $(=3 \times 3 \times 3 \times 3)($ caso $3 \mathrm{D}, i, j=1,2,3)$. No entanto, devido à simetria resultante da

\footnotetext{
${ }^{1}$ Em inglês, denominado stiffness.
} 
condição de equilíbrio, os tensores $\sigma$ e $\epsilon$ possuem 6 componentes diferentes ao invés de 9. Desse modo, o número de componentes de $A$ se reduz à 36. Porém, essa matriz (de 36 elementos) também é simétrica, resultando em 21 elementos independentes. Para um material isotrópico, as propriedades do material não variam com as direções espaciais, e como consequência, o tensor $A$ é ainda mais simplificado e nesse caso tem apenas dois parâmetros independentes, o módulo de compressibilidade $K$ e o módulo de rigidez $\mu_{R}$. O primeiro está relacionado com a deformação volumétrica do material, enquanto o segundo com a alteração da forma. Em termos desses dois parâmetros, a Equação 3.1 pode ser rescrita (em notação tensorial) como:

$$
\boldsymbol{\sigma}^{e}=K \operatorname{tr}\left(\boldsymbol{\epsilon}^{e}\right) \boldsymbol{I}+2 \mu_{R}\left(\boldsymbol{\epsilon}^{e}-\frac{1}{3} \operatorname{tr}\left(\boldsymbol{\epsilon}^{e}\right) \boldsymbol{I}\right)
$$

sendo que $\operatorname{tr}\left(\boldsymbol{\epsilon}^{e}\right)=\boldsymbol{\nabla} \cdot \mathbf{u}$, é o traço da matriz $\boldsymbol{\epsilon}^{e}, \mathbf{u}$ é vetor de deslocamento e $\boldsymbol{I}$ é a matriz identidade. O tensor de deformação está relacionado ao vetor deslocamento por:

$$
\epsilon_{i j}^{e}=\frac{\mathrm{u}_{i, j}+\mathrm{u}_{j, i}}{2}
$$

na qual $\mathrm{u}_{i, j}$ representa a derivada da componente $i$ em relação à componente $j$ (por exemplo, $\left.\mathrm{u}_{1,2} \equiv \partial \mathrm{u}_{1} / \partial x_{2}\right)$.

Expressando o tensor de deformação em função do tensor de esforços, tem-se:

$$
\boldsymbol{\epsilon}^{e}=\frac{1}{9 K} \operatorname{tr}\left(\boldsymbol{\sigma}^{e}\right) \boldsymbol{I}+\frac{1}{2 \mu_{R}}\left(\boldsymbol{\sigma}^{e}-\frac{1}{3} \operatorname{tr}\left(\boldsymbol{\sigma}^{e}\right) \boldsymbol{I}\right)
$$

Os módulos de compressibilidade e rigidez são relacionados ao módulo de Young $E$ e ao coeficiente de Poisson $\nu$ pelas seguintes expressões:

$$
\begin{aligned}
& K=\frac{E}{3(1-2 \nu)} \\
& \mu_{R}=\frac{E}{2(1+\nu)}
\end{aligned}
$$

O módulo de Young está relacionado com a deformação ao longo de uma direção longitudinal onde o esforço é aplicado, e o coeficiente de Poisson relaciona a deformação em uma direção transversal à aquela na qual o esforço é aplicado. A partir dessas relações, a Equação 3.4 é expressa como:

$$
\boldsymbol{\epsilon}^{e}=\frac{(1-2 \nu)}{3 E} \operatorname{tr}\left(\boldsymbol{\sigma}^{e}\right) \boldsymbol{I}+\frac{(1+\nu)}{E}\left(\boldsymbol{\sigma}^{e}-\frac{1}{3} \operatorname{tr}\left(\boldsymbol{\sigma}^{e}\right) \boldsymbol{I}\right)
$$

Então, o comportamento elástico, para o caso isotrópico, é dada pela Equação 3.7, que relaciona a deformação aos esforços aplicados e as propriedades do material dadas pelo módulo de Young e o coeficiente de Poisson. 


\subsubsection{Comportamento fluido}

Diferentemente do comportamento elástico, o comportamento fluido depende da taxa de deformação. Essa relação é dada por (Ricard, 2007):

$$
\sigma_{i j}^{v}=-P_{v} \delta_{i j}+A_{i j k l}^{v} \dot{\epsilon}_{k l}^{v}
$$

na qual $\delta_{i j}$ é o delta de Kronecker

$$
\delta_{i j}= \begin{cases}1, & i=j \\ 0, & i \neq j\end{cases}
$$

$P_{v}$ é a pressão, e $\dot{\epsilon}_{k l}^{v}$ a derivada temporal de $\epsilon_{k l}^{v}$, isto é, $\dot{\epsilon}_{k l}^{v}=\partial \epsilon_{k l}^{v} / \partial t$. Nesse caso, existem esforços relacionados à pressão mesmo sem haver variação da deformação do fluido com o tempo.

De modo semelhante ao desenvolvimento anterior (Seção 3.1.1), considerando um material isotrópico, o tensor de esforços pode ser escrito em termos de dois parâmetros relacionados com as propriedades do material:

$$
\boldsymbol{\sigma}^{v}=\left(-P_{v}+\zeta \operatorname{tr}\left(\dot{\boldsymbol{\epsilon}}^{v}\right)\right) \boldsymbol{I}+2 \eta\left(\dot{\boldsymbol{\epsilon}}^{v}-\frac{1}{3} \operatorname{tr}\left(\dot{\boldsymbol{\epsilon}}^{v}\right) \boldsymbol{I}\right)
$$

na qual $\zeta$ é o coeficiente bulk viscosity, relacionado a resistência do fluído ao movimento (sem ocorrer cisalhamento), $\eta$ é a viscosidade dinâmica (ou cisalhante) ${ }^{2}$ relacionada ao fluxo cisalhante, e $\operatorname{tr}\left(\dot{\boldsymbol{\epsilon}}^{v}\right)=\boldsymbol{\nabla} \cdot \mathbf{v}=\boldsymbol{\nabla} \cdot \dot{\mathbf{u}}$, é o traço do tensor $\dot{\boldsymbol{\epsilon}}^{v}$.

Invertendo a Equação 3.9, obtém-se a taxa de deformação em função dos esforços:

$$
\dot{\boldsymbol{\epsilon}}^{v}=\frac{1}{9 \zeta}\left(3 P_{v}+\operatorname{tr}\left(\boldsymbol{\sigma}^{v}\right)\right) \boldsymbol{I}+\frac{1}{2 \eta}\left(\boldsymbol{\sigma}^{v}-\frac{1}{3} \operatorname{tr}\left(\boldsymbol{\sigma}^{v}\right) \boldsymbol{I}\right)
$$

Na Equação 3.10, o primeiro termo do membro da direita da equação pode ser desconsiderado assumindo $\zeta \rightarrow+\infty$. Essa simplificação é razoável para os materiais terrestres, uma vez que qualquer mudança volumétrica por mudança na pressão é suportada integralmente pela elasticamente do material (Ricard, 2007). Desse modo, obtém-se a simplificação:

$$
\dot{\boldsymbol{\epsilon}}^{v}=\frac{1}{2 \eta}\left(\boldsymbol{\sigma}^{v}-\frac{1}{3} \operatorname{tr}\left(\boldsymbol{\sigma}^{v}\right) \boldsymbol{I}\right)
$$

A Equação 3.11 fornece, para o caso de um fluido, a relação entre a taxa de deformação e os esforços aplicados.

\footnotetext{
${ }^{2}$ Em inglês, shear viscosity.
} 


\subsubsection{Viscoelasticidade}

A viscoelasticidade apresenta conjuntamente as propriedades da deformação elástica e do comportamento de um fluido e é obtida a partir da união das Equações 3.7 e 3.11 . Um dos modelos utilizado para descrever a viscoelasticidade é o modelo de Maxwell, em que a deformação causada pelos esforços é distribuída entre a componente elástica e a componente dúctil. A Figura 3.3 ilustra esquematicamente o modelo de Maxwell representando a associação em série entre as duas componentes.
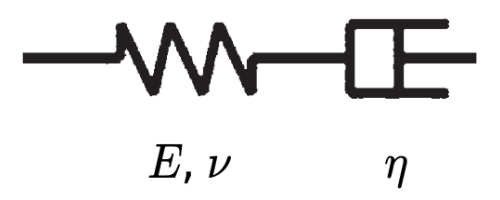

Figura 3.3: Representação esquemática do modelo viscoelástico de Maxwell. A componente elástica (mola) e a componente viscosa (amortecedor) são associados em série.

Matematicamente, as condições para o modelo de Maxwell são:

$$
\begin{gathered}
\boldsymbol{\sigma}=\boldsymbol{\sigma}^{e}=\boldsymbol{\sigma}^{v} \\
\boldsymbol{\epsilon}=\boldsymbol{\epsilon}^{e}+\boldsymbol{\epsilon}^{v}
\end{gathered}
$$

A partir das Equações 3.7 e 3.11 e assumindo as condições de deformação plana, dadas por,

$$
\begin{aligned}
& \dot{\epsilon}_{z z}^{e}=\dot{\epsilon}_{x z}^{e}=\dot{\epsilon}_{y z}^{e}=0 \\
& \dot{\epsilon}_{z z}^{v}=\dot{\epsilon}_{z z}^{v}=\dot{\epsilon}_{z z}^{v}=0
\end{aligned}
$$

e as condições do modelo de Maxwell (Equações 3.13 e 3.12), obtém-se a taxa de deformaçãd ${ }^{3}$ em relação aos esforços (e.g. Melosh e Raefsky, 1980):

$$
\begin{aligned}
& \dot{\epsilon}_{x x}=\frac{(1+\nu)}{E}\left[(1-\nu) \dot{\sigma}_{x x}-\nu \dot{\sigma}_{y y}\right]+\frac{\sigma^{n-1}}{4 \eta}\left(\sigma_{x x}-\sigma_{y y}\right) \\
& \dot{\epsilon}_{y y}=\frac{(1+\nu)}{E}\left[(1-\nu) \dot{\sigma}_{y y}-\nu \dot{\sigma}_{x x}\right]-\frac{\sigma^{n-1}}{4 \eta}\left(\sigma_{x x}-\sigma_{y y}\right) \\
& \dot{\epsilon}_{x y}=\frac{(1+\nu)}{E} \dot{\sigma}_{x y}+\frac{\sigma^{n-1}}{2 \eta} \sigma_{x y}
\end{aligned}
$$

\footnotetext{
${ }^{3}$ A dedução das equações é apresentada no Apêndice A.
} 
nas quais

$$
\sigma=\sqrt{\left(\frac{\sigma_{x x}-\sigma_{y y}}{2}\right)^{2}+\sigma_{x y}^{2}}
$$

é a raiz quadrada do segundo invariante do tensor deviatórico, e $n$ é o expoente da lei de potência relacionado a um fluido não linear. É importante ressaltar que nas Equações 3.15 levou-se em consideração uma modificação da Equação 3.11 para representar um fluido não linear, dado pela lei de potência. Essa modificação consistiu na substituição do numerador do termo multiplicativo $1 / 2 \eta$, na Equação 3.11, por $\sigma^{n-1}$, onde $\sigma$ é dado pela Equação 3.16, resultando em $\sigma^{n-1} / 2 \eta$. Assim, caso $n=0$, obtém-se o caso linear apresentado inicialmente.

Reescrevendo as Equações 3.15 na forma matricial, para a derivada temporal dos esforços, encontra-se:

$$
\left[\begin{array}{c}
\dot{\sigma}_{x x} \\
\dot{\sigma}_{y y} \\
\dot{\sigma}_{x y}
\end{array}\right]=\frac{E}{(1+\nu)(1-2 \nu)}\left[\begin{array}{ccc}
(1-\nu) & \nu & 0 \\
\nu & (1-\nu) & 0 \\
0 & 0 & (1-2 \nu)
\end{array}\right]\left\{\left[\begin{array}{l}
\dot{\epsilon}_{x x} \\
\dot{\epsilon}_{y y} \\
\dot{\epsilon}_{x y}
\end{array}\right]-\frac{\sigma^{n-1}}{4 \eta}\left[\begin{array}{ccc}
1 & -1 & 0 \\
-1 & 1 & 0 \\
0 & 0 & 2
\end{array}\right]\left[\begin{array}{l}
\sigma_{x x} \\
\sigma_{y y} \\
\sigma_{x y}
\end{array}\right]\right\}
$$

ou, de um modo mais sucinto,

$$
\dot{\sigma}=D\left(\dot{\epsilon}-\dot{\epsilon}^{v p}\right)
$$

na qual $D$ é matriz de propriedades elásticas:

$$
D=\frac{E}{(1+\nu)(1-2 \nu)}\left[\begin{array}{ccc}
(1-\nu) & \nu & 0 \\
\nu & (1-\nu) & 0 \\
0 & 0 & (1-2 \nu)
\end{array}\right]
$$

e o termo $\dot{\epsilon}^{v p}$, corresponde ao vetor da taxa de deformação viscosa:

$$
\dot{\epsilon}^{v p}=\beta(\sigma)=\frac{\sigma^{n-1}}{4 \eta}\left[\begin{array}{ccc}
1 & -1 & 0 \\
-1 & 1 & 0 \\
0 & 0 & 2
\end{array}\right]\left[\begin{array}{c}
\sigma_{x x} \\
\sigma_{y y} \\
\sigma_{x y}
\end{array}\right]
$$

A solução da Equação 3.18 permite estudar os esforços na litosfera ao longo do tempo.

\subsection{Formulação numérica}

O modelo numérico utilizado neste trabalho foi adaptado de Assumpção e Sacek (2013). As modificações envolveram a adequação do código para as condições de contorno variáveis 
no tempo, necessárias para simular as variações de topografia e cargas sedimentares e as tensões regionais aplicadas no modelo.

As equações constitutivas (Equações 3.17) são resolvidas pelo método dos elementos finitos (e.g. Zienkiewicz e Taylor, 2000; Hughes, 2012) através de um algoritmo explícito adotado na discretização das derivadas temporais. Para o caso puramente elástico, a equação constitutiva, reescrita aqui, são dadas por (Equação 3.1):

$$
\sigma_{i j}^{e}=A_{i j k l}^{e} \epsilon_{k l}^{e}
$$

A Equação 3.18 tem a mesma forma da Equação 3.21, a menos da derivada temporal e o termo correspondente à deformação dúctil. Assim, a formulação numérica do caso puramente elástico aplica-se ao caso viscoelástico, sendo necessário apenas adaptar a discretização temporal. Desse modo, por motivo de clareza, a formulação numérica será apresentada levando-se em conta a Equação 3.21 para as relações constitutivas.

A formulação numérica consiste em resolver uma aproximação discreta das equações contínuas de um problema de valor de contorno. No caso da elasticidade, além das relações constitutivas (Equação 3.21), o problema consiste em resolver as equações de equilíbrio e as condições de contorno:

$$
\begin{aligned}
\sigma_{i j, j}+f_{i}=0 & & \text { em } \Omega \\
u_{i}=q_{i} & & \text { em } \Gamma_{q_{i}} \\
\sigma_{i j} n_{j}=h_{i} & & \text { em } \Gamma_{h_{j}}
\end{aligned}
$$

em que $f_{i}: \Omega \rightarrow \mathbb{R}, q_{i}: \Gamma_{q_{i}} \rightarrow \mathbb{R}$ e $h_{i}: \Gamma_{h_{i}} \rightarrow \mathbb{R}$, sendo $\Omega$ o domínio e $\Gamma$ contorno desse domínio. $\sigma_{i j}$ é dado em termos das Equações 3.21 e 3.3 . Uma simples representação desse domínio é ilustrada na Figura 3.4 .

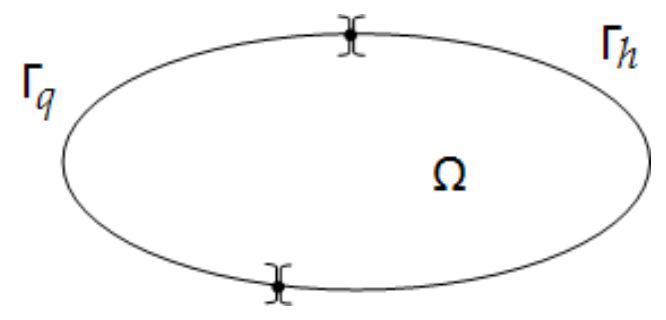

Figura 3.4: Representação do domínio $\Omega$ e dos contornos $\Gamma_{q}$ e $\Gamma_{h}$.

Hughes (2012) apresenta detalhadamente a formulação por elementos finitos do problema apresentado. Adiante, tal derivação será apresentada simplificadamente. 
Multiplicando a Equação 3.22 por uma função teste $w_{i}$ e integrando em $\Omega$ :

$$
\int_{\Omega} w_{i} \sigma_{i j, j} \mathrm{~d} \Omega+\int_{\Omega} w_{i} f_{i} \mathrm{~d} \Omega=0
$$

Fazendo a integração por partes para a primeira integral e rearranjando os termos:

$$
\int_{\Omega} w_{(i, j)} \sigma_{i j} \mathrm{~d} \Omega=\int_{\Omega} w_{i} f_{i} \mathrm{~d} \Omega+\sum_{i} \int_{\Gamma_{h_{i}}} w_{i} \sigma_{i j} n_{j} \mathrm{~d} \Gamma
$$

em que o somatório $\sum_{i}$ corresponde ao número de dimensões espaciais. Substituindo a Equação 3.21, a definição da deformação e a condição de contorno dada pela Equação 3.22c:

$$
\int_{\Omega} w_{(i, j)} A_{i j k l} u_{(k, l)} \mathrm{d} \Omega=\int_{\Omega} w_{i} f_{i} \mathrm{~d} \Omega+\sum_{i} \int_{\Gamma_{h_{i}}} w_{i} h_{j} \mathrm{~d} \Gamma
$$

sendo

$$
\begin{aligned}
u_{(i, j)} & =\frac{u_{i, j}+u_{j, i}}{2} \\
w_{(i, j)} & =\frac{w_{i, j}+w_{j, i}}{2}
\end{aligned}
$$

Utilizando a notação compacta:

$$
\begin{aligned}
a(w, u) & =\int_{\Omega} w_{(i, j)} A_{i j k l} u_{(k, l)} \mathrm{d} \Omega \\
(w, f) & =\int_{\Omega} w_{i} f_{i} \mathrm{~d} \Omega \\
(w, h)_{\Gamma} & =\sum_{i} \int_{\Gamma_{h_{i}}} w_{i} h_{j} \mathrm{~d} \Gamma
\end{aligned}
$$

reescreve-se a Equação 3.25 como:

$$
a(w, u)=(w, f)+(w, h)_{\Gamma}
$$

Utilizando as seguintes definições:

$$
\begin{gathered}
\epsilon(u)=\left\{\begin{array}{c}
u_{x, x} \\
u_{y, y} \\
\left(u_{y, x}+u_{x, y}\right) / 2
\end{array}\right\} \\
\epsilon(w)=\left\{\begin{array}{c}
w_{x, x} \\
w_{y, y} \\
\left(w_{y, x}+w_{x, y}\right) / 2
\end{array}\right\}
\end{gathered}
$$




$$
\boldsymbol{D}=\left[D_{I J}\right]=\left[\begin{array}{ccc}
D_{11} & D_{12} & D_{13} \\
& D_{22} & D_{23} \\
\text { Sim. } & D_{33}
\end{array}\right]
$$

e através da notação utilizando vetores e matrizes,

$$
w_{(i, j)} A_{i j k l} u_{(k, l)}=\boldsymbol{\epsilon}(\boldsymbol{w})^{\boldsymbol{T}} \boldsymbol{D} \boldsymbol{\epsilon}(\boldsymbol{u})
$$

a integral dada pela Equação 3.27 a é expressa como,

$$
a(w, u)=\int_{\Omega} \boldsymbol{\epsilon}(\boldsymbol{w})^{\boldsymbol{T}} \boldsymbol{D} \boldsymbol{\epsilon}(\boldsymbol{u}) \mathrm{d} \Omega
$$

e assim a Equação 3.24 pode ser reescrita como

$$
\int_{\Omega} \boldsymbol{\epsilon}(\boldsymbol{w})^{\boldsymbol{T}} \boldsymbol{D} \boldsymbol{\epsilon}(\boldsymbol{u}) \mathrm{d} \Omega=\int_{\Omega} \boldsymbol{\epsilon}(\boldsymbol{w})^{\boldsymbol{T}} f_{i} \mathrm{~d} \Omega+\sum_{i} \int_{\Gamma_{h_{i}}} w_{i} \sigma_{i j} n_{j} \mathrm{~d} \Gamma
$$

A Equação 3.24 (ou, na forma compacta, Equação 3.28), é a chamada formulação fraca do problema, na forma integral, e é equivalente a formulação inicial na forma de equações diferenciais, também chamada formulação forte (Hughes, 2012). A aproximação pelo método dos elementos finitos consiste em discretizar a forma fraca aproximando as funções contínuas em funções de um espaço finito, discretizado. Sendo $u^{h}$ a aproximação para $u$, tem-se a seguinte decomposição:

$$
u^{h}=v^{h}+q^{h}
$$

Devido a condição de contorno dada pela Equação $3.22 \mathrm{~b}, v^{h}$ se anula sobre a borda $\Gamma_{q_{i}}$. Assim, na forma compacta, utilizando $w^{h}$ como aproximação de $w$,

$$
a\left(w^{h}, u^{h}\right)=\left(w^{h}, f\right)+\left(w^{h}, h\right)_{\Gamma}
$$

Substituindo $u^{h}$ e rearranjando os termos,

$$
a\left(w^{h}, v^{h}\right)=\left(w^{h}, f\right)+\left(w^{h}, h\right)_{\Gamma}-a\left(w^{h}, q^{h}\right)
$$

As funções $v^{h}$ e $q^{h}$ podem ser escritas em termos de funções de forma e dos valores nos nós da malha:

$$
\begin{gathered}
v^{h}=v_{i}^{h} e_{i} \\
q^{h}=q_{i}^{h} e_{i} \\
w^{h}=w_{i}^{h} e_{i}
\end{gathered}
$$


Para o caso 2D $(i, j=1,2), e_{1}=\left\{\begin{array}{lll}1 & 0\end{array}\right\}^{T}$ e $\left\{\begin{array}{ll}0 & 1\end{array}\right\}^{T}$, e

$$
\begin{aligned}
v_{i}^{h} & =\sum_{A} N_{A} d_{i A} \\
q_{i}^{h} & =\sum_{A} N_{A} q_{i A} \\
w_{i}^{h} & =\sum_{A} N_{A} c_{i A}
\end{aligned}
$$

nas quais $N_{A}$ são as funções de forma sobre elementos triangulares e $A$ corresponde ao índice de cada nó com exceção aos nós onde as condições de contorno são especificadas, cujos índices são representados por $A^{*}$. Substituindo as Equações 3.39 na Equação 3.37 e simplificando a expressão, obtém-se (para o caso $2 \mathrm{D}, 1 \leq i \leq 2$ ):

$$
\sum_{j=1}^{2}\left(\sum_{B} a\left(N_{A} e_{i}, N_{B} e_{j}\right) d_{j B}\right)=\left(N_{A} e_{i}, f\right)+\left(N_{A} e_{i}, h\right)_{\Gamma}-\sum_{j=1}^{2}\left(\sum_{B} a\left(N_{A} e_{i}, N_{B} e_{j}\right) q_{j B}\right)
$$

A última equação, na forma matricial, representa um sistema linear, e é dada por

$$
K d=F
$$

sendo

$$
\begin{array}{r}
K=\left[K_{P Q}\right] \\
d=\left\{d_{Q}\right\} \\
F=\left\{F_{P}\right\}
\end{array}
$$

As Equações 3.42 e e 3.42 c representam uma matriz e um vetor dados por:

$$
\begin{gathered}
K_{P Q}=a\left(N_{A} e_{i}, N_{B} e_{j}\right) \\
F_{P}=\left(N_{A} e_{i}, f\right)+\left(N_{A} e_{i}, h\right)_{\Gamma}-\sum_{j=1}^{2}\left(\sum_{B} a\left(N_{A} e_{i}, N_{B} e_{j}\right) q_{j B}\right)
\end{gathered}
$$

nas quais os índices $P$ e $Q$ correspondem à numeração global das equações, mapeados pelos graus de liberdade $i$ e $j$ dos nós $A$ e $B$.

Pelas definições das Equações 3.29, 3.30 e 3.33 ,

$$
\epsilon\left(N_{A} e_{i}\right)=\left[\begin{array}{cc}
N_{A, 1} & 0 \\
0 & N_{A, 2} \\
N_{A, 2} & N_{A, 1}
\end{array}\right]=B_{A} e_{i}
$$


e assim, a Equação 3.43 é escrita explicitamente como

$$
K_{P Q}=e_{i}^{T} \int_{\Omega} B_{A}^{T} D B_{B} \mathrm{~d} \Omega e_{j}
$$

De modo semelhante,

$$
\begin{aligned}
\left(N_{A} e_{i}, f\right) & =\int_{\Omega} N_{A} f_{i} \mathrm{~d} \Omega \\
\left(N_{A} e_{i}, h\right)_{\Gamma} & =\int_{\Gamma_{h_{i}}} N_{A} h_{i} \mathrm{~d} \Gamma
\end{aligned}
$$

e, então, a Equação 3.44 toma a forma

$$
F_{P}=\int_{\Omega} N_{A} f_{i} \mathrm{~d} \Omega+\int_{\Gamma_{h_{i}}} N_{A} h_{i} \mathrm{~d} \Gamma-\sum_{j=1}^{2}\left(\sum_{B} a\left(N_{A} e_{i}, N_{B} e_{j}\right) q_{j B}\right)
$$

A montagem do sistema linear (Equação 3.41) é feita através da soma da contribuição individual de cada elemento na matriz global,

$$
\begin{aligned}
& K=\sum_{e} k^{e} \\
& F=\sum_{e} f^{e}
\end{aligned}
$$

sendo que

$$
\begin{gathered}
k^{e}=\left[k_{p q}^{e}\right]=e_{i}^{T} \int_{\Omega} B_{a}^{T} D B_{b} \mathrm{~d} \Omega e_{j} \\
f^{e}=\left[f_{p}^{e}\right]=\int_{\Omega} N_{a} f_{i} \mathrm{~d} \Omega+\int_{\Gamma_{h_{i}}^{e}} N_{a} h_{i} \mathrm{~d} \Gamma-\sum_{j=1}^{2} k_{p q}^{e} q_{q}^{e} \\
B_{a}=\left[\begin{array}{cc}
N_{a, 1} & 0 \\
0 & N_{a, 2} \\
N_{a, 2} & N_{a, 1}
\end{array}\right]
\end{gathered}
$$

Os índices $a$ e $b$ correspondem à numeração local dos nós de um elemento e juntamente com os índices $i$ e $j$ determinam a contribuição de cada elemento na matriz e vetor globais do sistema da Equação 3.41 .

\subsection{Validação do modelo numérico}

Para verificar o resultado do modelo numérico foi realizada a comparação com o resultado de uma solução analítica para um caso simples, em uma dimensão (1D) do modelo viscoelástico apresentado por Kusznir e Bott (1977). 
Assumindo um modelo de litosfera composto por duas camadas horizontais, uma superior de espessura $l_{s}$ e viscosidade $\eta_{s}$ e uma inferior de espessura $l_{i}$ e viscosidade $\eta_{i}$, ambas com mesmo módulo de elasticidade $E$, o esforço em cada camada $\left(\sigma_{s}\right.$ e $\left.\sigma_{i}\right)$ está relacionado ao esforço horizontal $T$ aplicado em toda a litosfera por (Kusznir e Bott, 1977):

$$
\sigma_{s} l_{s}+\sigma_{i} l_{i}=l T
$$

na qual $l=l_{s}+l_{i}$ é a espessura total da litosfera.

A taxa de deformação $(\dot{\epsilon})$ em cada camada é dada por (Kusznir e Bott, 1977):

$$
\dot{\epsilon}=\frac{\dot{\sigma}}{E}+\frac{\sigma}{4 \eta}
$$

e assumindo que as camadas estão unidas, os esforços na camada superior e inferior são:

$$
\begin{gathered}
\sigma_{s}=T\left[f \eta_{s}+\left(1-\eta_{s}\right) \exp \left(\frac{-E t}{4 \eta_{s} \eta_{i} f}\right)\right] \\
\sigma_{i}=T\left[f \eta_{i}+\left(1-\eta_{i}\right) \exp \left(\frac{-E t}{4 \eta_{s} \eta_{i} f}\right)\right]
\end{gathered}
$$

nas quais $f=l /\left(l_{s} \eta_{s}+l_{i} \eta_{i}\right)$.

O modelo numérico utilizado para comparar com o resultado analítico é apresentado na Figura 3.5. O modelo é composto por duas camadas horizontais de espessuras $l_{s}$ e $l_{i}$, e viscosidades $\eta_{s}$ e $\eta_{i}$, nas camadas superior e inferior, respectivamente. Aplicou-se um esforço compressivo em uma das bordas verticais do modelo, sobre uma camada lateral de espessura $l=l_{s}+l_{i}$. Foram escolhidos valores altos para a viscosidade e para o módulo elástico dessa camada lateral, de modo a representar um bloco infinitamente rígido, transferindo igualmente o esforço aplicado às duas camadas horizontais adjacentes. A outra borda vertical do modelo foi mantida fixa na horizontal, permitindo que houvesse deformação apenas na direção vertical. Para a borda inferior, restringiu-se o movimento na direção vertical. O restante do modelo movimenta-se livremente nas direções horizontal e vertical.

A Figura 3.6 apresenta a comparação dos resultados numéricos e da solução analítica assumindo os valores de módulo de elasticidade $E=70 \mathrm{GPa}$, viscosidades $\eta_{s}=10^{24} \mathrm{~Pa} \cdot \mathrm{s} \mathrm{e}$ $\eta_{i}=10^{23} \mathrm{~Pa} \cdot \mathrm{s}$ e espessuras $l_{s}=l_{i}=50 \mathrm{~km}$. Como pode ser observado, existe uma pequena diferença, menor do que $2 \%$ do valor do esforço, apenas durante um intervalo de tempo no qual os esforços variam ao longo do tempo. O resultado numérico não coincide exatamente 


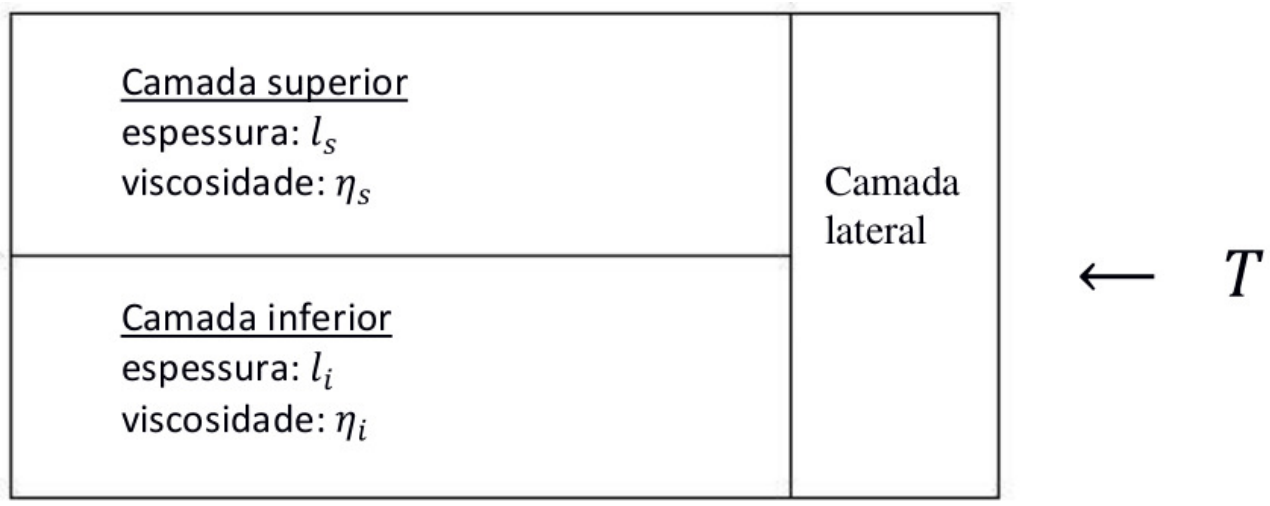

Figura 3.5: Representação esquemática do modelo numérico utilizado na comparação com uma solução analítica. $T$ é o esforço aplicado no modelo.
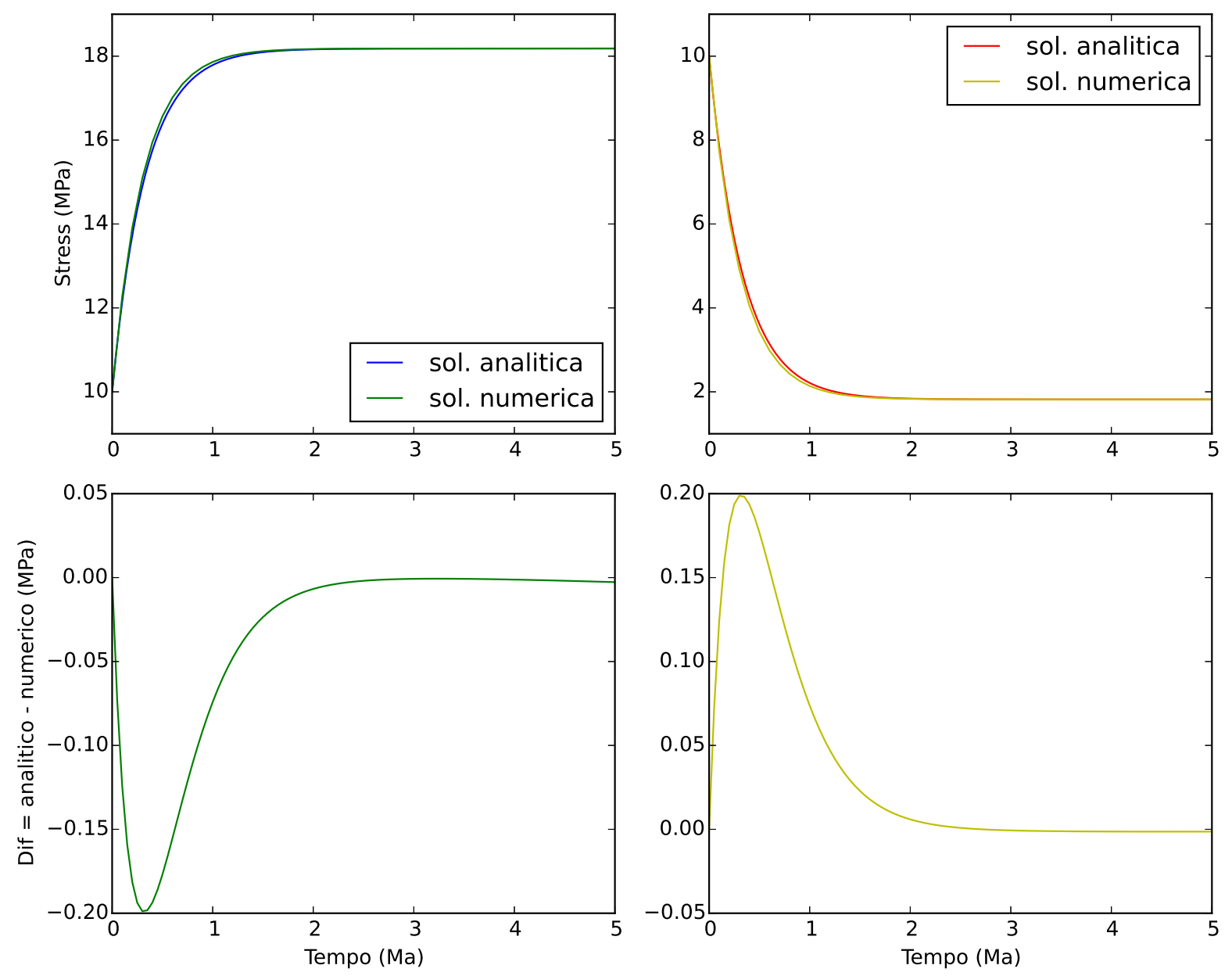

Figura 3.6: Esforço horizontal e diferença entre a solução analítica e o resultado numérico na camada superior (gráficos à esquerda) e inferior (gráficos à direita) do modelo.

com o analítico devido a este representar um modelo unidimensional, em comparação com modelo numérico, bidimensional. 
Com a intenção de obter uma representação mais próxima do modelo analítico, modificou-se o modelo numérico removendo as contribuições do esforço horizontal na deformação vertical. Essa condição é obtida assumindo o valor zero para o coeficiente de Poisson. Com essa modificação, a influência dos esforços horizontais na deformação vertical do modelo numérico é limitada e desse modo os esforços obtidos no modelo numérico se aproximaram mais do resultado analítico (Fig. 3.7). Nesse caso, reduziu-se a diferença em duas ordem de grandeza em relação ao resultado anterior, na comparação da solução numérica e analítica. Desse modo, esse teste mostra que o modelo numérico de fato reproduz o padrão de esforços no modelo como esperado pela solução analítica. A modificação feita, assumindo um valor nulo para o coeficiente de Poisson, tratou apenas de tornar o modelo mais fidedigno ao coso unidimensional.

\subsection{Envelope de ruptura}

O modelo numérico utilizado nesse trabalho simula o comportamento viscoelástico da litosfera ao longo do tempo. Uma limitação do modelo é que não incorpora o comportamento plástico das rochas. Esse comportamento está relacionado com a ruptura (falhamento) das rochas na crosta superior. Se os esforços deviatóricos superarem o limite de resistência das rochas, então uma falha será formada e a rocha sofrerá ruptura. No caso de regiões frágeis preexistentes, a deformação plástica pode ser concentrada nessas regiões, susceptíveis ao falhamento. Embora o modelo numérico não incorpore esse fenômeno, utilizou-se o critério de ruptura de Mohr-Coulomb (e.g. Ranalli, 1995) para determinar se os esforços deviatóricos atingiriam a tensão necessária para a ruptura das rochas no modelo viscoelástico.

O critério de ruptura de Mohr-Coulomb estabelece a condição de ruptura de uma rocha em um plano. Segundo esse critério, a ruptura ocorre quando o esforço cisalhante $\tau$, no plano, atinge o valor (Turcotte e Schubert, 2002)

$$
|\tau|=S+\mu \sigma_{n}
$$

na qual $\sigma_{n}$ é o esforço normal ao plano, $S$ é o coeficiente de coesão da superfície e $\mu=\tan \phi$ é o coeficiente de fricção interna, sendo $\phi$ o ângulo de fricção interna. $S$ é o valor que uma reta tangente ao círculo de Mohr intercepta o eixo vertical (eixo- $\tau$ ). O valor de $\phi$ para muitas rochas é de $\simeq 30^{\circ}$ (Ranalli, 1995). 

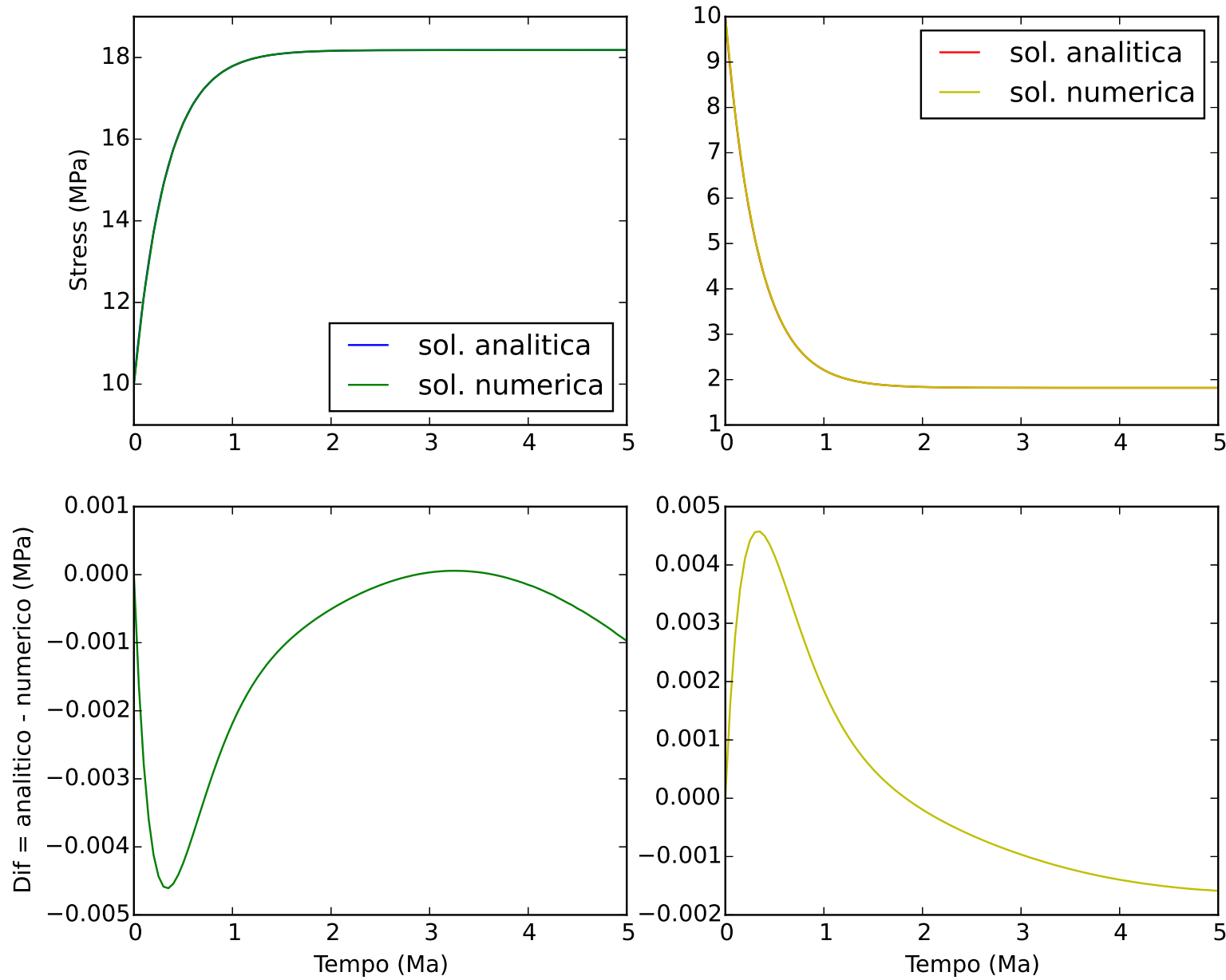

Figura 3.7: Esforço horizontal e diferença entre a solução analítica e o resultado numérico na camada superior (gráficos à esquerda) e inferior (gráficos à direita) do modelo. Para este resultado foi assumido valor nulo para o coeficiente de Poisson no modelo numérico.

Em termos dos esforços principais, a condição de ruptura ocorre quando a seguinte expressão for satisfeita (Turcotte e Schubert, 2002)

$$
\sigma_{1}\left[\left(\mu^{2}+1\right)^{1 / 2}-\mu\right]-\sigma_{3}\left[\left(\mu^{2}+1\right)^{1 / 2}+\mu\right]=2 S
$$

Utilizando o critério de Mohr-Coulomb calculou-se a profundidade, ao longo do modelo, na qual a condição dada pela Equação 3.59 é satisfeita, obtendo-se assim um envelope de ruptura. Desse modo, esse envelope de ruptura representa o limite máximo (profundidade) na qual as rochas sofreriam ruptura de acordo com o critério adotado. Esse envelope de ruptura foi utilizado para comparar os modelos nos diferentes testes numéricos. 
Capítulo 4

\section{Configuração numérica}

\subsection{Vínculos de erosão e sedimentação}

Os processos superficiais de erosão e sedimentação modificam continuamente a superfície terrestre ao transportar sedimentos de um local a outro, contribuindo para modificar o estado de tensão no interior da litosfera pela redistribuição de cargas sobre a placa. Como resultado, a topografia tende a ser arrasada e uma grande carga de sedimentos acumula-se nas bacias sedimentares. Devido à natureza desse processo, a quantidade de denudação em uma área não pode ser obtida diretamente. Uma forma indireta para quantificar a magnitude da denudação, e consequente exumação das rochas subjacentes, é através de métodos termocronológicos.

A termocronologia é um método de datação que permite obter a história térmica das rochas, isto é, a variação da temperatura da rocha ao longo do tempo (e.g. Gallagher et al., 1998). A partir da história térmica das rochas que afloram na superfície, é possível inferir a história de exumação das rochas. No entanto, essa relação é susceptível às suposições acerca do gradiente geotérmico e sua variação espacial e temporal. Os métodos termocronológicos tem sido amplamente aplicados para entender a evolução da paisagem no contexto de margens passivas (e.g. Gallagher et al., 1998). Na região sudeste do Brasil, diversos estudos baseados na termocronologia foram realizados com intuito de estudar a evolução da margem continental após a ruptura do Gondwana (e.g. Gallagher et al., 1994; Saenz et al., 2005; Hiruma et al., 2010, Cogné et al., 2011, 2012). Esses trabalhos fornecem vínculos da denudação na região sudeste do Brasil.

Gallagher et al. (1994), com base nos dados de traços de fissão em apatita (em inglês: Apatite Fission Track, AFT), reportaram $3 \mathrm{~km}$ de denudação na região costal e $1 \mathrm{~km}$ no 
interior do continente. Cogné et al. (2011) apresentaram novos dados termocronológicos baseados na metodologia (U-Th)/He em apatita (AHe) além de reanalisar um subconjunto dos dados de AFT do trabalho de Gallagher et al. (1994) e obtiveram resultados consistentes com aqueles anteriormente estabelecidos inferindo até $4 \mathrm{~km}$ de denudação na região costal e cerca de $2 \mathrm{~km}$ no interior do continente. A diferença da denudação inferida, no entanto, como mencionado, é dependente das hipóteses assumidas para o gradiente geotérmico. Cogné et al. (2012) apresentaram dados (AFT e AHe) para a região das Bacias de Taubaté e Resende e das Serras da Mantiqueira e do Mar e a região costal, que mostraram um período de resfriamento entre 100 e 70 Ma, e um período de resfriamento acentuado posterior, entre 60 e $40 \mathrm{Ma}$, nas amostras das bacias.

A partir das histórias térmicas reinterpretadas por Cogné et al. (2011) fez-se uma estimativa para a denudação total. Na Figura 4.1 é apresentada a região sudeste do Brasil com indicação (triângulos) da localização das amostras (Gallagher et al., 1994; Cogné et al., 2011) cujas histórias térmicas foram utilizadas para se estimar a denudação. Na mesma figura é apresentado também um perfil topográfico/batimétrico aproximadamente ortogonal à linha de costa indicando as principais feições morfológicas da área.

Para obter a denudação é necessário estabelecer o gradiente geotérmico. O gradiente geotérmico é dado pela razão do fluxo de calor $\left(Q_{T}\right)$ e da condutividade térmica $\left(\kappa_{T}\right)$. Considerando a temperatura $(T)$ estimada dos dados de termocronologia, e a temperatura na superfície $\left(T_{S}\right)$, a denudação é dada por (e.g Gallagher e Brown, 2004):

$$
z=\kappa_{T}\left(T-T_{S}\right) / Q_{T}
$$

A Equação 4.1 consiste em uma aproximação para obter a denudação, pois assume que o fluxo térmico é constante (Gallagher e Brown, 2004). Como o paleogradiente geotérmico, assim como sua variação ao longo do tempo, não são conhecidos, essa aproximação é necessária para se estimar a denudação. Assumindo o gradiente geotérmico de $30^{\circ} \mathrm{C} / \mathrm{km}$ a denudação máxima obtida é indicada pelas barras verticais acima do perfil topográfico na Figura 4.1. A posição ao longo do perfil foi obtida pela projeção das posições das amostras no perfil (indicado no mapa na mesma figura). O valor utilizado está no intervalo, embora ligeiramente superior, já utilizado em outros trabalhos (e.g. Cogné et al., 2011) cujo valor foi de $20 \pm 5{ }^{\circ} \mathrm{C} / \mathrm{km}$. Quanto menor o gradiente geotérmico maior a estimativa da denudação, assim, a estimativa utilizada subestima a denudação. Os detalhes de como essa estimativa 
da denudação foi aplicada no modelo numérico é apresentada na Seção 4.2 .

Na Figura 4.1 também é ilustrada uma parte da seção estratigráfica da Bacia de Santos apresentada por Contreras et al. (2010) e representa o espesso pacote sedimentar acumulado ao longo da evolução da margem desde a abertura do Oceano Atlântico. Essa carga sedimentar foi utilizada para estimar a sedimentação no modelo numérico. Os detalhes de como a carga sedimentar foi incorporada no modelo numérico também é apresentada na Seção 4.2 .

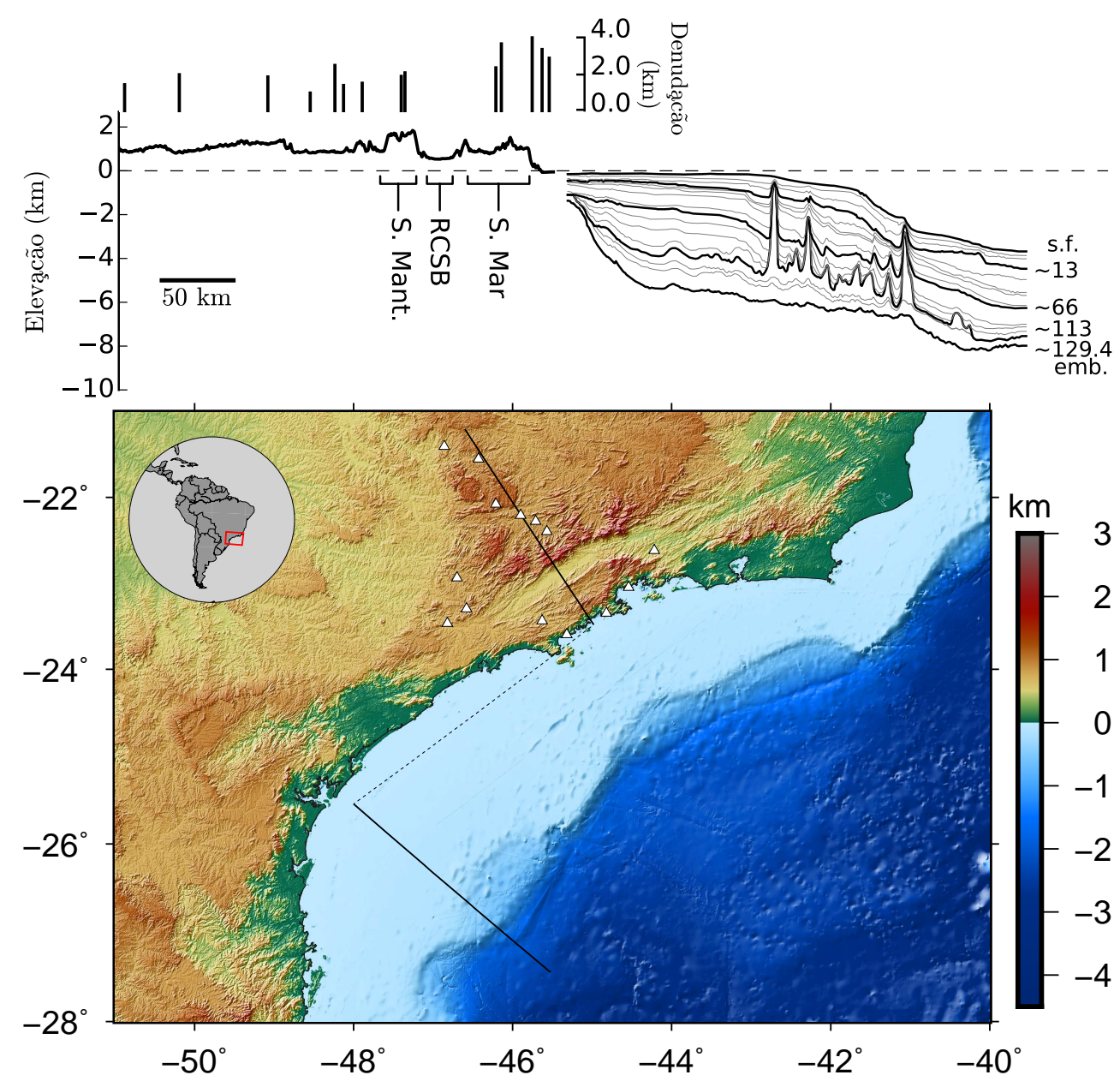

Figura 4.1: Mapa do sudeste do Brasil e perfil topográfico/batimétrico. Os triângulos indicam as posições das amostras utilizadas para obter o vínculo de denudação (Gallagher et al., 1994, Cogné et al., 2011). O perfil representa a topografia e as barras verticais indicam a denudação máxima para cada amostra projetada ao longo do perfil. Estão indicadas as áreas que correspondem à Serra da Mantiqueira (S. Mant.), às bacias cenozóicas do Rifte Continental do Sudeste do Brasil (RCSB), e à Serra do Mar (S. Mar). A seção estratigráfica da bacia de Santos foi digitalizada de Contreras et al. (2010). O números (à direita) referem-se às idades (Ma) aproximadas para os horizontes estratigráficos em traços espessos. emb.: embasamento; s.f.: fundo do oceano. 


\subsection{Configuração do modelo}

Para simular a evolução do padrão de esforços na margem sudeste do Brasil foram considerados a variação de carga sob o modelo, devido à erosão e sedimentação, o efeito do soerguimento causado pela passagem de uma anomalia térmica mantélica e o esforço compressivo regional associado com o empurrão pela expansão da cadeia meso-oceânica.

A configuração do modelo utilizada nos experimentos numéricos representa uma margem continental estirada. O modelo foi obtido considerando o equilíbrio isostático pelo modelo de compensação de Airy-Heiskanen (e.g. Turcotte e Schubert, 2002) entre duas colunas: uma coluna de referência, com espessura da crosta $H_{c}$ e uma com crosta afinada, de espessura $h$ (Figura 4.2). Considerando a espessura do manto $h_{m}$ e da lâmina d'água $h_{w}$, do equilíbrio isostático entre as colunas A e B (Figura 4.2) resulta

$$
H_{c} \rho_{c} g=h_{w} \rho_{w} g+h \rho_{c} g+\left(H_{c}-h-h_{w}\right) \rho_{m} g
$$

em que $\rho_{c}$ é a densidade da crosta, $\rho_{m}$ é a densidade do manto e $\rho_{w}$ é a densidade da água. Simplificando os termos comuns, obtém-se

$$
h_{w}\left(\rho_{m}-\rho_{w}\right)=\left(\rho_{m}-\rho_{c}\right)\left(H_{c}-h\right)
$$

e assim a batimetria é dada por:

$$
h_{w}=\frac{\rho_{m}-\rho_{c}}{\rho_{m}-\rho_{w}}\left(H_{c}-h\right)
$$

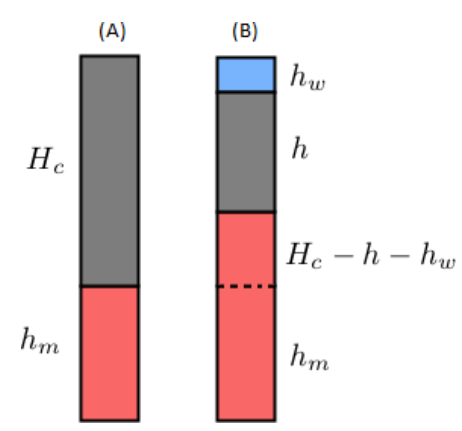

Figura 4.2: Colunas litosféricas em equilíbrio isostático (Airy-Heiskanen). (A) Coluna continental de referência com espessura da crosta $H_{c}$ e (B) coluna com crosta afinada de espessura $h$ e lâmina d'água de espessura $h_{w} . h_{m}$ é a espessura do manto litosférico original.

A batimetria do modelo foi calculada pela Equação 4.3 assumindo-se um valor padrão para a espessura da crosta na coluna de referência e dos valores da crosta afinada. Para 
determinar os valores de $h$, ou seja, um perfil de variação da crosta afinada ao longo do modelo, foi considerado um fator de estiramento $\beta$ igual a 3 (Chang et al., 1992). O fator $\beta$ corresponde ao estiramento sofrido pela litosfera, isto é, a razão entre o comprimento após estiramento e o inicial (McKenzie, 1978). Esse valor também já foi utilizado em outros trabalhos ao se tratar de um modelo genérico de margem estirada (e.g. Gallagher et al., 1994) representativo do sudeste do Brasil. Assim, a espessura da crosta afinada $h_{a}$ é:

$$
h_{a}=\frac{H_{c}}{\beta}=\frac{H_{c}}{3}
$$

A partir dos valores de $H_{c}$ e $h_{a}$, foi obtido um perfil da variação da espessura da crosta, e a partir da Equação 4.3 calculou-se o perfil de variação da batimetria. A espessura da crosta entre a região de referência e a de crosta afinada foi obtida assumindo uma variação linear para o intervalo de transição de $60 \mathrm{~km}$. Considerando esses parâmetros, a profundidade da Moho $h_{m o h o}$ é dada por:

$$
h_{m o h o}=-h_{w}-h
$$

em que $h$ é a espessura da crosta ao longo do perfil.

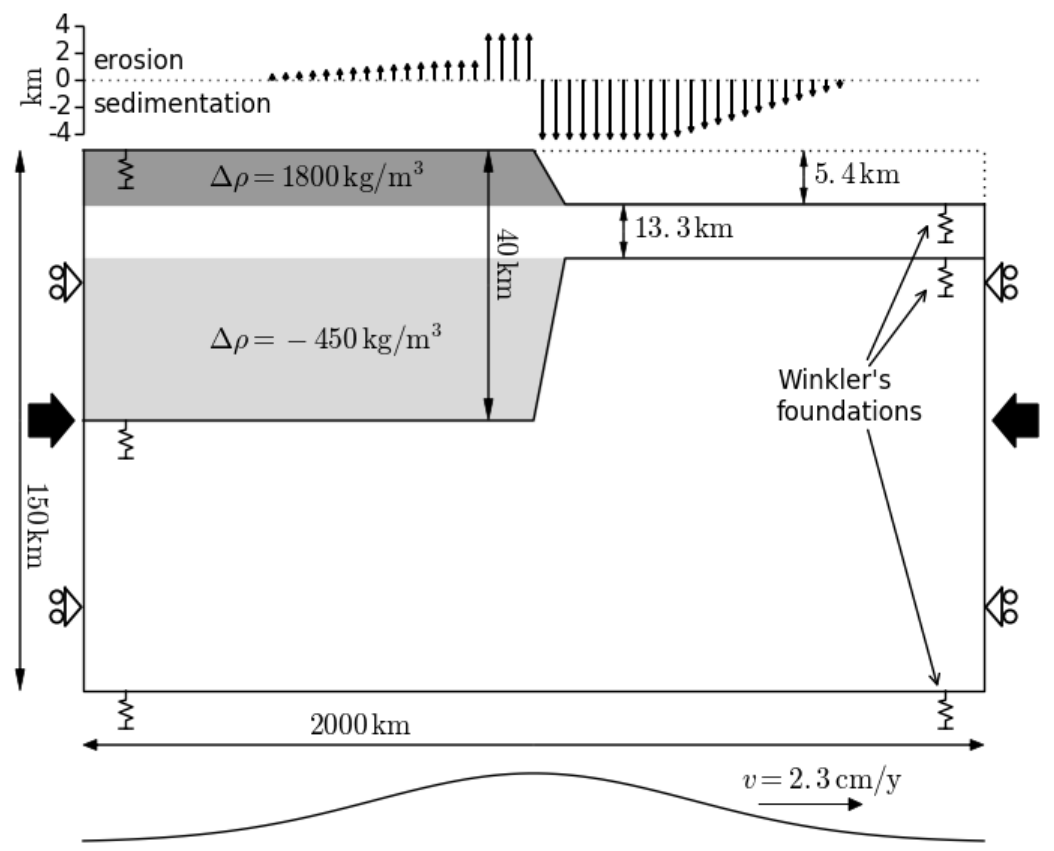

Figura 4.3: Configuração do modelo numérico. A crosta tem espessura variável entre $H_{c}$ e $h_{a}$. Sob a crosta não estirada, o manto litosférico tem espessura de $110 \mathrm{~km}$. A espessura da lâmina d'água é indicada por $h_{w}$. 
Tabela 4.1 - Parâmetros do modelo numérico.

\begin{tabular}{cccc}
\hline Descrição & Parâmetro & Valor & Unidade \\
\hline \hline Espessura da crosta no continente & $H_{c}$ & 40 & $\mathrm{~km}$ \\
Espessura da crosta afinada & $h_{a}$ & 13.3 & $\mathrm{~km}$ \\
Comprimento da zona de transição & & 60 & $\mathrm{~km}$ \\
Fator de estiramento & $\beta$ & 3 & \\
Densidade da crosta & $\rho_{c}$ & 2800 & $\mathrm{~kg} / \mathrm{m}^{3}$ \\
Densidade do manto & $\rho_{m}$ & 3250 & $\mathrm{~kg} / \mathrm{m}^{3}$ \\
Densidade da água & $\rho_{w}$ & 1030 & $\mathrm{~kg} / \mathrm{m}^{3}$ \\
Espessura da litosfera & $L_{z}$ & 150 & $\mathrm{~km}$ \\
Extensão do modelo & $L_{x}$ & 2000 & $\mathrm{~km}$ \\
Coeficiente de Poisson & $\nu$ & 0.25 & \\
Módulo de Young & $E$ & 70 & $\mathrm{GPa}$ \\
Aceleração da gravidade & $g$ & 9.8 & $\mathrm{~m} / \mathrm{s}^{2}$ \\
\hline
\end{tabular}

* Conferir texto para detalhes.

A viscosidade efetiva (não Newtoniana) da litosfera foi calculada pela relação (e.g Grana e Richardson, 1996)

$$
\eta_{\mathrm{eff}}=\frac{\exp ((E+P V) / R T)}{2 A \sigma^{(n-1)}}
$$

sendo $E$ a energia de ativação, $P$ a pressão, $V$ o volume de ativação, $R\left(=8.314 \mathrm{JK}^{-1} \mathrm{~mol}^{-1}\right)$ a constante universal dos gases, $T$ a temperatura, $A$ o fator pré-exponencial (constante da lei de potência), $\sigma$ a raiz quadrada do segundo invariante do tensor de esforço deviatórico, e $n$ o coeficiente (expoente) da lei de potência. A viscosidade efetiva é incorporada no modelo numérico através do termo relacionado ao comportamento viscoso (Equação 3.20 ). A Tabela 4.2 apresenta os parâmetros reológicos obtidos de Ranalli (1995) e Karato e $\mathrm{Wu}$ (1993). A temperatura na superfície e na base do modelo foi de 0 e $1300^{\circ} \mathrm{C}$, respectivamente, variando linearmente na porção continental do modelo. Na porção oceânica a temperatura variou linearmente até a profundidade $L_{z} / \beta$ e foi mantida constante (em $1300^{\circ} \mathrm{C}$ ) abaixo dessa profundidade.

Tabela 4.2 - Parâmetros reológicos.

\begin{tabular}{ccccc}
\hline & $A\left(\mathrm{~Pa}^{-\mathrm{n}} \mathrm{s}^{-1}\right)$ & $n$ & $E(\mathrm{~kJ} / \mathrm{mol})$ & $V\left(\mathrm{~m}^{3} \mathrm{~mol}^{-1}\right)$ \\
\hline \hline Crosta & $2.08 \times 10^{-23}$ & 3.2 & 238 & 0 \\
Manto & $2.42 \times 10^{-16}$ & 3.5 & 540 & $2 \times 10^{-5}$ \\
\hline
\end{tabular}

A configuração do modelo é representada na Figura 4.3. O tamanho do modelo é de 
$2000 \times 150 \mathrm{~km}^{2}$, sendo que na porção continental a crosta tem $40 \mathrm{~km}$ de espessura. O modelo tem $201 \times 61=12261$ nós, resultando em 23600 elementos triangulares e a Figura 4.4 ilustra a malha triangular utilizada. A variação da crosta e a batimetria foi obtida pelo método descrito anteriormente. Nas três interfaces com contraste de densidade (superfície, base da crosta e base do modelo), foram aplicadas forças restauradoras de acordo com a formulação de fundações de Winkler (Desai, 1979). Apenas nas laterais do modelo o movimento dos nós das bordas foram restringidos na direção horizontal, permanecendo livres para se movimentar na direção vertical. A densidade das rochas foi incorporada no modelo através do contraste de densidade assumindo o perfil de variação vertical de densidade na porção oceânica como referência. Desse modo, como indicado na Figura 4.3. na região oceânica o contraste de densidade é nulo, enquanto na região continental a porção superior da crosta tem contraste de densidade positiva de $1800 \mathrm{~kg} / \mathrm{m}^{3}$ e a base da crosta tem contraste de densidade negativa de $-450 \mathrm{~kg} / \mathrm{m}^{3}$. As setas nas laterais do modelo indicam a componente compressiva aplicada em alguns dos testes numéricos. Essa componente foi incorporada deslocando-se horizontalmente os nós das laterais do modelo pela quantidade resultante da deformação elástica unidimensional da força aplicada.

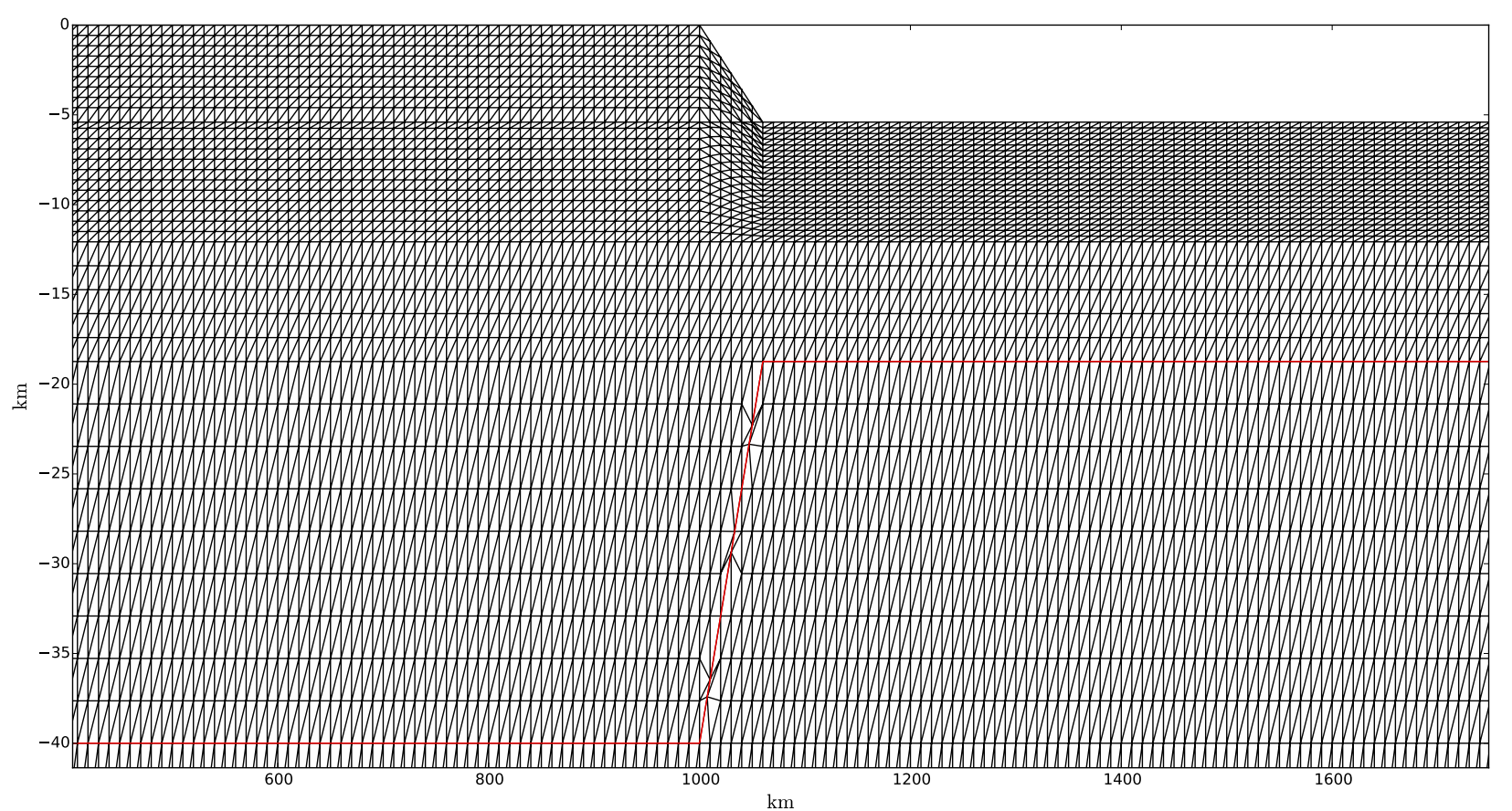

Figura 4.4: Malha triangular do modelo. A malha é composta por $201 \times 61$ nós. A linha vermelha indica a profundidade da Moho. Apenas uma parte da malha é representada na figura.

A variação de carga (erosão/sedimentação) foi incorporada através da aplicação da força gravitacional equivalente na superfície do modelo. Nesse caso, a erosão corresponde a uma 
força vertical negativa, enquanto a sedimentação corresponde a uma força vertical positiva. Essa mesma abordagem foi utilizada para aplicar a força correspondente à passagem de uma anomalia térmica sob a base do modelo. Os demais valores dos parâmetros utilizados no modelo são apresentados na Tabela 4.1.

$\mathrm{Na}$ parte superior da Figura 4.3 estão indicados, por setas verticais, os valores de denudação e sedimentação aplicados no modelo ao longo da simulação. Os valores indicam a quantidade total até o fim da simulação. Considerou-se a erosão máxima de $3 \mathrm{~km}$ ao longo de $100 \mathrm{~km}$ próximo à costa, $1 \mathrm{~km}$ ao longo de $100 \mathrm{~km}$ e diminuindo linearmente (até zero) por 400 km em direção ao interior do continente. Para a sedimentação, considerou-se o máximo de $4 \mathrm{~km}$ ao longo de $300 \mathrm{~km}$ próximo à margem e diminuindo linearmente (até zero) ao longo de $400 \mathrm{~km}$. A variação temporal de aplicação da erosão e sedimentação é descrita adiante.

Na parte inferior da Figura 4.3 é representado esquematicamente um perfil da anomalia térmica sob a base da litosfera, obtido pela relação

$$
s(x, t)=A e^{-(x-v t+\Delta x)^{2} / r^{2}}
$$

na qual $s(x, t)$ é a amplitude da anomalia na posição $x$ e no intervalo de tempo $t, A$ é a amplitude máxima, $v$ é a velocidade horizontal de movimento (constante), $r$ é o comprimento de onda associado à anomalia e $\Delta x$ é um parâmetro para deslocar a posição inicial da anomalia. Assumiu-se, em todos os testes, que a amplitude máxima da anomalia estivesse no centro do modelo (posição $L_{x} / 2$ ) no instante $70 \mathrm{Ma}$, assim, $\Delta x$ pode ser expresso por

$$
\Delta x=v t_{c}-\frac{L_{x}}{2}
$$

com $t_{c}=70 \mathrm{Ma}$. Utilizou-se os valores de referência de amplitude e comprimento de $1000 \mathrm{~m}$ e $1330 \mathrm{~km}$, respectivamente, associados à anomalia térmica de Trindade-Martin Vaz (Ito e van Keken, 2007), correspondendo aos valores de $A$ e $r$ de $1000 \mathrm{~m}$ e $600 \mathrm{~km}$, respectivamente. Foi realizado também um teste com um menor comprimento para a anomalia, considerando $r=200 \mathrm{~km}$ neste caso. A velocidade foi mantida constante com valor de $2.3 \mathrm{~cm} / \mathrm{yr}$ (Ferrari e Riccomini, 1999). Essa estimativa foi obtida pelos autores considerando que o centro da anomalia térmica atingiu a margem continental em 47,5 Ma, correspondente à idade média do vulcanismo de Abrolhos, e à distância da costa à ilha de Martin Vaz. 
O esforço compressivo regional foi incorporado assumindo-se um aumento exponencial da força associado à expansão do assoalho oceânico na dorsal meso-oceânica, dado por

$$
F(t)=F_{R P}\left(1-e^{-t / \tau}\right)
$$

sendo $F(t)$ a força atuando na lateral do modelo no intervalo de tempo $t$ e $\tau$ um parâmetro característico associado ao decaimento exponencial. $F_{R P}$ é o máximo da força e é expresso por (Turcotte e Schubert, 2002)

$$
F_{R P}=g \alpha \rho_{m}\left(T_{1}-T_{0}\right) L_{z}^{2}\left[\frac{1}{6}+\frac{\alpha \rho_{m}\left(T_{1}-T_{0}\right)}{8\left(\rho_{m}-\rho_{w}\right)}\right]
$$

na qual $g$ é a aceleração da gravidade, $\rho_{m}$ e $\rho_{w}$ são as densidades do manto e da água, respectivamente, $L_{z}$ é a espessura da litosfera, $\alpha$ é o coeficiente de expansão térmica e $T_{1}-T_{0}$ é a diferença de temperatura entre a base e a superfície da litosfera. Essa força é baseada no modelo de resfriamento de placa para a litosfera oceânica e representa a força entre a dorsal meso-oceânica e a bacia oceânica adjacente. Os seguintes valores foram utilizados para os parâmetros das equações 4.7 e 4.3. $\tau=60 \mathrm{Myr}, \alpha=3 \times 10^{-5} \mathrm{~K}^{-1}$, $T_{1}-T_{0}=1300 \mathrm{~K}$, e aqueles da Tabela 4.1 .

Foram considerados diferentes cenários nos testes numéricos:

- Erosão constante.

Considerou-se apenas a erosão sob a porção continental do modelo com taxa constante durante toda a simulação.

- Erosão e sedimentação constantes.

Considerou-se tanto a erosão como a sedimentação com taxa constante durante toda a simulação.

- Erosão variável.

Considerou-se apenas a erosão sob a porção continental do modelo com aumento expressivo na taxa de denudação no intervalo entre 90 a 60 Ma.

- Erosão e sedimentação variáveis.

Considerou-se tanto a erosão como a sedimentação com aumento expressivo na taxa de denudação e sedimentação no intervalo entre 90 a 60 Ma. 
- Soerguimento devido à anomalia térmica.

Considerou-se o efeito do soerguimento causado pela passagem de uma anomalia térmica com comprimento de onda de 200 e 600 km. Esse cenário foi sobreposto aos cenários de erosão e sedimentação em alguns testes numéricos.

- Compressão regional.

Considerou-se o efeito de uma compressão regional, associado ao efeito de espalhamento do assoalho oceânico na dorsal meso-oceânica e a um posterior aumento no esforço compressivo regional associado à um episódio da orogenia andina. Esse cenário também foi sobreposto aos cenários de erosão e sedimentação em alguns testes numéricos.

A Tabela 4.3 relaciona a nomenclatura utilizada para referência dos diferentes testes numéricos e a composição de cada um dos testes considerando os cenários descritos anteriormente. Os resultados dos modelos apresentados na Tabela 4.3 são apresentados no Capítulo5. 
Tabela 4.3 - Nomenclatura dos testes numéricos.

\begin{tabular}{|c|c|}
\hline Nomenclatura & Descrição \\
\hline \multirow{2}{*}{ padrão } & Modelo de referência, não inclui \\
\hline & nenhum efeito adicional. \\
\hline \multirow{3}{*}{ soerg 600} & Inclui o efeito do soerguimento devido à passagem \\
\hline & de uma anomalia térmica com comprimento \\
\hline & de $600 \mathrm{~km}(\mathrm{r}=600 \mathrm{~km}$ na Eq. 4.5$)$. \\
\hline \multirow{2}{*}{ ero cont } & Inclui apenas a denudação na porção continental \\
\hline & do modelo com taxa constante no tempo. \\
\hline \multirow{3}{*}{ ero var } & Inclui apenas a denudação na porção continental \\
\hline & do modelo variando linearmente no tempo \\
\hline & e taxa maior no intervalo entre 90 e 60 Ma. \\
\hline \multirow{2}{*}{ ero/sed var } & Inclui a denudação e sedimentação variando \\
\hline & linearmente no tempo e taxa maior entre 90 e 60 Ma. \\
\hline \multirow{3}{*}{ ero/sed var + soerg 200} & Inclui o efeito do soerguimento devido à passagem \\
\hline & de uma anomalia térmica com comprimento de $200 \mathrm{~km}$ \\
\hline & $(\mathrm{r}=200 \mathrm{~km}$ na Eq. 4.5$)$ no modelo ero/sed var. \\
\hline \multirow[b]{2}{*}{ ero/sed var + soerg 600} & Inclui o efeito do soerguimento devido à passagem \\
\hline & $\begin{array}{l}\text { de uma anomalia térmica com comprimento de } 600 \mathrm{~km} \\
(\mathrm{r}=600 \mathrm{~km} \text { na Eq. } 4.5 \text { no modelo ero } / \text { sed var. }\end{array}$ \\
\hline \multirow{2}{*}{ ero/sed var + comp } & Inclui uma compressão regional no \\
\hline & modelo ero/sed var. \\
\hline \multirow{4}{*}{ ero/sed var + comp + Andes } & Inclui uma compressão regional adicional \\
\hline & em 45 Ma no modelo ero/sed var + comp, \\
\hline & inicialmente nula e variando linearmente até o valor limite \\
\hline & equivalente à $F_{R P}$. \\
\hline
\end{tabular}


Capítulo 5

\section{Resultados e discussão}

Neste capítulo são apresentados os resultados para os modelos especificados na Tabela 4.3. Esses modelos constituem uma seleção representativa dos testes numéricos realizados acerca das investigações pretendidas no trabalho.

A Figura 5.1 apresenta os resultados para o modelo padrão, em que não há erosão, sedimentação ou outra perturbação tectônica. Nesta figura é apresentado o padrão de esforços deviatóricos no instante inicial (após a solução da componente elástica) e final da simulação numérica (após 130 Myr). Para facilitar a visualização, apenas uma parte da seção total do modelo é apresentada, entre 800 e $1200 \mathrm{~km}$ e até a profundidade de $30 \mathrm{~km}$. A seção completa do modelo é apresentada no ApêndiceB. Na parte superior da figura estão indicadas, esquematicamente, as regiões correspondentes à Serra do Mar (verde escuro), ao RCSB (marrom claro) e à Serra da Mantiqueira (verde claro) em referência à configuração do modelo (Figuras 4.1 e 4.3).

Inicialmente, o comportamento do padrão de esforços na litosfera é a distribuição elástica dos esforços por toda a litosfera. Posteriormente, os esforços concentram-se na crosta superior e na porção logo abaixo da Moho (manto superior), devido ao alívio dos esforços nas porções mais viscosas do modelo, que correspondem à base da crosta e abaixo da porção superior do manto. O padrão de esforços observados para o modelo padrão (Figura 5.1) resulta da diferença lateral da distribuição de densidade entre a porção continental e a oceânica. É possível notar a concentração dos esforços na porção superior da crosta devido a variação temporal do envelope de ruptura. Apesar da pequena variação, no final da simulação, o envelope estende-se por toda a porção continental e a profundidade aumenta ligeiramente (Figuras 5.1 e B.1). O esforço máximo compressivo, não litostático, na porção continental, é vertical e o esforço mínimo compressivo é horizontal. Os esforços principais 
a)

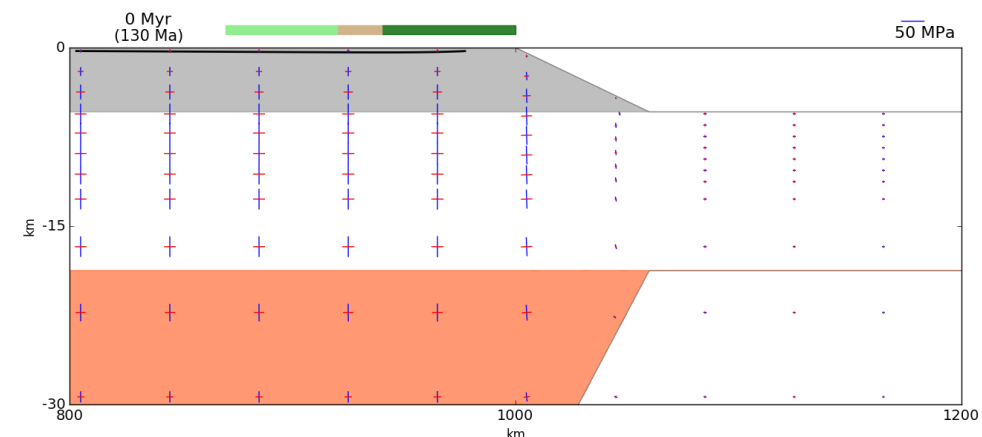

b)

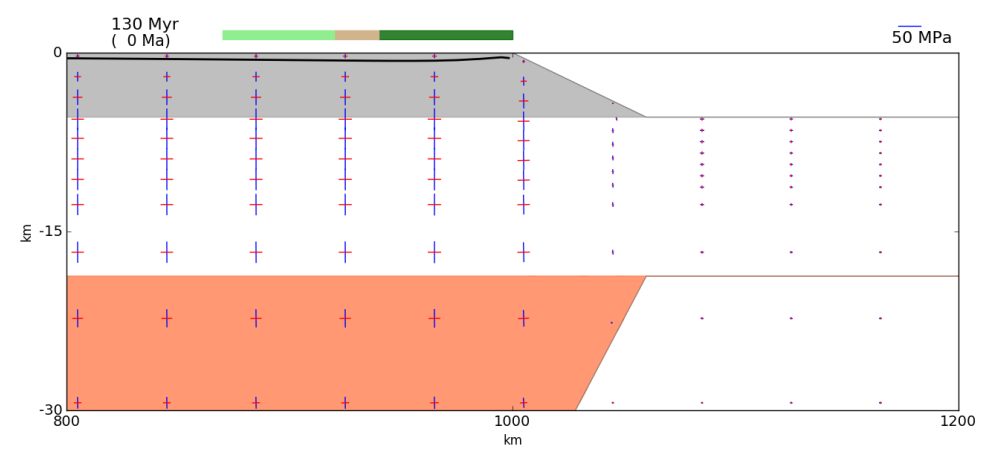

Figura 5.1: Esforços não litostáticos deviatóricos e envelope de ruptura para o modelo de referência ( adrão). São representados os instantes inicial e final da simulação. A curva preta indica o envelope de ruptura considerando coesão nula e $\phi=30^{\circ}$. As cores azul e vermelha dos traços representam compressão e tensão, respectivamente, e a orientação corresponde à direção dos esforços principais.

deviatóricos não litostáticos resultantes são compressivos verticalmente e tensionais horizontalmente, de modo que $\sigma_{v}=\sigma_{1}$ e $\sigma_{h}=\sigma_{3}$, condizente com o regime tectônico de falhas normais. A curva preta indica o envelope de ruptura pelo critério de Mohr-Coulomb para o caso de coesão interna nula. Neste caso pode-se observar que uma baixa coesão das rochas é suficiente para impedir a ruptura das rochas, uma vez que o limite de ruptura para o caso de coesão nula encontra-se a uma profundidade rasa $(<1 \mathrm{~km})$.

O efeito do soerguimento causado por uma anomalia térmica, que se move sob a base da litosfera, causa esforços flexurais compressivos na direção vertical e tensionais na direção horizontal. Como consequência, os esforços deviatóricos resultantes têm maior magnitude em ambas as direções (Figura 5.2). Essa resposta dos esforços ao soerguimento diminui com a distância do centro do soerguimento (indicado pela seta na base do modelo nas Figuras B.2 e B.3p. No entanto, apesar da magnitude maior, o envelope de ruptura é restrito à porção mais superior da crosta $(<1.5 \mathrm{~km})$, e longe do centro da anomalia, a profundidade do envelope é menor do que aquela do modelo padrão. Quando a anomalia se aproxima da transição continente-oceano, o envelope de ruptura progressivamente diminui. 
Esse resultado deve-se ao fato do soerguimento da porção oceânica ser mais expressivo do que na região continental, uma vez que ao soerguer o oceano, há uma alívio de cargas adicional devido à diminuição do peso da lâmina d'água pelo soerguimento, naturalmente reproduzido pelo modelo numérico pelo contraste da fundação de Winkler na superfície oceânica ser diferente da porção continental. Consequentemente, essa diferença resulta em esforços flexurais compressivos, na direção horizontal, na porção superior da crosta continental que se opõem ao padrão tensional. Como resultado, os esforços deviatóricos têm menor magnitude e não atingem o limite de ruptura, mesmo para a coesão nula. Esse resultado mostra que o efeito causado por um soerguimento regional pode atuar contrariamente ao falhamento na região próxima à costa ao invés de promovê-los. O efeito do soerguimento causado pela anomalia térmica, porém, é dependente do seu comprimento de onda. Quanto menor o comprimento de onda mais local é a pertubação dos esforços. Para um curto comprimento de onda, o padrão de esforços na região continental seria o mesmo, e o envelope de ruptura teria uma diminuição menos pronunciada próximo à margem, devido a abrangência mais local da perturbação. No entanto, uma vez que a anomalia estivesse sob o oceano, o efeito que atua contrariamente à ruptura na região continental também seria mais pronunciado e a condição de ruptura não seria atingida.

No modelo soerg 600, o comprimento da anomalia térmica causadora do soerguimento regional tem a ordem de magnitude daquela que seria causada pela anomalia TrindadeMartin Vaz (Ito e van Keken, 2007). Na região sudeste, essa anomalia seria responsável pelo soerguimento regional e magmatismo na região continental e oceânica (e.g. Meisling et al. 2001; Zalán e Oliveira, 2005; Franco-Magalhaes et al., 2014). Como o centro da anomalia estaria a norte, o soerguimento induzido por uma anomalia térmica mantélica teria amplitude progressivamente menor em direção ao sul, e assim a magnitude imposta no modelo numérico representaria um limite superior da amplitude.

Os esforços no modelo em que foi simulado apenas a denudação contínua ao longo do tempo (ero cont) (Figura 5.3) seguem o mesmo comportamento observado no modelo padrão, porém, a magnitude dos esforços é maior apenas localmente, na região onde houve a maior denudação (entre 850 e $1000 \mathrm{~km}$ ) e a porção oceânica adjacente. O envelope de ruptura é apresentado para três valores de coesão: nula (curva contínua); $50 \mathrm{MPa}$ (curva tracejada); e $100 \mathrm{MPa}$ (curva pontinhada). Os esforços verticais e horizontais também são condizentes com o regime de falhas normais. Devido à flexura da litosfera, 
a)

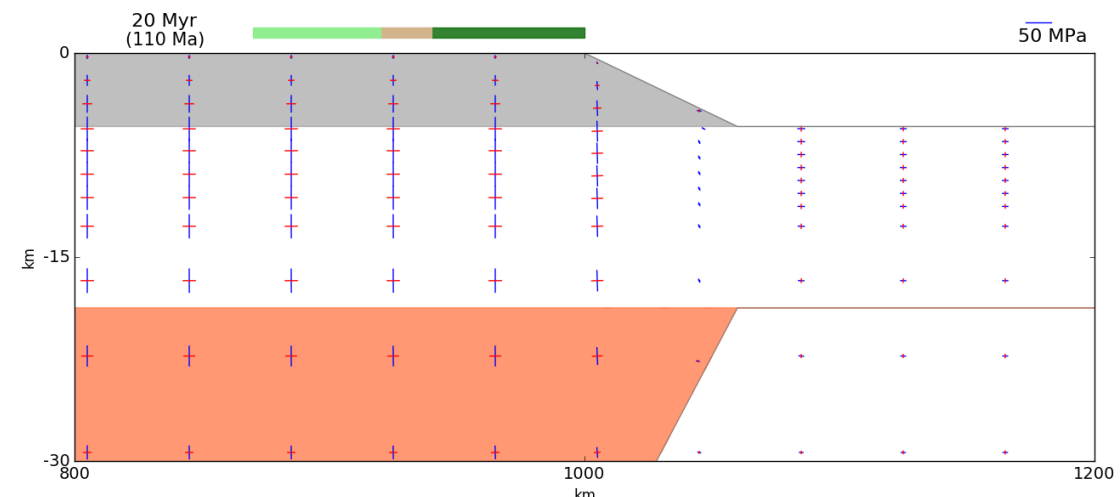

b)

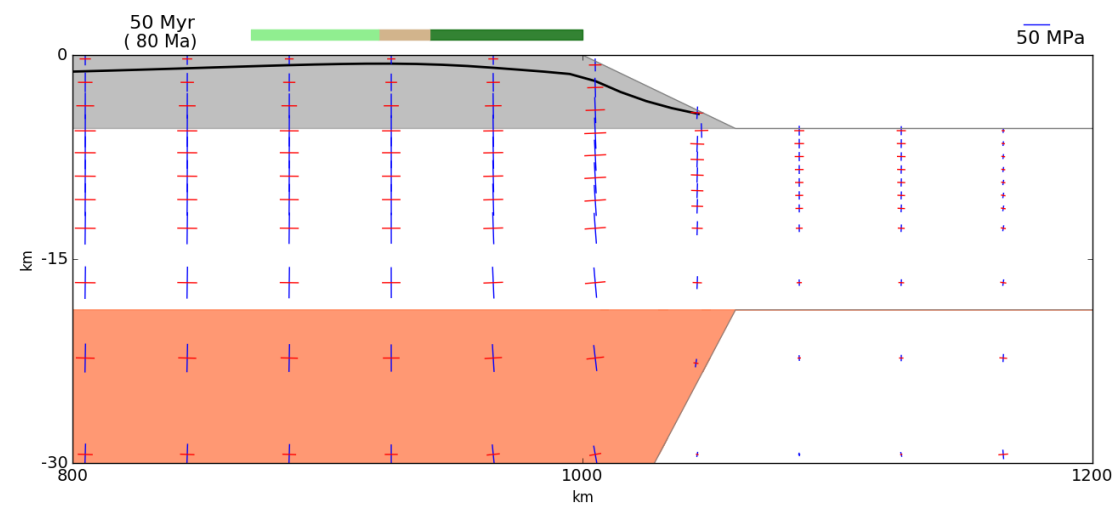

c)

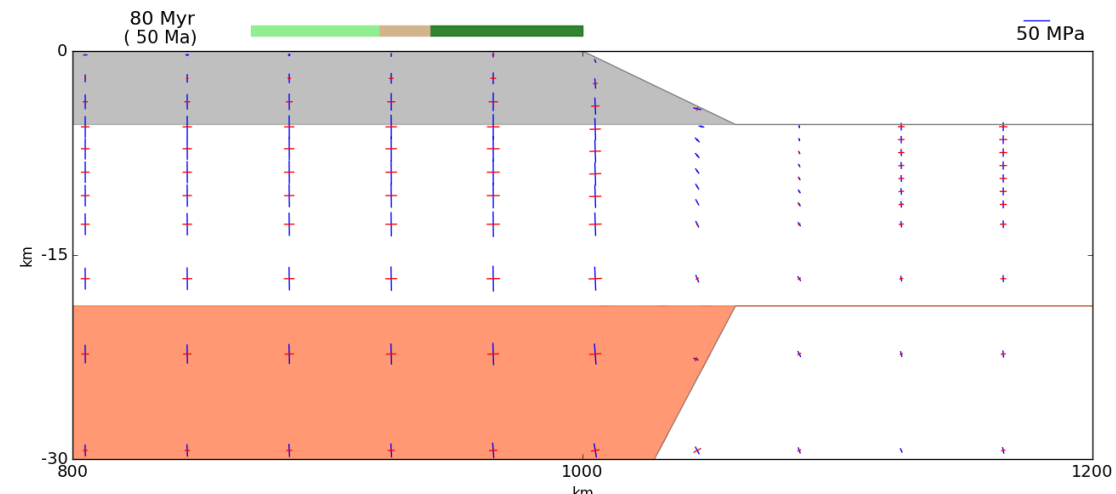

d)

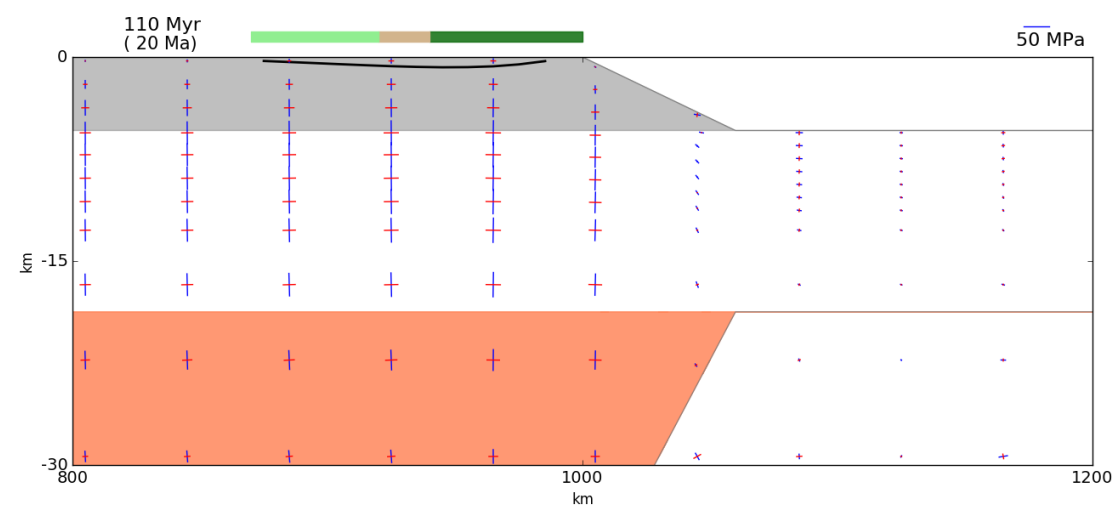

Figura 5.2: Esforços não litostáticos deviatóricos e envelope de ruptura para o modelo com efeito do soerguimento causado por uma anomalia térmica de comprimento de onda de $600 \mathrm{~km}$ (soerg 600, cf. Tabela 4.3). Ver posição do centro do soerguimento regional nas Figuras B.2 e B.3, indicado por uma seta preta na base do modelo. Conferir Figura 5.1 para demais parâmetros. 
na porção superior do manto os esforços têm características opostas, em que a compressão é horizontal e a tensão é vertical (Figuras B.4 e B.5). Nesse caso, o envelope de ruptura atinge profundidas progressivamente maiores. Entre 90 e $80 \mathrm{Ma}$, o limite de ruptura é atingido para o valor de coesão de $50 \mathrm{MPa}$ (Figura $5.3 \mathrm{~b}$, curva preta tracejada), e entre 40 e $30 \mathrm{Ma}$ para a coesão de $100 \mathrm{MPa}$ (Figura $5.3 \mathrm{~d}$, curva preta pontilhada). Sob a porção continental, a profundidade máxima atingida foi de $c .7 \mathrm{~km}$. Apesar da magnitude dos esforços também aumentar na região oceânica adjacente, devido ao efeito flexural causado pela denudação, o limite de ruptura não foi atingido. Esse resultado sugere que a denudação, apesar de ocorrer em uma região extensa no continente, tem um efeito local na magnitude dos esforços na crosta superior.

A partir dos dados de termocronologia, diversos estudos sugerem um episódio de maior taxa de exumação entre o Cretáceo Superior e o Paleoceno Inferior (e.g. Cogné et al., 2011; Franco-Magalhaes et al., 2014). O modelo ero var simula a mesma magnitude de denudação no continente que o modelo anterior (ero cont), porém com taxa de denudação maior entre 90 e $60 \mathrm{Ma}$, como sugerido pelo vínculo das interpretações dos dados termocronológicos. Inicialmente, a denudação é menor que no modelo (ero cont), devido a uma taxa menor de denudação, e observa-se que o envelope de ruptura também é mais raso (Figura 5.43). Logo após o episódio com taxa de denudação maior, a quantidade total denudada é maior que no modelo (ero cont) e o envelope de ruptura é ligeiramente mais profundo (Figura 5.4 ). Nesse caso, em 50 Ma os esforços atingem a condição de ruptura para a coesão de $100 \mathrm{MPa}$, na região costeira, evidenciando o efeito da maior denudação. Esse resultado sugere que a magnitude da denudação influencia os esforços de modo a atingir a ruptura das rochas em profundidades maiores, em um menor intervalo de tempo, refletindo a maior taxa de denudação.

As bacias marginais de Santos e Campos registram espesso pacote sedimentar. A Figura 5.5 corresponde ao modelo ero/sed var, onde foi incorporado o efeito da carga sedimentar na porção oceânica no modelo anterior (ero var). Assumiu-se a mesma variação temporal da denudação para a sedimentação. A estratigrafia das bacias de Santos e Campos refletem uma migração da sedimentação em direção NE. O padrão de sedimentação utilizado no experimento numérico é uma aproximação para avaliar o efeito da carga sedimentar no padrão de esforços na região continental. O efeito da carga sedimentar induz esforços tensionais na direção horizontal na porção do continente próxima à margem, intensificando 
a)

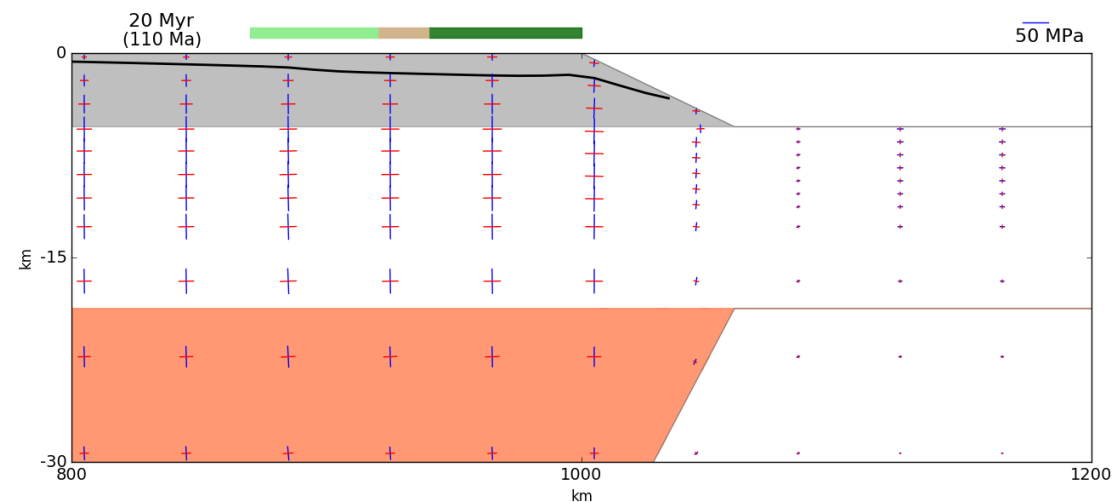

b)

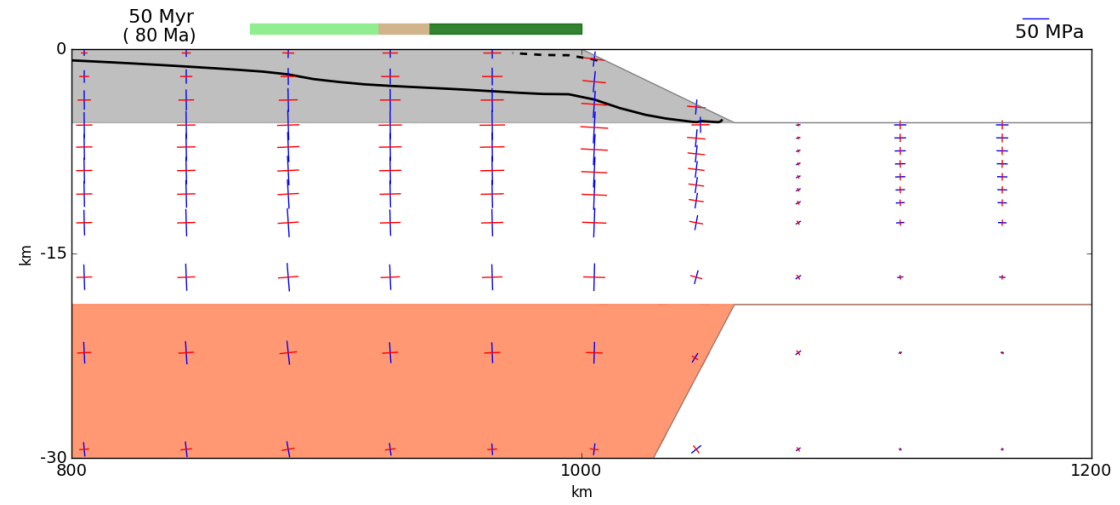

c)

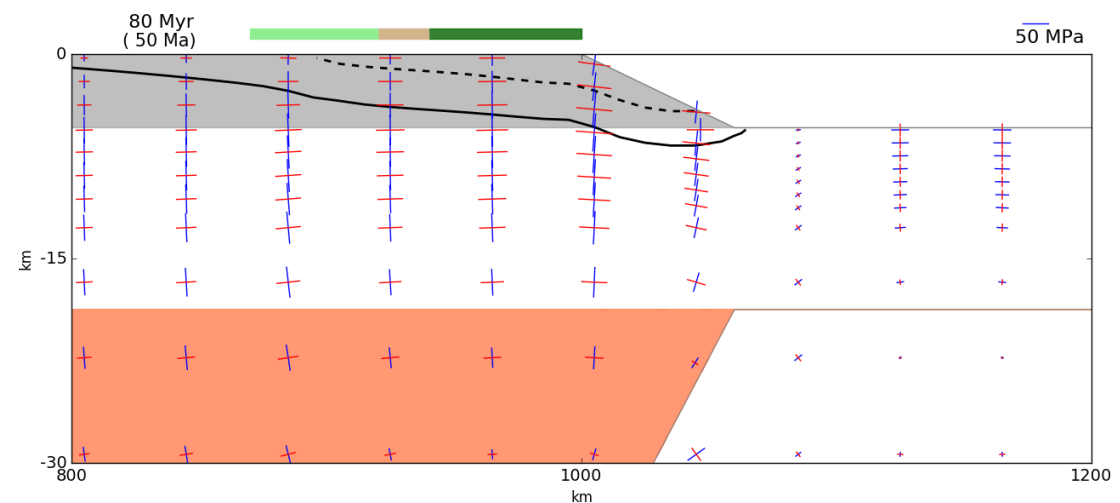

d)

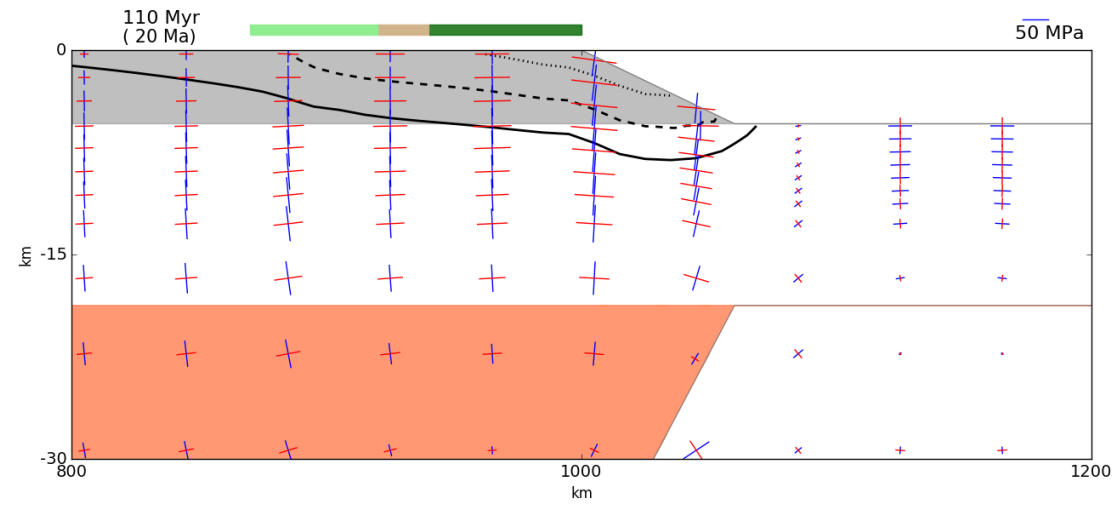

Figura 5.3: Esforços não litostáticos deviatóricos e envelope de ruptura para o modelo com erosão continua (ero cont, cf. Tabela 4.3). Conferir Figura 5.1 para demais parâmetros. 
a)

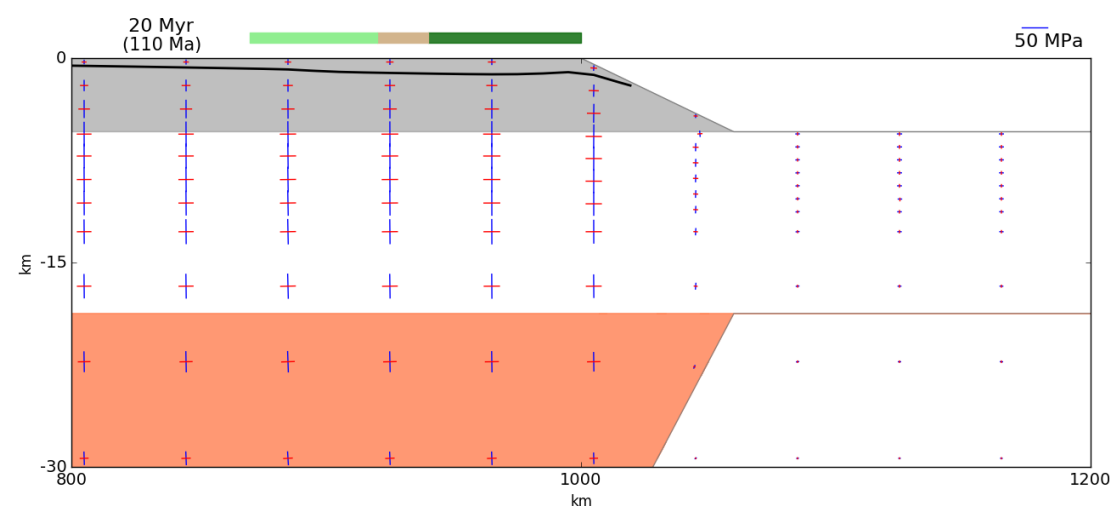

b)

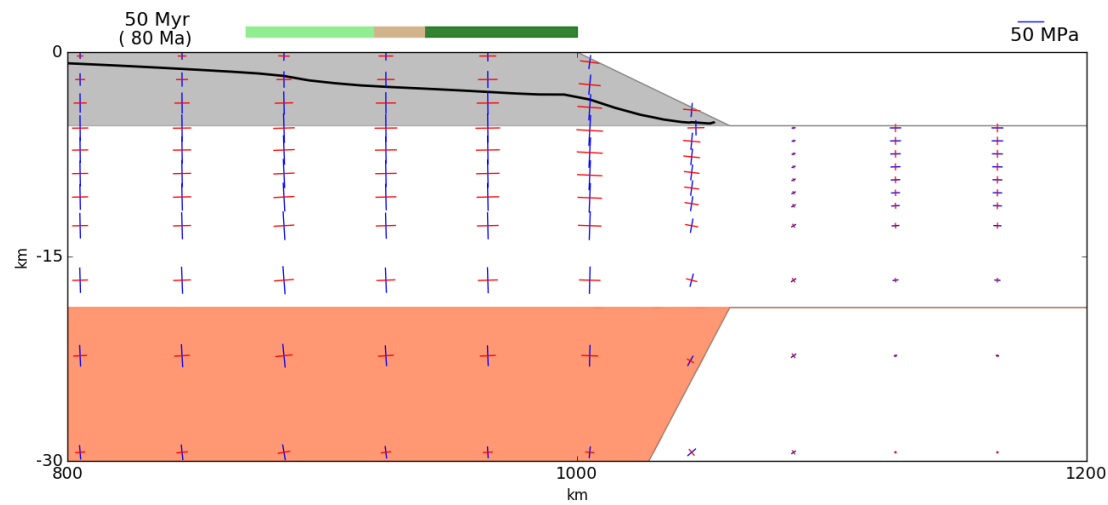

c)

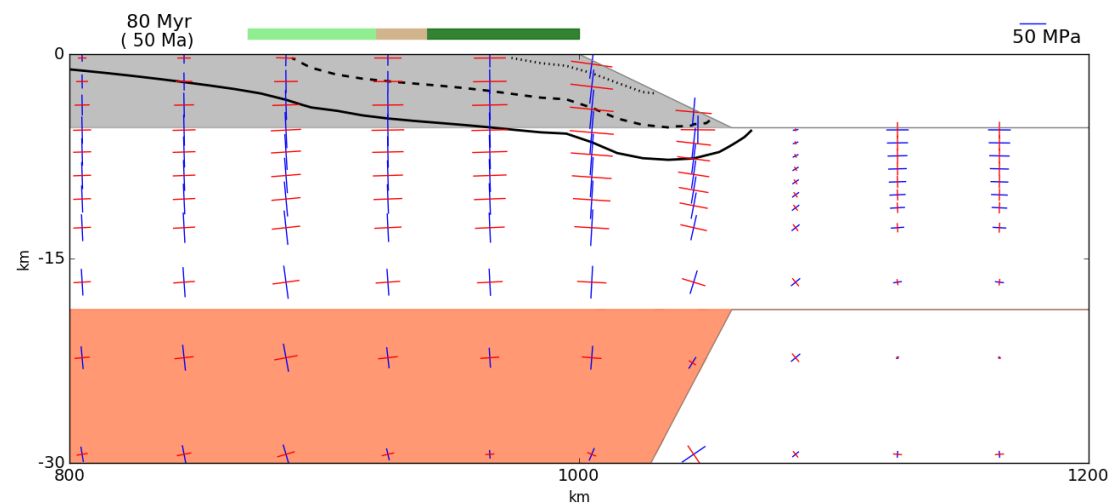

d)

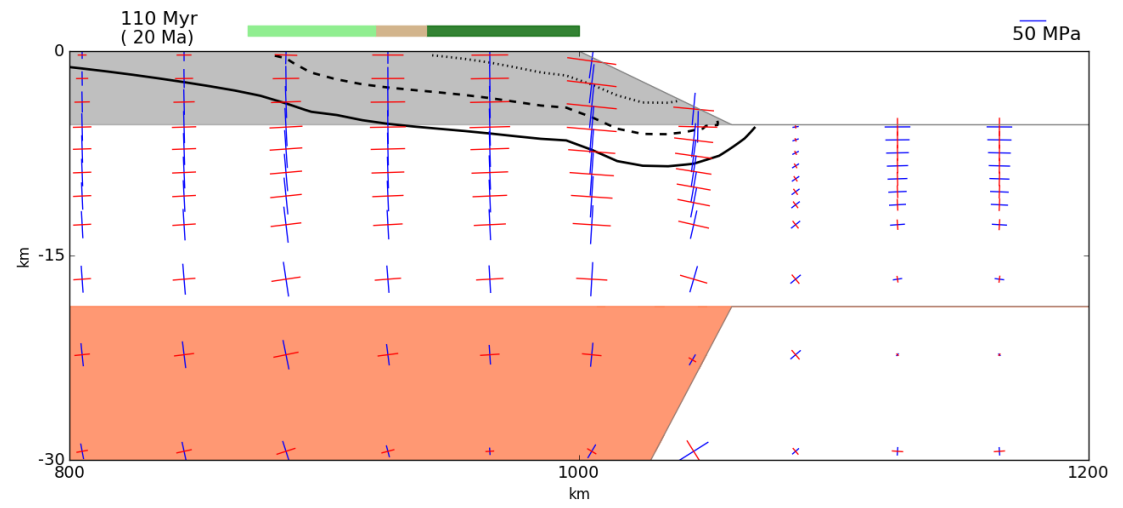

Figura 5.4: Esforços não litostáticos deviatóricos e envelope de ruptura para o modelo com erosão variável (ero var, cf. Tabela 4.3). Conferir Figura 5.1 para demais parâmetros. 
o padrão causado pela denudação. Como consequência, o limite de ruptura é atingido para uma profundidade maior. Por exemplo, em $80 \mathrm{Ma}$, o envelope de coesão nula atinge a profundidade de c. $5 \mathrm{~km}$ (na posição $1000 \mathrm{~km}$ ), aproximadamente o dobro daquele somente com o efeito da denudação. Nesse mesmo intervalo de tempo, o limite de ruptura já é superado mesmo para uma maior coesão (50 MPa) (Figura 5.5b). No final da simulação, o envelope de ruptura tem profundidade aproximada de $11 \mathrm{~km}$. O efeito flexural do pacote sedimentar amplifica o padrão de esforços com compressão horizontal na região oceânica. Observa-se que o limite de ruptura é atingido no topo da crosta, com regime tectônico de falhamento inverso.

Nas Figuras 5.6 e 5.7 são apresentados os resultados do modelo anterior (ero/sed var) com o efeito do soeguimento regional sobreposto para o comprimento da anomalia, de 200 e $600 \mathrm{~km}$, respectivamente. O efeito do soerguimento de maior comprimento de onda na região próxima à costa (modelo soerg 600, Figura 5.2) atuou de modo a inibir a ruptura das rochas. No modelo com menor comprimento de onda (ero/sed var + soerg 200), enquanto a anomalia se desloca sob o continente, a envelope de ruptura tem profundidade ligeiramente maior do que aquele com apenas erosão e sedimentação (Figura 5.6b). Porém, uma vez sob a porção oceânica, o envelope de ruptura no continente é pouco afetado. No caso do maior comprimento de onda (ero/sed var + soerg 600), a profundidade do envelope é ligeiramente menor.

Como descrito anteriormente, os esforços compressivos na direção horizontal, na região continental, devido ao soerguimento, opõe-se ao padrão devido à erosão e sedimentação e consequentemente tendem a reduzir o envelope de ruptura. O padrão de esforços nos modelos ero/sed var + comp e ero/sed var + comp + Andes (Figuras 5.8 e 5.9) reforçam essa observação. No primeiro, em que uma compressão regional atua desde o início da simulação, o envelope de ruptura tem profundidade menor, na região continental, do que aquele sem essa componente compressiva. No porção oceânica, os esforços horizontais já eram compressivos e desse modo observa-se o aumento do envelope de ruptura. Para o segundo, uma componente compressiva adicional foi adicionada após $70 \mathrm{Ma}$, reduzindo o envelope na região continental e amplificando-o na região oceânica.

Uma comparação entre os diferentes modelos é feita na Figura 5.10, para o instante de tempo de 80 Ma. Essa comparação mostra o efeito pouco expressivo do soerguimento regional (de longo comprimento de onda) na condição de ruptura na região continental. 
a)

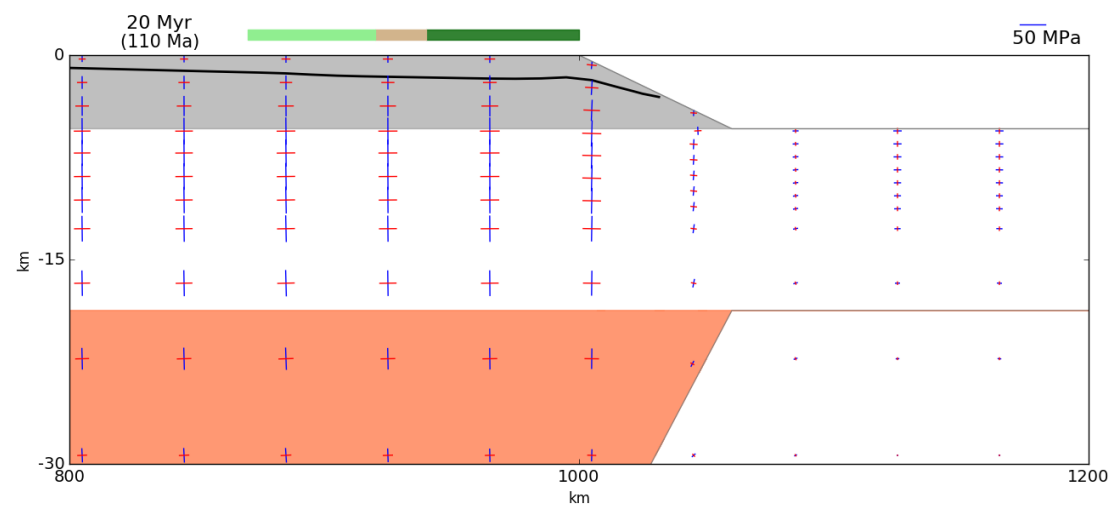

b)

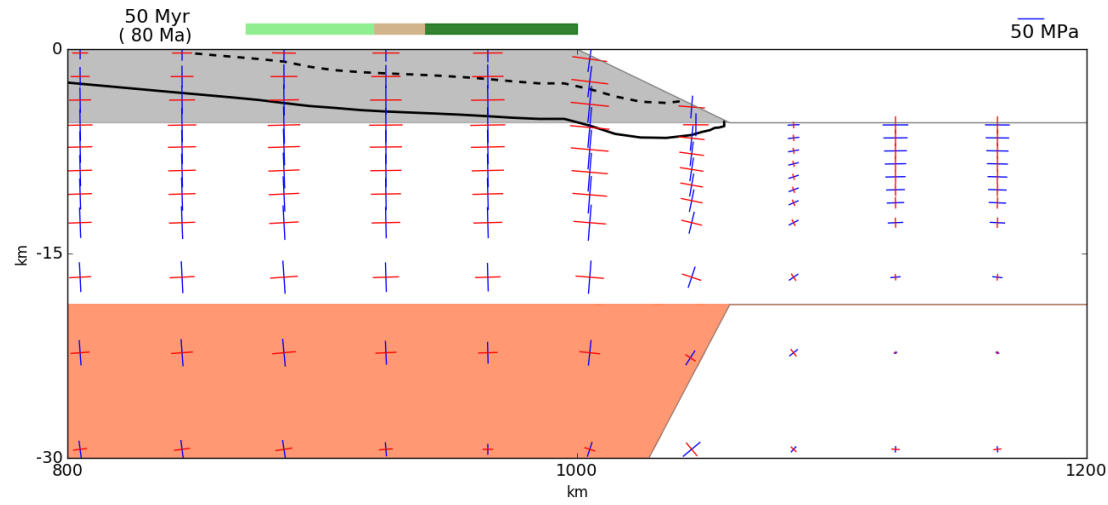

c)

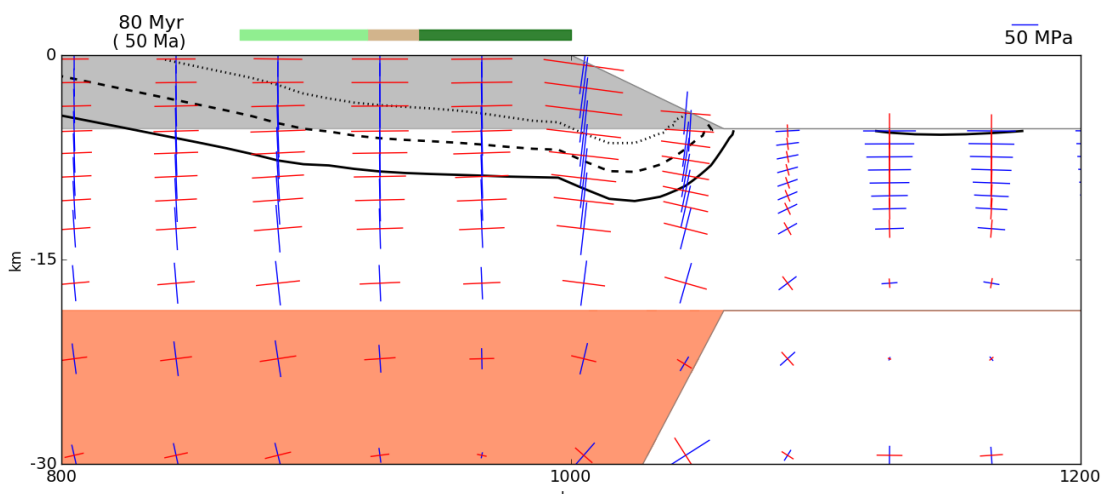

d)

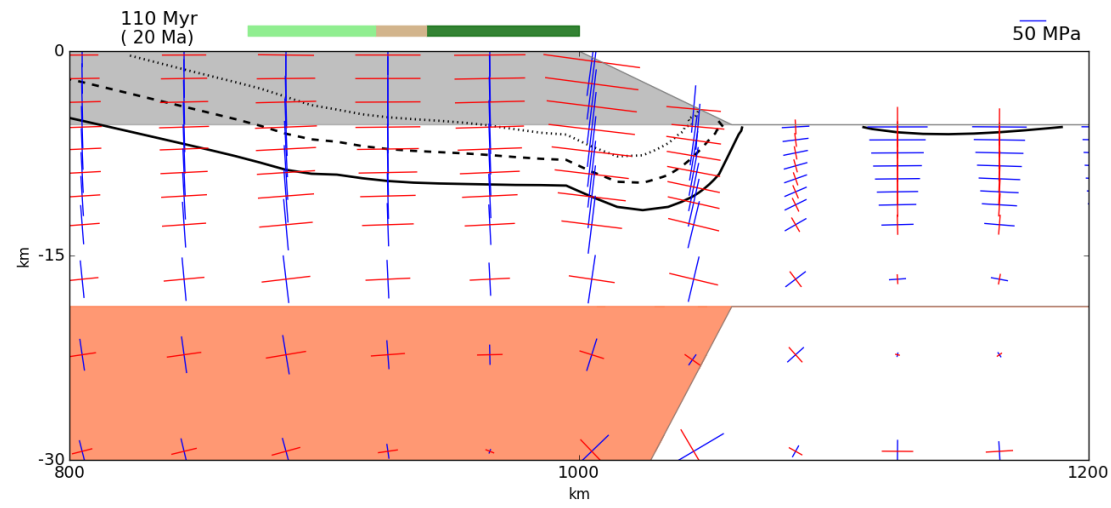

Figura 5.5: Esforços não litostáticos deviatóricos e envelope de ruptura para o modelo com denudação e sedimentação variáveis (ero/sed var, cf. Tabela 4.3. Conferir Figura 5.1 para demais parâmetros. 
a)

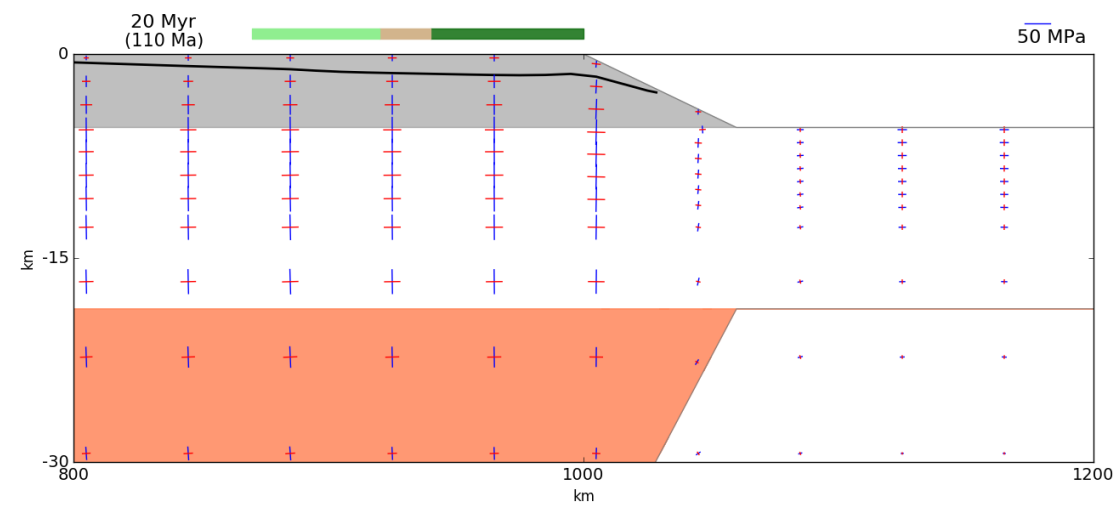

b)

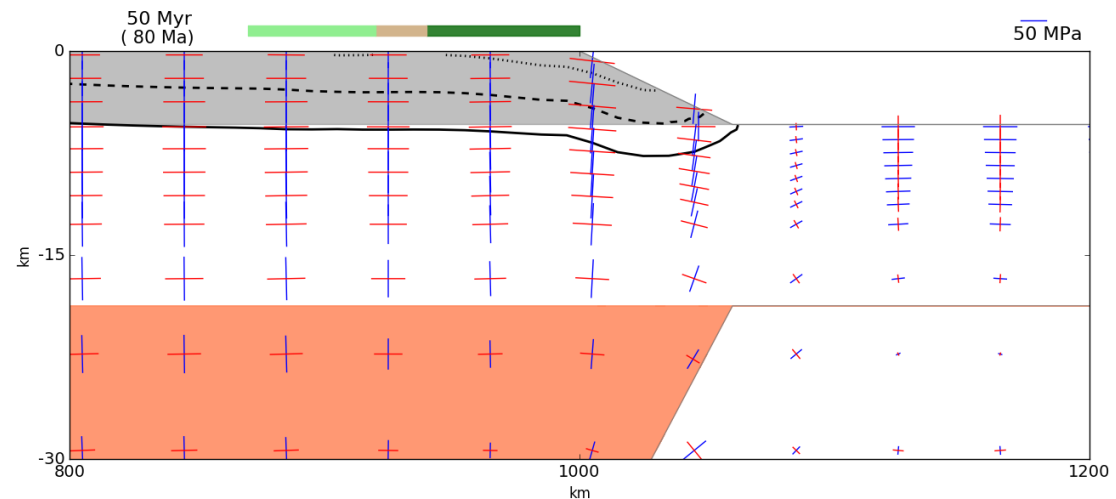

c)

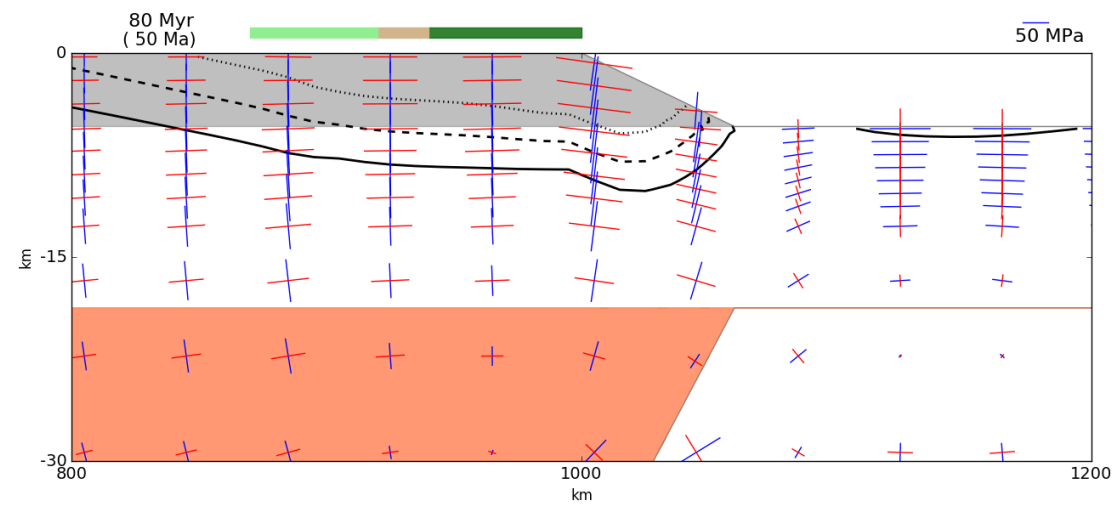

d)

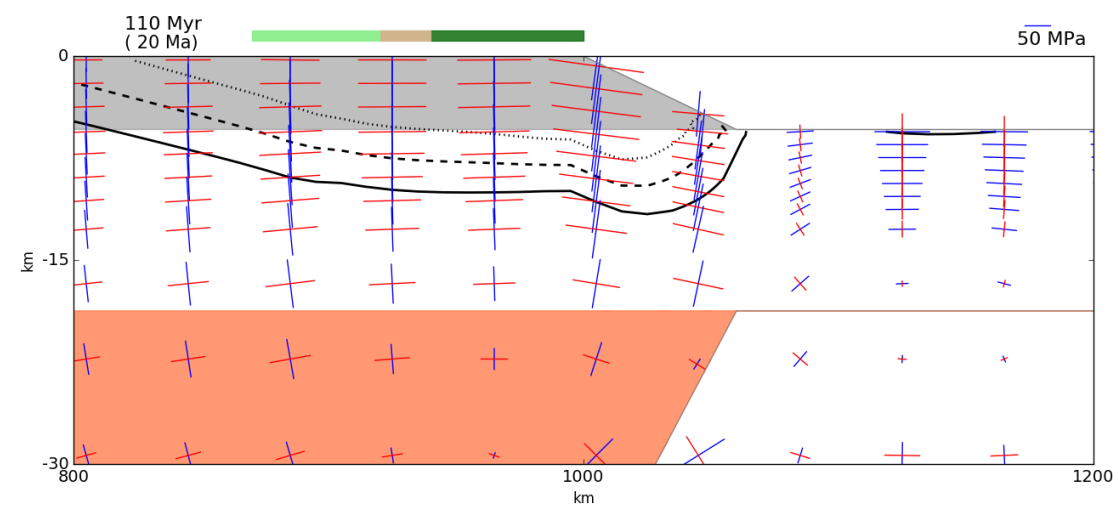

Figura 5.6: Esforços não litostáticos deviatóricos e envelope de ruptura para o modelo com denudação e sedimentação variáveis e efeito do soerguimento causado por uma anomalia térmica de comprimento de onda de $200 \mathrm{~km}$ (ero/sed var + soerg 200, cf. Tabela 4.3). Ver posição do centro do soerguimento regional nas Figuras B.10 B.11, indicado por uma seta preta na base do modelo. Conferir Figura 5.1 para demais parâmetros. 
a)

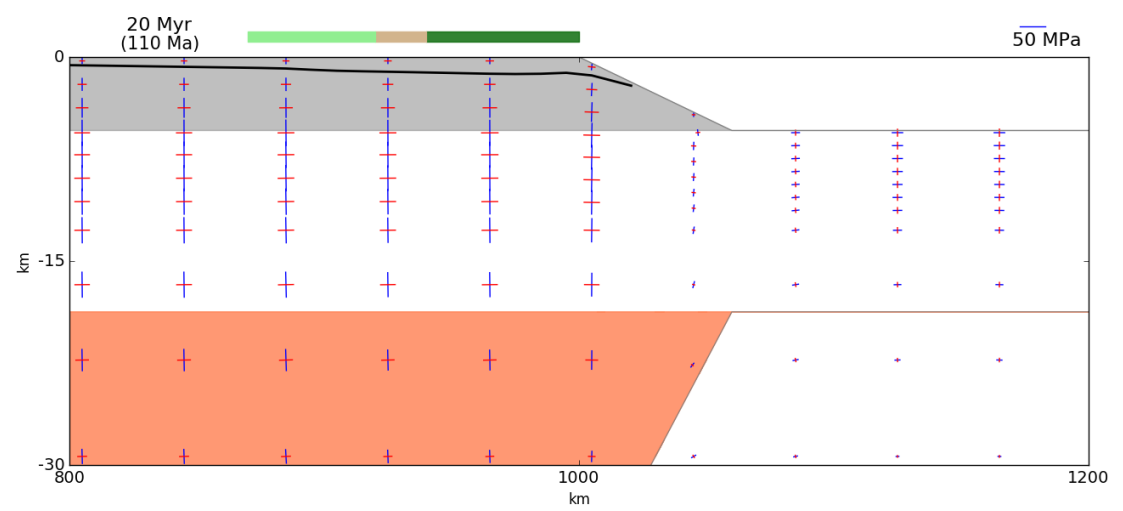

b)

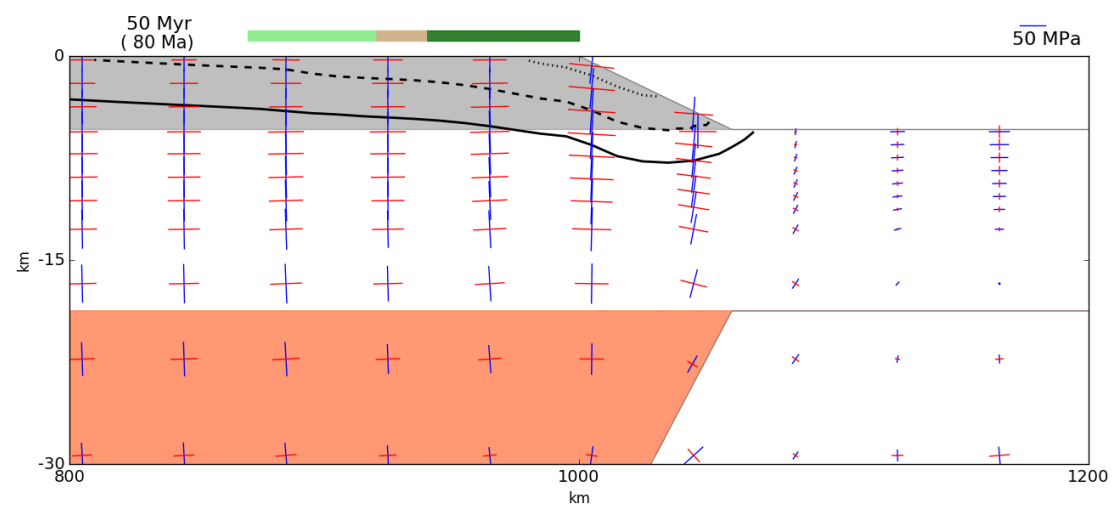

c)

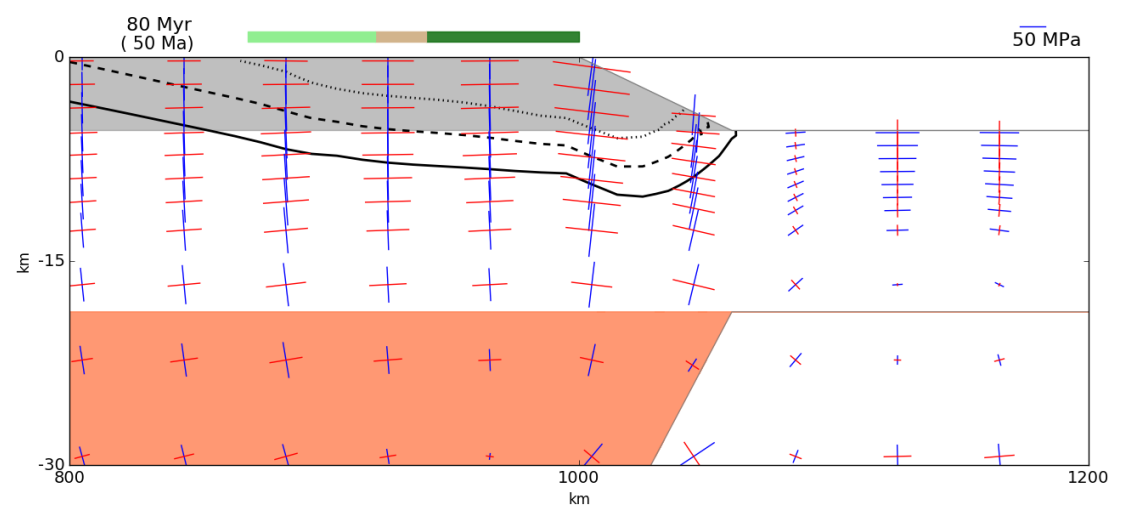

d)

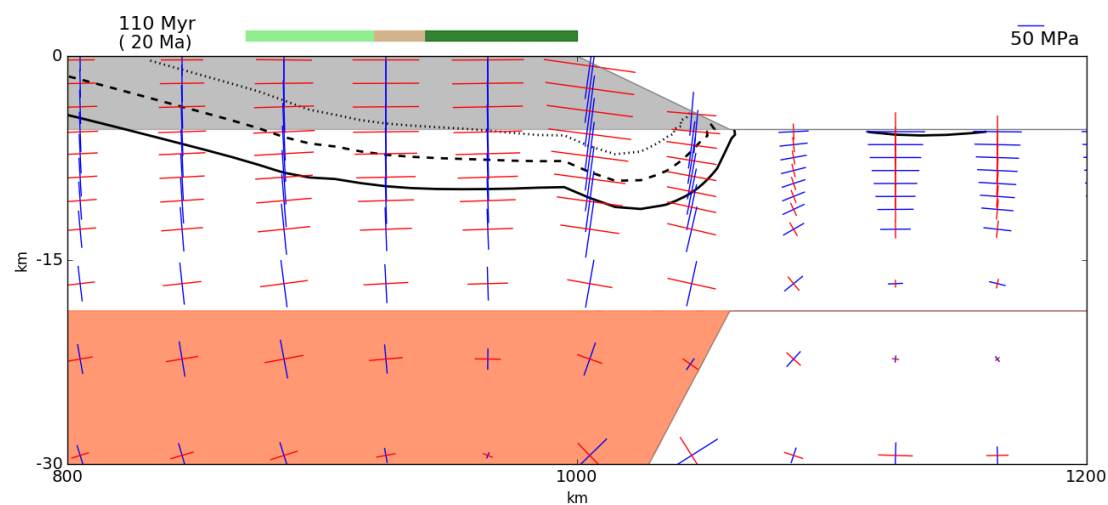

Figura 5.7: Esforços não litostáticos deviatóricos e envelope de ruptura para o modelo com denudação e sedimentação variáveis e efeito do soerguimento causado por uma anomalia térmica de comprimento de onda de $600 \mathrm{~km}$ (ero/sed var + soerg 600, cf. Tabela 4.3). Ver posição do centro do soerguimento regional nas Figuras B.12 e B.13, indicado por uma seta preta na base do modelo. Conferir Figura 5.1 para demais parâmetros. 
a)

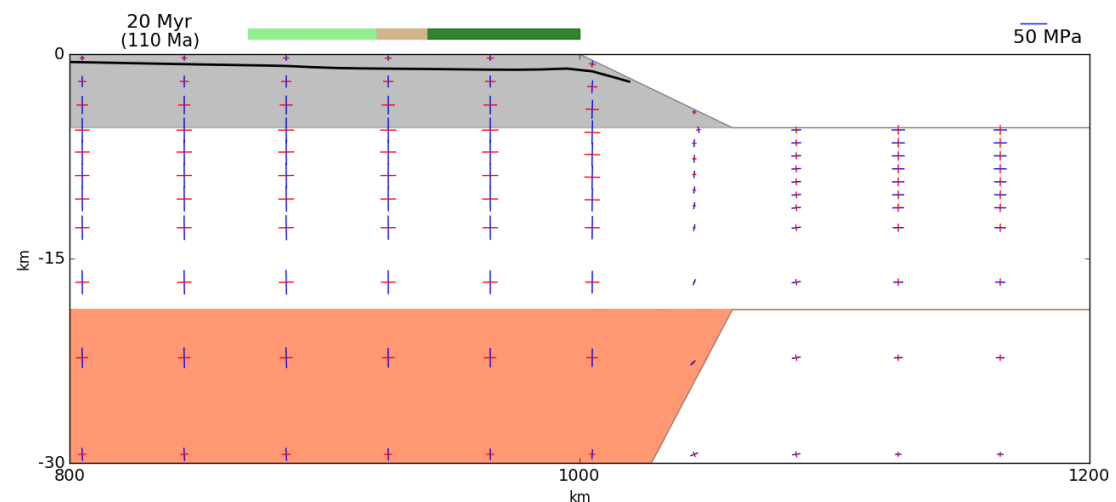

b)

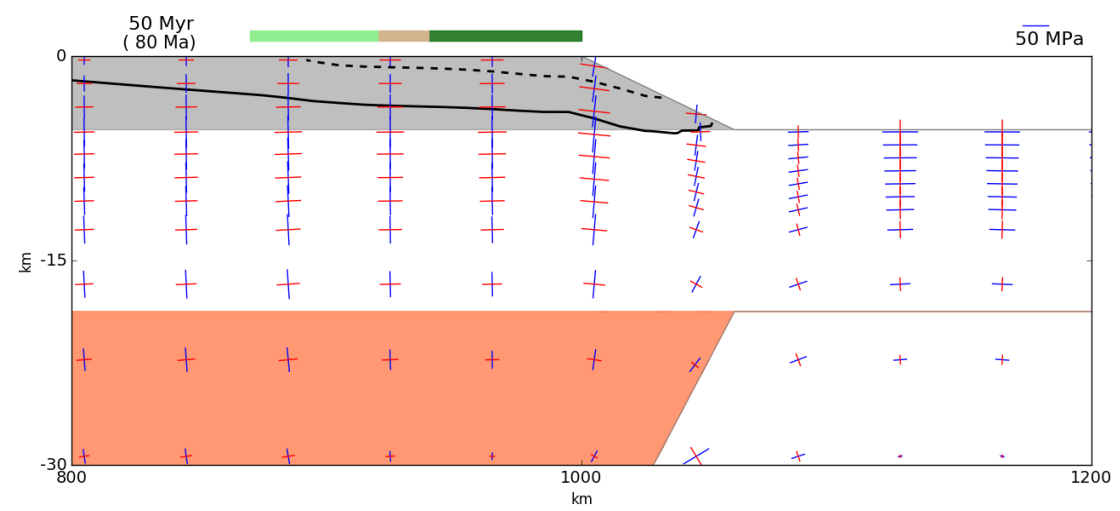

c)

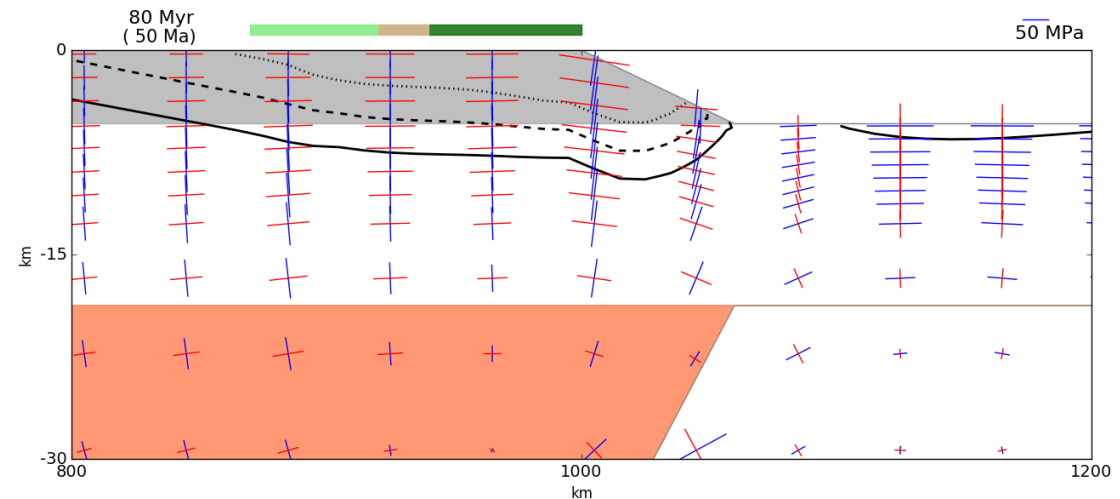

d)

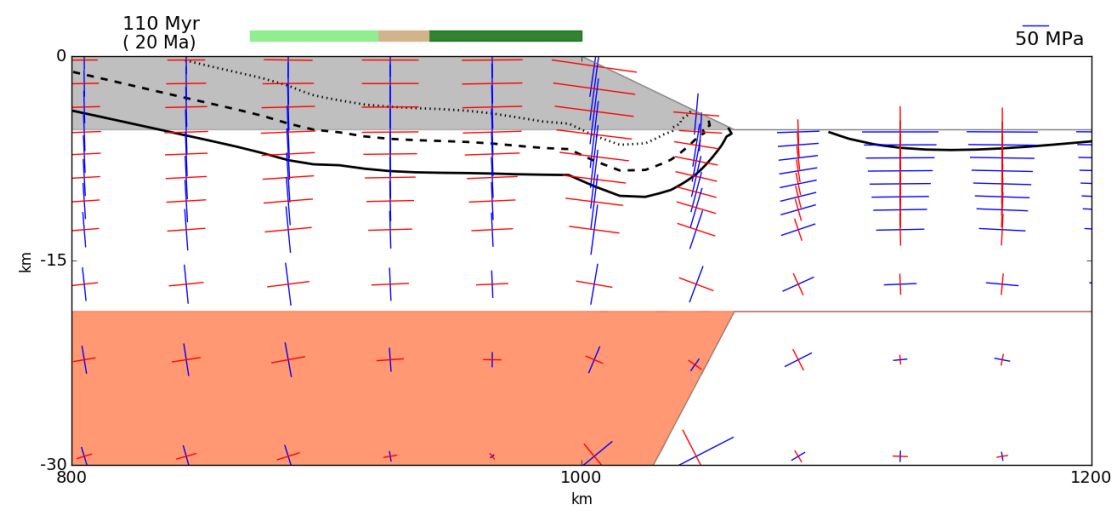

Figura 5.8: Esforços não litostáticos deviatóricos e envelope de ruptura para o modelo com denudação e sedimentação variáveis e e compressão regional (ero/sed var + comp, cf. Tabela 4.3). Conferir Figura 5.1 para demais parâmetros. 
a)

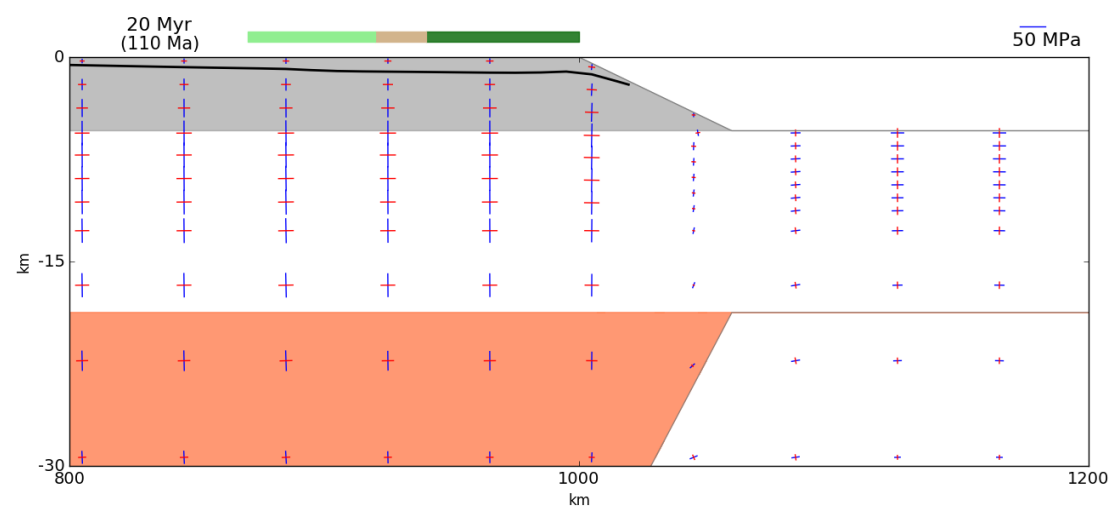

b)

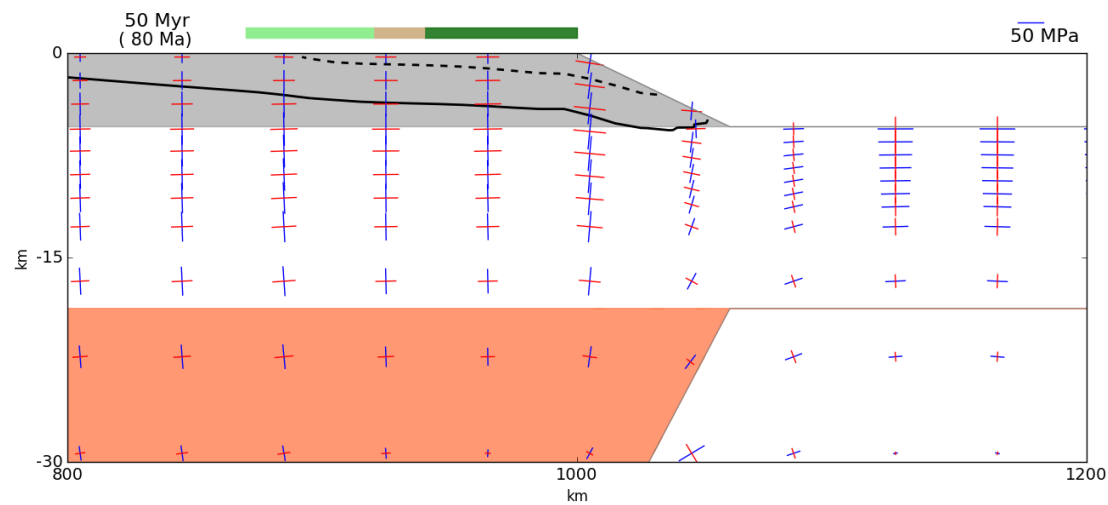

c)

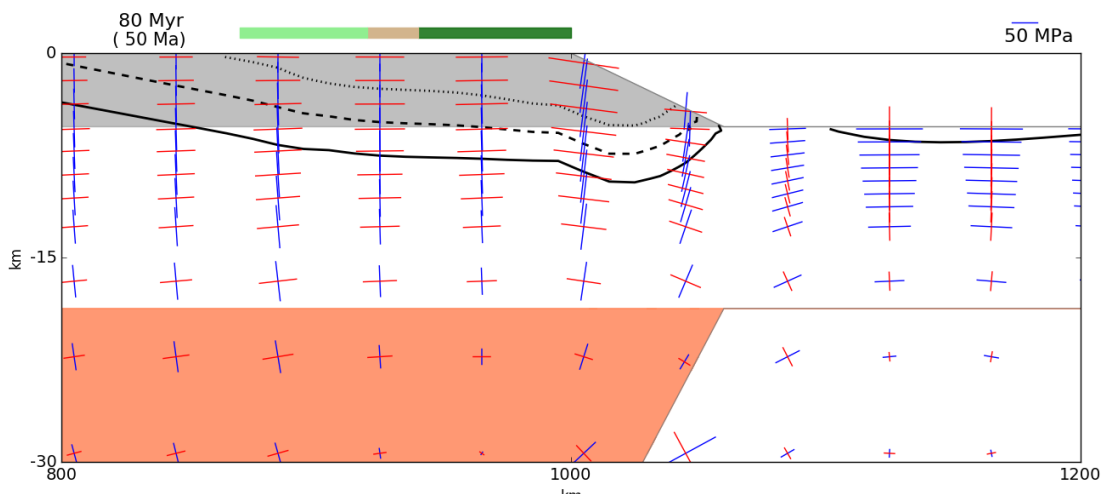

d)

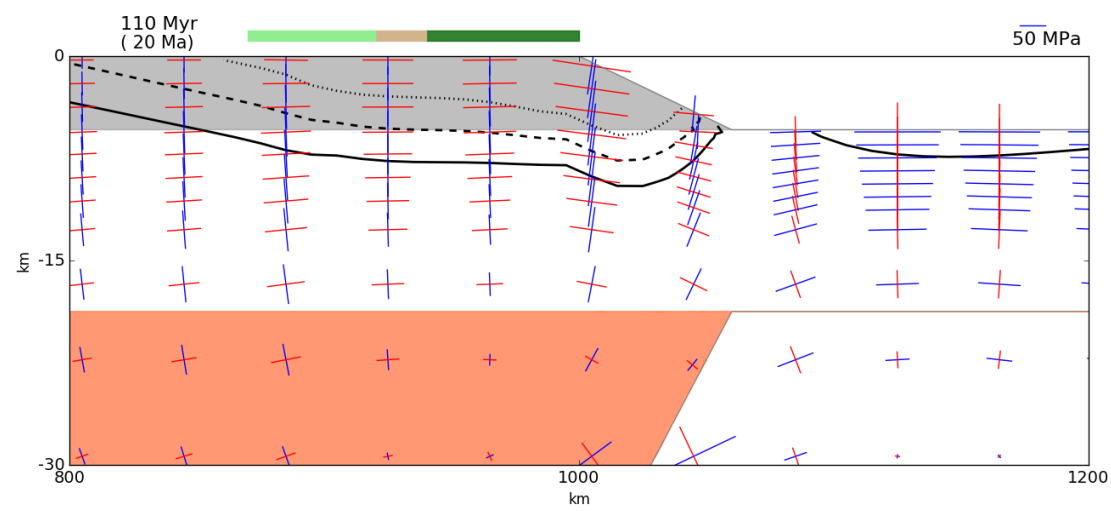

Figura 5.9: Esforços não litostáticos deviatóricos e envelope de ruptura para o modelo com denudação e sedimentação variáveis, compressão regional e compressão adicional a partir de $45 \mathrm{Ma}$ (ero/sed var + comp + Andes, cf. Tabela 4.3. Conferir Figura 5.1 para demais parâmetros. 


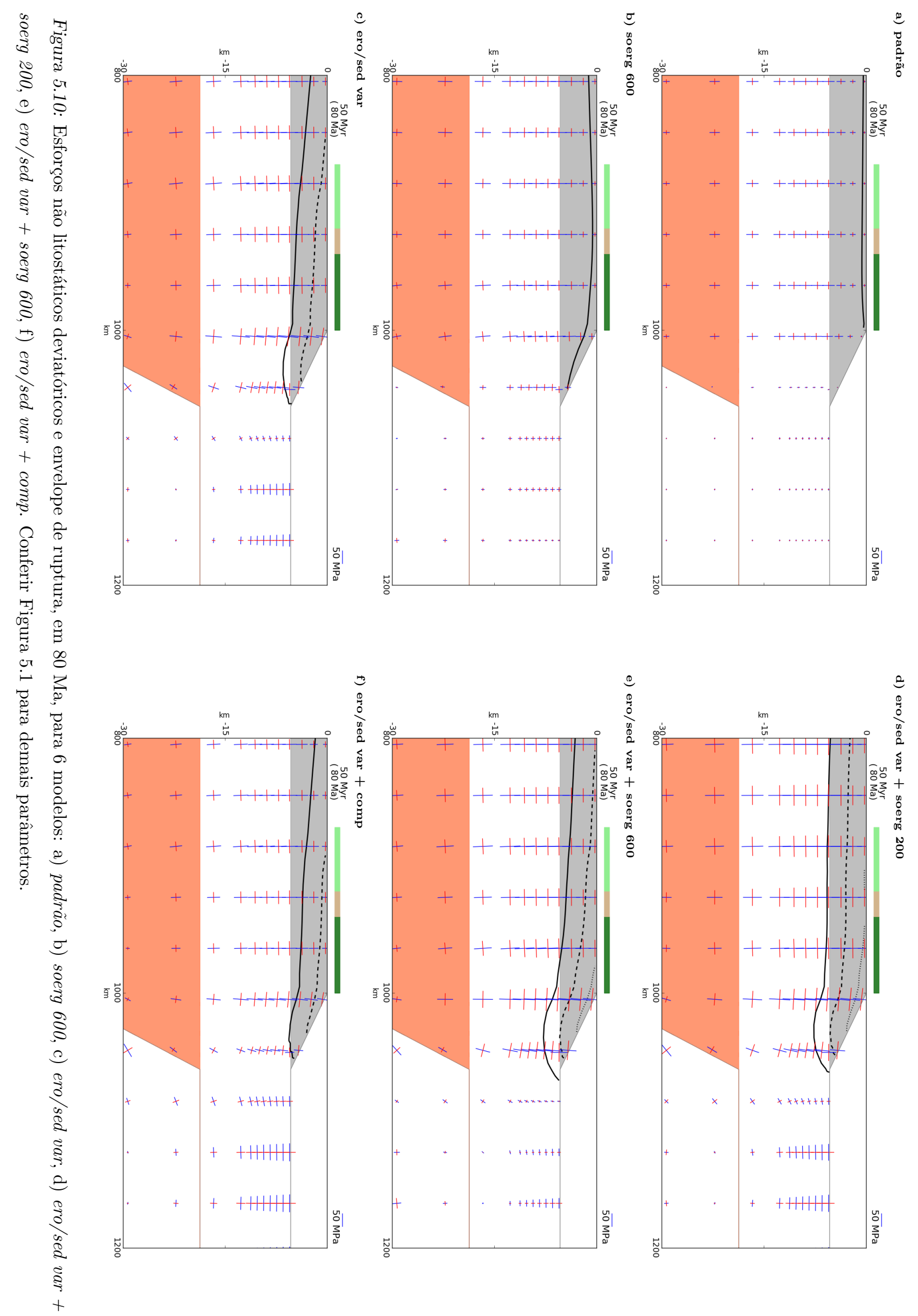


A influência dos valores de coesão das rochas (Equação 3.58) na profundidade máxima do envelope de ruptura ao longo do tempo pode ser observada na Figura 5.11. O efeito da baixa coesão resulta na maior profundidade alcançado pelo envelope de ruptura. Considerando valores mais elevados de coesão, o limite de ruptura não foi atingido no modelo sem variação de carga (padrão) e no modelo considerando apenas o soerguimento regional (soerg 600). Nota-se ainda, que no caso de coesão nula, o limite de ruptura não foi atingido no modelo soerg 600 durante dois períodos de tempo (em torno de 100 Ma e 50 Ma). A profundidade máxima, nesse caso, ocorreu no período em que o centro da anomalia (amplitude máxima) estava sob à margem (i.e., $70 \mathrm{Ma}$ ). Nessa figura, observa-se que o efeito do soerguimento regional, de diferentes comprimentos de onda, sobrepostos à erosão e sedimentação, não alterou significativamente a profundidade máxima do limite de ruptura. Uma alteração na profundidade é observada no intervalo de tempo no qual o máximo do soerguimento está sob a região da costa. Ao atuar na região oceânica, o soerguimento induz esforços compressivos na região costeira que se opõem aos causados pela erosão e sedimentação e, consequentemente, a profundidade do limite de ruptura diminui. Esse efeito é mais proeminente quanto menor o comprimento de onda do soerguimento. A anomalia térmica, ao se afastar da costa, não influencia o padrão de esforços na região continental próxima à margem, e os esforços nessa porção tendem para aqueles observados no modelo com apenas e erosão e sedimentação variáveis.

Ainda, pode-se observar que o efeito da compressão regional tende a diminuir a profundidade máxima observada. Ao se considerar um efeito adicional de uma nova componente de esforço compressivo regional, esse efeito foi ainda mais amplificado e consequentemente a profundidade do limite tende a diminuir. Esse resultado deve-se ao fato da compressão atuar contrariamente ao padrão de esforços deviatóricos tensionais sob a região continental.

Os resultados obtidos dos experimentos numéricos envolvendo uma compressão regional mostraram que a condição favorável à formação de falhas normais é inibida quanto maior os esforços compressivos. É importante notar que o modelo viscoelástico adotado não incorpora uma componente de deformação plástica, e desse modo, não reproduz a formação de falhamentos na crosta superior. Uma consequência da deformação plástica da porção superior do modelo seria o alívio dos esforços e desse modo, a compressão regional poderia inverter o regime tectônico e favorecer a ocorrência de falhamentos inversos. A evolução do RCSB de fato envolve episódios tectônicos que modificaram as bacias, no Mioceno, devido 


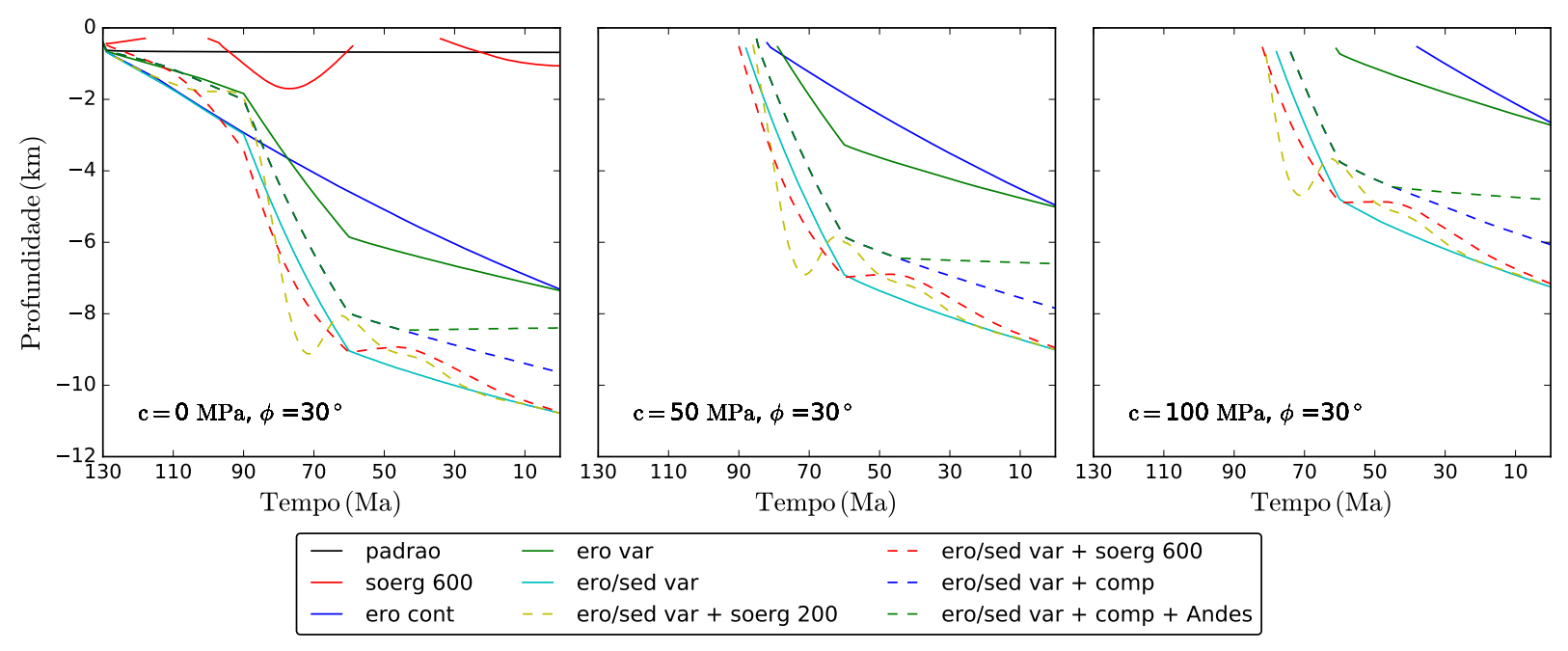

Figura 5.11: Profundidade máxima do envelope do limite de ruptura das rochas ao longo do tempo.

à transcorrência sinistral, com compressão na direção NE-SW e tensão na direção NWSE; no Neógeno-Quaternário, em um regime de transcorrência dextral, com compressão de direção NW-SE; e no Pleistoceno-Holoceno, cujos esforços são tensionais com direção entre E-W e WNW-ESE (Riccomini et al., 2004). Esse tectonismo modificador não pode ser analisado com o presente modelo. Entretanto, a direção dos esforços tensionais que reativaram as antigas zonas de fraqueza pre-cambrianas, associadas à formação das bacias cenozóicas do RCSB, foi essencialmente NW-SE (Riccomini et al., 2004; Cogné et al., 2012). Desse modo, apesar do modelo ser bidimensional, essa direção coincide com a direção da seção do modelo, ortogonal às estruturas do rifte. Por conta da condição de deformação plana, não é possível estudar em detalhe os efeitos de regimes transcorrentes no modelo. A reativação das falhas, no entanto, é vinculada com esforços intra-placa devido às forças de empurrão da cadeia meso-oceânica e à fase Incáica da orogenia Andina (e.g. Cogné et al. 2012 ).

Um episódio de maior taxa de denudação entre 90 e 60 Ma também é observada nos estudos de termocronologia (e.g. Gallagher et al., 1994; Cogné et al., 2011; Franco-Magalhaes et al. 2014). Os resultados dos experimentos numéricos indicam que o efeito da denudação, e a sedimentação na bacia oceânica adjacente, causariam a ruptura das rochas, promovendo falhas profundas possivelmente até a base da crosta superior. Desse modo, o efeito local da erosão e sedimentação são condizentes com a formação do RCSB no início do Cenozóico, após um episódio de maior denudação no Cretáceo Superior.

O soerguimento da região sudeste, devido ao efeito de uma anomalia térmica, é apon- 
tada como responsável pelo magmatismo alcalino na região, no Cretáceo Superior Cobbold et al., 2001; Franco-Magalhaes et al., 2014). Como visto, o soerguimento regional não modifica significantemente o estado de esforços na litosfera, não contribuindo expressivamente para a ruptura das rochas. A profundidade máxima do envelope de ruptura nos modelos com o soerguimento não foi maior do que aqueles com o efeito apenas da erosão e sedimentação (Figura 5.11). O soerguimento, no entanto, altera os processos superficiais contribuindo com a denudação. Braun et al. (2013) mostraram que a perturbação topográfica, criada por uma fonte mantélica, pode gerar feições de longo comprimento de onda e baixa amplitude, que podem induzir altas taxas de denudação na superfície, apesar da suavidade da perturbação. Assim, apesar do soerguimento regional não contribuir expressivamente para o amplificar o estado de tensão deviatórico na crosta superior, pode ter induzido o aumento da taxa de denudação da margem emersa e consequente deposição ao longo das bacias marginais, que por sua vez geraram tensões flexurais suficientes para criar falhas normais profundas no continente ao longo de zonas de falhas com baixa coesão interna.

Como resultado da comparação dos diversos cenários numéricos apresentados neste trabalho, conclui-se que a alta taxa de denudação da porção emersa e concomitante deposição sedimentar ao longo da margem estirada contribuíram expressivamente para a formação de falhas normais profundas em uma região em que as rochas da crosta superior apresentavam baixa coesão interna, sendo que outros processos geotectônicos, como soerguimento e compressão regional, teriam efeito secundário na evolução dessas falhas normais.

A combinação da alta taxa denudação da porção emersa, resultando em uma erosão total superior a $3 \mathrm{~km}$ ao longo da margem sudeste brasileira desde a abertura do Atlântico Sul, juntamente com a pré-existência de uma larga zona de falhas paralelas à margem contribuíram para criar um cenário adequado para a formação do RCSB.

Outras margens divergentes ao redor do planeta possivelmente não possuem esses dois fatores presentes simultaneamente, desse modo não induzindo à formação de um rifte continental interno: a margem divergente do sudeste da Australia, que se formou entre 90 e $100 \mathrm{Ma}$, apresentou uma baixa taxa de denudação pós-rifte, indicada por dados termocronológicos (O'Sullivan et al., 1996; Persano et al., 2002), o que deve ter contribuído para o inexpressivo tectonismo pós-rifte desta margem (cf. Bishop e Goldrick, 2000). A margem atlântica do sudoeste africano ao longo da costa da Namíbia e África do Sul 
apresenta denudação pós-rifte total da porção emersa da mesma ordem da denudação observada na margem sudeste brasileira (Gallagher e Brown, 2004), porém a largura das faixas móveis paralelas à costa são bem mais estreitas do que a Faixa Ribeira, impossibilitando a formação de um sistema de falhas normais sobre o cinturão. Uma exceção é a faixa móvel entre os crátons do Congo e do Kalahari (Damara belt), que se estende por centenas de quilômetros para dentro do continente, porém com orientação das zonas de cisalhamento essencialmente perpendiculares à margem, desse modo não favorecendo a formação de falhas normais paralelas a margem induzidas pela combinação de denudação continental e deposição marginal, ou seja, as tensões flexurais no interior da litosfera originadas pelos processos superficiais ao longo da margem não poderiam contribuir para reativar essas falhas ortogonais à costa.

Certamente muitos outros cenários poderão ser testados a partir da presente formulação numérica. A incorporação do comportamento rúptil em um modelo visco-elasto-plástico permitirá observar o desenvolvimento das falhas normais sem a necessidade de sobrepor, como pós-processamento, as curvas de envelope de resistência da rocha sobre o modelo viscoelástico. Adicionalmente a ampliação do problema para o caso 3-D permitirá explorar outras configurações geométricas entre a forma da margem e zonas de fragilidade juntamente com tensões regionais e padrão de denudação e sedimentação, tanto para a margem sudeste brasileira quanto para outras margens divergentes ao redor do planeta. 


\section{Capítulo 6}

\section{Conclusões}

O presente trabalho analisou o padrão de esforços na litosfera a partir de um modelo numérico, bidimensional, para simular o comportamento viscoelástico da litosfera durante a evolução da margem divergente do sudeste do Brasil. Foram realizados experimentos numéricos levando-se em conta a denudação da margem continental, a sedimentação na bacia oceânica, o soerguimento regional da litosfera, causado por uma anomalia térmica, e a compressão regional devido a esforços intraplaca, causada pela expansão do assoalho oceânico e pela orogenia andina, para avaliar quantitativamente a influência desses fatores na origem do RCSB.

Os resultados mostraram que a denudação na porção emersa do continente, juntamente com a sedimentação na bacia oceânica, afetaram expressivamente o estado de esforços na litosfera resultando em uma condição favorável à formação de falhas normais profundas na crosta superior. Adicionalmente, a formação de falhas normais profundas paralelas à costa é favorecida pela pré-existência de zonas em que as rochas da crosta superior possuem baixa coesão interna. Em contrapartida, tanto as componentes de esforço regional como o soerguimento regional não resultaram em alterações expressivas do padrão de esforços na litosfera, e consequentemente não modificaram significativamente as condições de ruptura das rochas na crosta superior.

Os resultados deste trabalho fornecem informações quantitativas importantes acerca dos mecanismos relacionados à origem do RCSB e indicam que a denudação e a sedimentação na margem sudeste do Brasil podem ter grande influência no seu processo de formação.

A modelagem do estado de esforços na litosfera apresentada neste trabalho pode ser aprimorada incorporando a componente de deformação plástica no modelo numérico. No presente modelo, apenas a viscoelasticidade não é capaz de reproduzir os falhamentos na 
crosta. Ademais, o modelo é bidimensional, e limita-se, portanto, à deformação plana. A modelagem 3-D tornaria possível o estudo de componentes cisalhantes no padrão de esforços da litosfera. Ainda, outro aprimoramento do modelo seria a incorporação da variação do estado térmico da litosfera ao longo do tempo, uma vez que a temperatuta influencia a reologia da litosfera. Os trabalhos futuros, suportados por um modelo mais complexo, podem averiguar não somente a origem do RCSB, no contexto evolutivo da margem sudeste do Brasil, como também outros episódios tectônicos que afetaram sua evolução. 


\section{Referências Bibliográficas}

Almeida, F. F. M., e C. D. Carneiro (1998). Origem e evolução da Serra do Mar, Revista Brasileira de Geociências, 28(2), 135-150.

Almeida, F. F. M., Y. Hasui, B. B. Brito Neves, e R. A. Fuck (1981). Brazilian structural provinces: An introduction, Earth-Science Reviews, 17(1), 1-29.

Almeida, F. F. M. D. (1976). The system of continental rifts bordering the Santos basin, Brazil, Anais da Academia Brasileira de Ciências, 48, 15-26.

Asmus, H. E., e A. L. Ferrari (1978). Hipótese sobre a causa do tectonismo cenozóico na região sudeste do Brasil, Projeto REMAC, 4, 75-78.

Assumpção, M., e V. Sacek (2013). Intra-plate seismicity and flexural stresses in central Brazil, Geophysical Research Letters, 40(3), 487-491.

Birot, P. (1959). Esboço morfológico da região litorânea do Estado do Rio de Janeiro, Not. Geomorfol., 2, 1-9.

Bishop, P., e Goldrick G. (2000). Geomorphological evolution of the East Australian continental margin, In: M. A. Summerfield, Geomorphology and Global Tectonics, John Wiley, Chichester, N. Y, 225-254.

Braun, J., X. Robert, e T. Simon-Labric (2013). Eroding dynamic topography, Geophysical Research Letters, 40(8), 1494-1499.

Chang, H. K., R. O. Kowsmann, A. M. F. Figueiredo, e A. Bender (1992). Tectonics and stratigraphy of the East Brazil Rift system: an overview, Tectonophysics, 213(1), $97-138$. 
Cobbold, P. R., K. E. Meisling, e V. S. Mount (2001). Reactivation of an obliquely rifted margin, Campos and Santos basins, southeastern Brazil, AAPG Bulletin, 85(11), 19251944.

Cogné, N., K. Gallagher, e P. R. Cobbold (2011). Post-rift reactivation of the onshore margin of southeast Brazil: Evidence from apatite (U-Th)/He and fission-track data, Earth and Planetary Science Letters, 309(1-2), 118-130.

Cogné, N., K. Gallagher, P. R. Cobbold, C. Riccomini, e C. Gautheron (2012). Postbreakup tectonics in southeast Brazil from thermochronological data and combined inverse-forward thermal history modeling, Journal of Geophysical Research, 117(B11), B11413.

Cogné, N., P. R. Cobbold, C. Riccomini, e K. Gallagher (2013). Tectonic setting of the Taubaté Basin (Southeastern Brazil): Insights from regional seismic profiles and outcrop data, Journal of South American Earth Sciences, 42, 194-204.

Contreras, J., R. Zühlke, S. Bowman, e T. Bechstädt (2010). Seismic stratigraphy and subsidence analysis of the southern Brazilian margin (Campos, Santos and Pelotas basins), Marine and Petroleum Geology, 27(9), 1952-1980.

Desai, C. (1979). Elementary finite element method, Prentice Hall, Inc, Englewood Cliffs, New Jersey.

Ferrari, A. L., e C. Riccomini (1999). Campo de esforços plio-pleistocênicos na Ilha da Trindade (Oceano Atlântico Sul, Brasil) e sua relação com a tectônica regional, Brazilian Journal of Geology, 29(2), 195-202.

Franco-Magalhaes, A., M. Cuglieri, P. Hackspacher, e A. Saad (2014). Long-term landscape evolution and post-rift reactivation in the southeastern Brazilian passive continental margin: Taubaté basin, International Journal of Earth Sciences, 103(2), 441-453.

Freitas, R. (1956). Considerações sobre a tectônica e geologia do Vale do Paraíba, Engenharia, Mineração e Metalurgia, 24 (143), 276-284.

Gallagher, K., e R. Brown (1999). The Mesozoic denudation history of the Atlantic margins of southern Africa and southeast Brazil and the relationship to offshore sedimentation, 
In: Cameron, N. R. and Bate, R. H. and Clure, V. S. (Eds.), The Oil and Gas Habitats of the South Atlantic, Geological Society, Special Publications, London, 41-53.

Gallagher, K., C. J. Hawkesworth, e M. S. M. Mantovani (1994). The denudation history of the onshore continental margin of SE Brazil inferred from apatite fission track data, Journal of Geophysical Research, 99(B9), 18117-18145.

Gallagher, K., R. Brown, e C. Johnson (1998). Fission track analysis and its applications to geological problems, Annu. Rev. Earth Planet. Sci., (26), 519-572.

Grana, J. P., e R. M. Richardson (1996). Tectonic stress within the New Madrid seismic zone, Journal of Geophysical Research: Solid Earth, 101 (B3), 5445-5458.

Hiruma, S. T., C. Riccomini, M. C. Modenesi-Gauttieri, P. C. Hackspacher, J. C. H. Neto, e A. O. Franco-Magalhães (2010). Denudation history of the Bocaina Plateau, Serra do Mar, southeastern Brazil: Relationships to Gondwana breakup and passive margin development, Gondwana Research, 18(4), 674-687.

Hughes, T. J. (2012). The finite element method: linear static and dynamic finite element analysis, Courier Corporation, Mineola, NY.

Ito, G., e P. E. van Keken (2007). Hotspots and melting anomalies, Treatise on Geophysics, 7, 371-436.

Karato, S.-i., e P. Wu (1993). Rheology of the upper mantle: A synthesis, Science, 260(5109), 771-778.

Karner, G. D., e N. W. Driscoll (1999). Tectonic and stratigraphic development of the West African and eastern Brazilian Margins: insights from quantitative basin modelling, Geological Society, London, Special Publications, (153), 11-40.

King, L. (1956). A geomorfologia do Brasil Oriental, Revista Brasileira de Geografia, 18, $147-165$.

Kusznir, N., e M. Bott (1977). Stress concentration in the upper lithosphere caused by underlying visco-elastic creep, Tectonophysics, 43, 247-256.

Martonne, E. de (1943). Problemas morfológicos do Brasil tropical atlântico, Revista Brasileira de Geografia, 5(4), 523-550. 
McKenzie, D. (1978). Some remarks on the development of sedimentary basins, Earth and Planetary science letters, 40(1), 25-32.

Meisling, K. E., P. R. Cobbold, e V. S. Mount (2001). Segmentation of an obliquely rifted margin, Campos and Santos basins, southeastern Brazil, AAPG bulletin, 85(11), 19031924.

Melo, M., C. Riccomini, Y. Hasui, F. Almeida, e A. Coimbra (1985). Geologia e evolução do sistema de bacias tafrogênicas continentais do sudeste do Brasil, Revista Brasileira de Geociências, 15(3), 193-201.

Melosh, H. J., e A. Raefsky (1980). The dynamical origin of subduction zone topography, Geophysical Journal of the Royal Astronomical Society, 60(3), 333-354.

Milani, E. J. (2004). Considerações sobre a estratigrafia do Fanerozóico no Brasil, In: Léo A. Hartmann, Anais da Reunião Aberta da Comissão Brasileira de Estratigrafia, $S B G$, Porto Alegre, 1-7.

O’Sullivan, P. B., D. A. Foster, B. P. Kohn, e A. J. Gleadow (1996). Multiple postorogenic denudation events: An example from the eastern Lachlan fold belt, Australia, Geology, $24(6), 563-566$.

Padilha, A., N. Trivedi, I. Vitorello, e J. da Costa (1991). Geophysical constraints on tectonic models of the Taubaté Basin, southeastern Brazil, Tectonophysics, 196(1-2), $157-172$

Persano, C., F. M. Stuart, P. Bishop, e D. N. Barfod (2002). Apatite (U-Th)/He age constraints on the development of the Great Escarpment on the southeastern Australian passive margin, Earth and Planetary Science Letters, 200(1), 79-90.

Ranalli, G. (1995). Rheology of the Earth, Springer Science \& Business Media.

Ricard, Y. (2007). Physics of Mantle Convection, In Schubert, G. (Ed.), Treatise on Geophysics, Vol. 7: Mantle Convection (Ed. Bercovici, D.), Elsevier B.V., 31-87.

Riccomini, C. (1989). O Rift Continental do Sudeste do Brasil, tese de doutorado, p. 256. pp., Universidade de São Paulo. 
Riccomini, C., L. Sant'Anna, e A. Ferrari (2004). Evolução geológica do rift continental do sudeste do Brasil, In: Mantesso-Neto, V., Bartorelli, A., Carneiro, C.D.R., Neves, B.B.B. (Eds.), Geologia do continente Sul-Americano: evolução da obra de Fernando Flávio Marques de Almeida, Beca, São Paulo, 383-405.

Ruellan, F. (1947). Evolução geomorfológica da baía de Guanabara e das regiões circunvizinhas, Revista Brasileira de Geografia, (6), 145-508.

Saenz, C. T., J. H. Neto, P. Iunes, S. Guedes, P. Hackspacher, L. Ribeiro, S. Paulo, e others (2005). Thermochronology of the South American platform in the state of São Paulo, Brazil, through apatite fission tracks, Radiation Measurements, 39(6), 635-640.

Trouw, R. A. J., M. Heilbron, A. Ribeiro, F. Paciullo, C. M. Valeriano, J. C. H. Almeida, M. Tupinamba, e R. R. Andreis (2000). The central segment of the Ribeira Belt, In: Cordani, U. G., Milani, E. J., Thomas Filho, A., Campos, D. A. (Eds.), Tectonic Evolution of South America, Fundo Setorial de Pet. e Gás Nat., Rio de Janeiro, 287310.

Turcotte, D. L., e G. Schubert (2002). Geodynamics, 2 edn., Cambridge Univ. Press, Cambridge, UK,

Watts, A., S. Zhong, e J. Hunter (2013). The behavior of the lithosphere on seismic to geologic timescales, Annual Review of Earth and Planetary Sciences, 41, 443-468.

Zalán, P. V. (1986). A tectônica transcorrente na exploração de petróleo: uma revisão, Revista Brasileira de Geociências, 16(3), 245-257.

Zalán, P. V., e J. A. B. Oliveira (2005). Origem e evoluçao do Sistema de Riftes Cenozóicos do Sudeste do Brasil, B. Geoci. Petrobras, 13(2), 269-300.

Zienkiewicz, O., e R. Taylor (2000). The finite element method: solid mechanics, Butterworth-Heinemann. 
Apêndice 



\section{Apêndice A}

\section{Modelo viscoelástico de Maxwell}

O modelo viscoelástico de Maxwell é definido pela distribuição da deformação, em série, nas componentes elástica e viscosa, para o mesmo esforço aplicado nas duas componentes:

$$
\begin{gathered}
\boldsymbol{\sigma}=\boldsymbol{\sigma}^{e}=\boldsymbol{\sigma}^{v} \\
\boldsymbol{\epsilon}=\boldsymbol{\epsilon}^{e}+\boldsymbol{\epsilon}^{v}
\end{gathered}
$$

As componentes $\boldsymbol{\epsilon}^{e}$ e $\boldsymbol{\epsilon}^{v}$ são dadas pelas Equações 3.7 e 3.11, respectivamente, assim:

$$
\begin{gathered}
\dot{\boldsymbol{\epsilon}}=\frac{(1-2 \nu)}{3 E} \operatorname{tr}(\dot{\boldsymbol{\sigma}}) \boldsymbol{I}+\frac{(1+\nu)}{E}\left(\dot{\boldsymbol{\sigma}}-\frac{1}{3} \operatorname{tr}(\dot{\boldsymbol{\sigma}}) \boldsymbol{I}\right)+\frac{1}{2 \eta}\left(\boldsymbol{\sigma}-\frac{1}{3} \operatorname{tr}(\boldsymbol{\sigma}) \boldsymbol{I}\right) \\
\dot{\boldsymbol{\epsilon}}=\frac{(1+\nu)}{E} \dot{\boldsymbol{\sigma}}-\frac{\nu}{E} \operatorname{tr}(\dot{\boldsymbol{\sigma}}) \boldsymbol{I}+\frac{1}{2 \eta}\left(\boldsymbol{\sigma}-\frac{1}{3} \operatorname{tr}(\boldsymbol{\sigma}) \boldsymbol{I}\right)
\end{gathered}
$$

Chamando

$$
\begin{gathered}
\dot{\boldsymbol{\epsilon}}^{e}=\frac{(1+\nu)}{E} \dot{\boldsymbol{\sigma}}-\frac{\nu}{E} \operatorname{tr}(\dot{\boldsymbol{\sigma}}) \boldsymbol{I} \\
\dot{\boldsymbol{\epsilon}}^{v}=\frac{1}{2 \eta}\left(\boldsymbol{\sigma}-\frac{1}{3} \operatorname{tr}(\boldsymbol{\sigma}) \boldsymbol{I}\right)
\end{gathered}
$$

e considerando a condição de deformação plana

$$
\dot{\epsilon}_{z z}^{e}=\dot{\epsilon}_{z z}^{v}=0
$$

segue

$$
\begin{aligned}
\dot{\epsilon}_{z z}^{e} & =\frac{(1+\nu)}{E} \dot{\sigma}_{z z}-\frac{\nu}{E}\left(\dot{\sigma}_{x x}+\dot{\sigma}_{y y}+\dot{\sigma}_{z z}\right)=0 \\
& \Rightarrow(1+\nu) \dot{\sigma}_{z z}=\nu\left(\dot{\sigma}_{x x}+\dot{\sigma}_{y y}+\dot{\sigma}_{z z}\right)
\end{aligned}
$$

obtendo

$$
\dot{\sigma}_{z z}=\nu\left(\dot{\sigma}_{x x}+\dot{\sigma}_{y y}\right)
$$


e

$$
\begin{aligned}
\dot{\epsilon}_{z z}^{v} & =\frac{1}{2 \eta}\left(\sigma_{x x}-\frac{1}{3}\left(\sigma_{x x}+\sigma_{y y}+\sigma_{z z}\right)\right)=0 \\
& \Rightarrow 3 \sigma_{z z}=\sigma_{x x}+\sigma_{y y}+\sigma_{z z}
\end{aligned}
$$

resultando

$$
\sigma_{z z}=\frac{\sigma_{x x}+\sigma_{y y}}{2}
$$

Substituindo a Equação A.9 na Equação A.5 para a componente $\epsilon_{x x}^{e}$ :

$$
\begin{aligned}
\dot{\epsilon}_{x x}^{e} & =\frac{(1+\nu)}{E} \dot{\sigma}_{x x}-\frac{\nu}{E}\left(\dot{\sigma}_{x x}+\dot{\sigma}_{y y}+\dot{\sigma}_{z z}\right) \\
& =\frac{(1+\nu)}{E} \dot{\sigma}_{x x}-\frac{\nu}{E}(\underbrace{\dot{\sigma}_{x x}+\dot{\sigma}_{y y}+\nu\left(\dot{\sigma}_{x x}+\dot{\sigma}_{y y}\right)}_{=(1+\nu)\left(\dot{\sigma}_{x x}+\dot{\sigma}_{y y}\right)}) \\
& =\frac{(1+\nu)}{E}\left[(1-\nu) \dot{\sigma}_{x x}-\nu \dot{\sigma}_{y y}\right]
\end{aligned}
$$

De modo semelhante, para a componente $\epsilon_{y y}^{e}$ :

$$
\dot{\epsilon}_{y y}^{e}=\frac{(1+\nu)}{E}\left[(1-\nu) \dot{\sigma}_{y y}-\nu \dot{\sigma}_{x x}\right]
$$

Substituindo a Equação A.11 na Equação A.6 para a componente $\epsilon_{x x}^{v}$ :

$$
\begin{aligned}
\dot{\epsilon}_{x x}^{v} & =\frac{1}{2 \eta}\left[\sigma_{x x}-\frac{1}{3}\left(\sigma_{x x}+\sigma_{y y}+\sigma_{z z}\right)\right] \\
& =\frac{1}{2 \eta}\left[\sigma_{x x}-\frac{1}{3}\left(\sigma_{x x}+\sigma_{y y}+\frac{\left(\sigma_{x x}+\sigma_{y y}\right)}{2}\right)\right] \\
& =\frac{1}{2 \eta}\left[\sigma_{x x}-\frac{\left(\sigma_{x x}+\sigma_{y y}\right)}{2}\right] \\
& =\frac{1}{4 \eta}\left(\sigma_{x x}+\sigma_{y y}\right)
\end{aligned}
$$

A componente $\epsilon_{y y}^{v}$ é obtida de modo análoga:

$$
\dot{\epsilon}_{y y}^{v}=-\frac{1}{4 \eta}\left(\sigma_{x x}+\sigma_{y y}\right)
$$

Na Equação A.4, devido a matriz identidade $\boldsymbol{I}$, os termos para $i \neq j$, são dados por:

$$
\dot{\epsilon}_{i j}=\frac{1+\nu}{E} \dot{\sigma}_{i j}+\frac{1}{2 \eta} \sigma_{i j}(i \neq j)
$$

Para deformação plana, e considerando a simetria $\dot{\epsilon}_{x y}=\dot{\epsilon}_{y x}$ :

$$
\dot{\epsilon}_{x y}=\frac{1+\nu}{E} \dot{\sigma}_{x y}+\frac{1}{2 \eta} \sigma_{x y}
$$


As soma das Equações A.12 e A.14 fornece a componente $\dot{\epsilon}_{x x}$ e a soma das Equaçãoes A.13 e A.15 correspondem a componente $\dot{\epsilon}_{y y}$. Juntamente com a Equação A.17, essas equações relacionam a taxa de deformação plana para o modelo viscoelástico linear. A diferença entre essas equações e as Equações 3.15 da Seção 3.1 .3 é o segundo termo no membro à direita, que envolve a viscosidade dinâmica. Para levar em conta o comportamento não linear, considera-se que $\dot{\boldsymbol{\epsilon}}^{v}$ é dado pela seguinte expressão, onde assume-se a lei de potência para o comportamento não linear:

$$
\dot{\boldsymbol{\epsilon}}^{v}=\frac{\sigma^{n-1}}{2 \eta}\left(\boldsymbol{\sigma}-\frac{1}{3} \operatorname{tr}(\boldsymbol{\sigma}) \boldsymbol{I}\right)
$$

no qual

$$
\sigma=\sqrt{\left(\frac{\sigma_{x x}-\sigma_{y y}}{2}\right)^{2}+\left(\sigma_{x y}\right)^{2}}
$$

é a raiz quadrada do segundo invariante do tensor de esforços.

Levando-se em consideração a forma de $\dot{\boldsymbol{\epsilon}}^{v}$ dada pela Equação A.18, na dedução descrita acima, obtêm-se as equações apresentadas na Seção 3.1 .3 . 


\section{Apêndice B}

\section{Esforços e envelope de ruptura (figuras)}

No Capítulo 5 foram apresentadas os resultados dos esforços e os envelopes de ruptura para os modelos da Tabela 4.3 para uma porção reduzida da seção completa do modelo. A seguir são apresentados as seções completas das figuras correspondentes, apresentadas no Capítulo 5. A simbologia é descrita na Figura 5.1. As curvas pretas contínua, tracejada e pontilhada, quando presentes, representam o envelope de ruptura para as coesões nula, $50 \mathrm{MPa}$ e $100 \mathrm{MPa}$, respectivamente. O simbolo triangular na base do modelo, quando presente, indica a posição do máximo da amplitude do soerguimento devido à anomalia térmica sob a base da litosfera. 


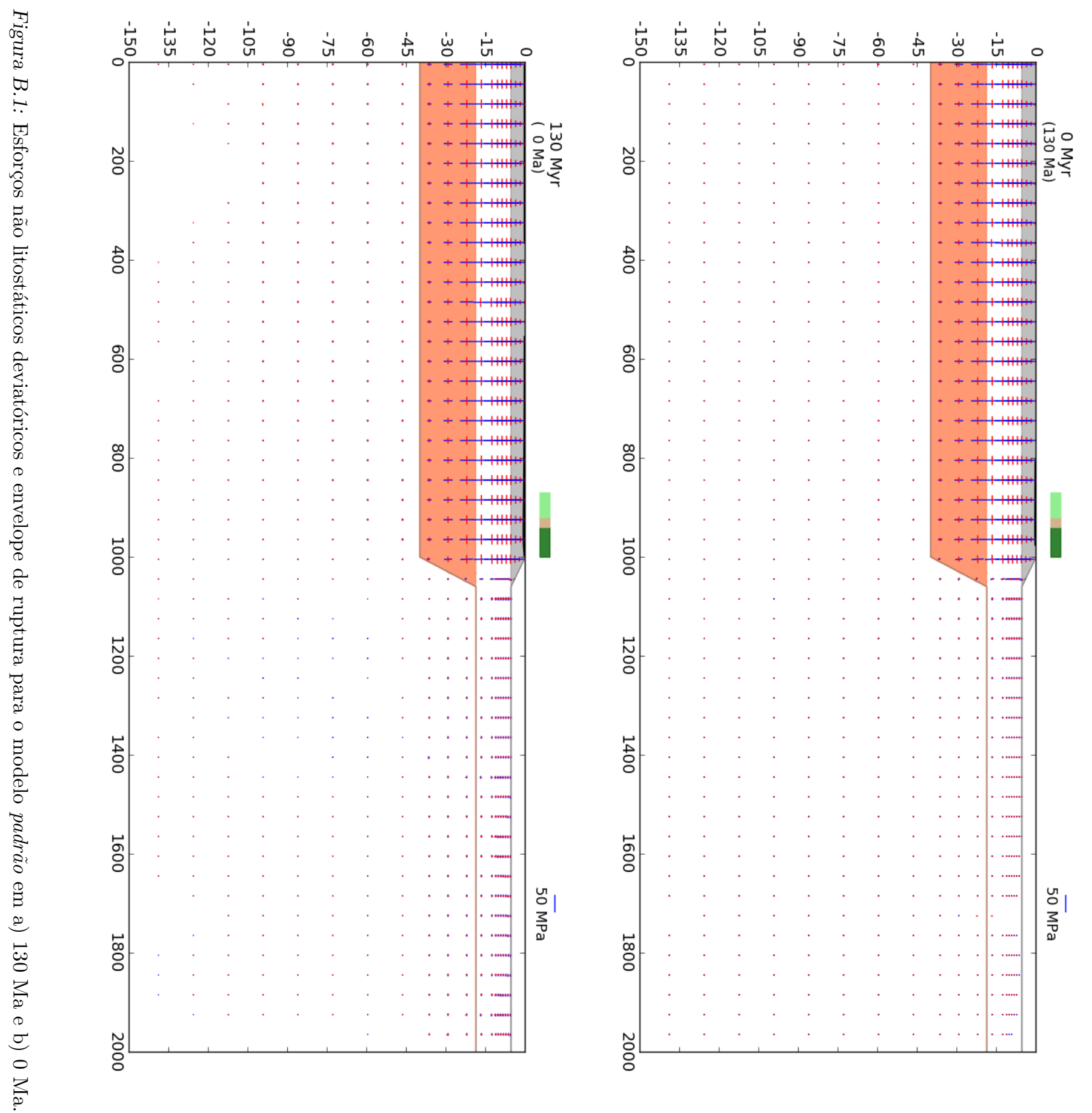




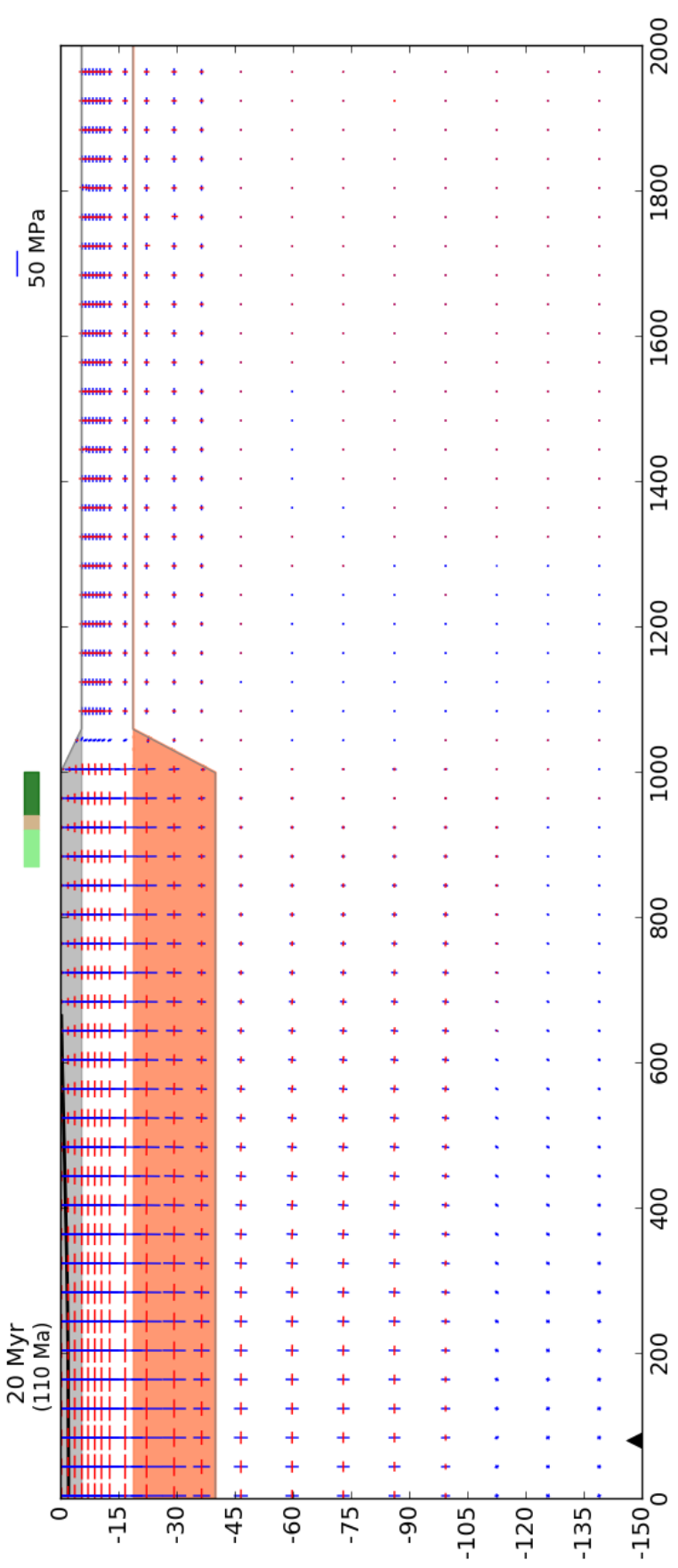

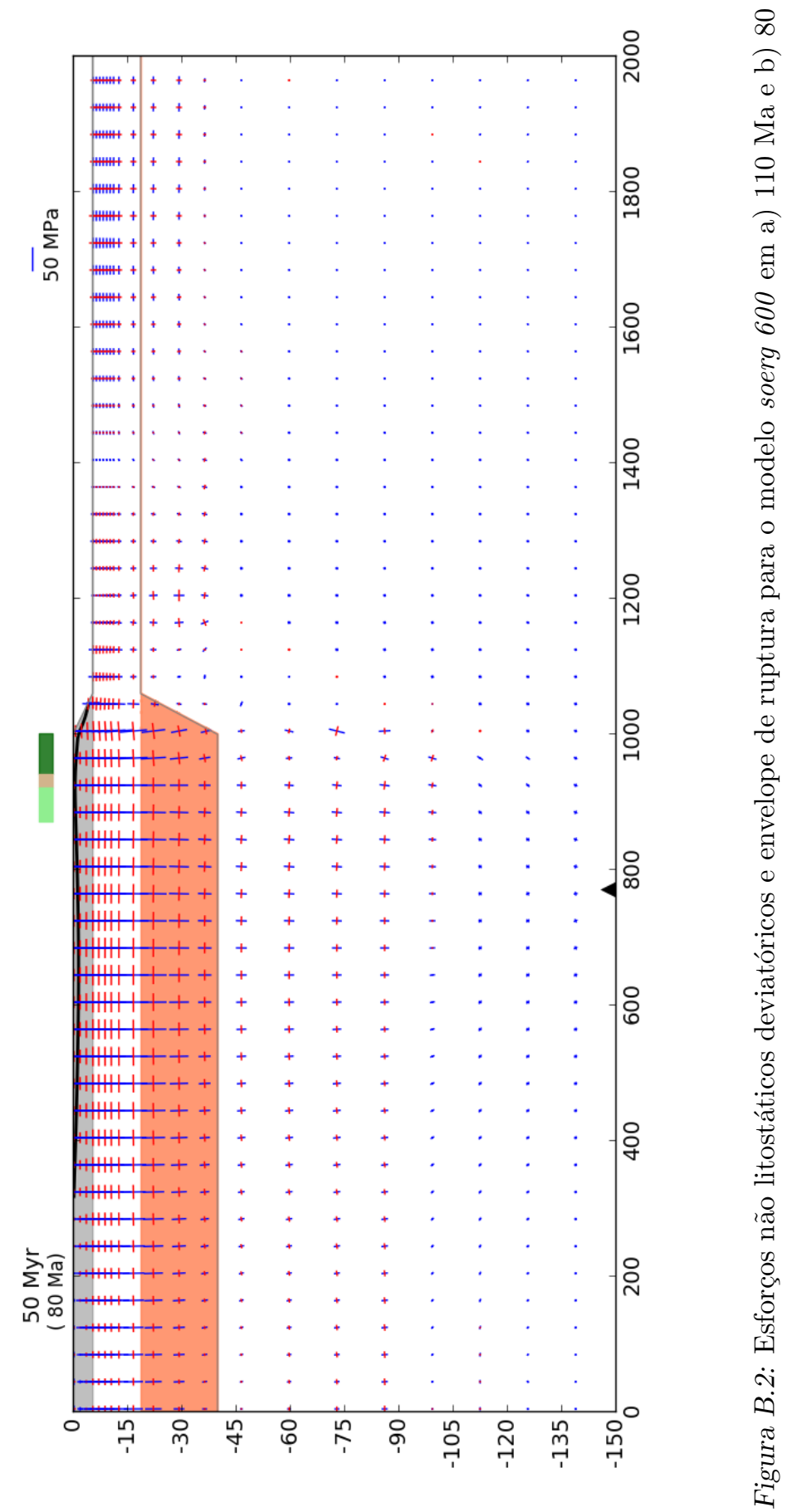



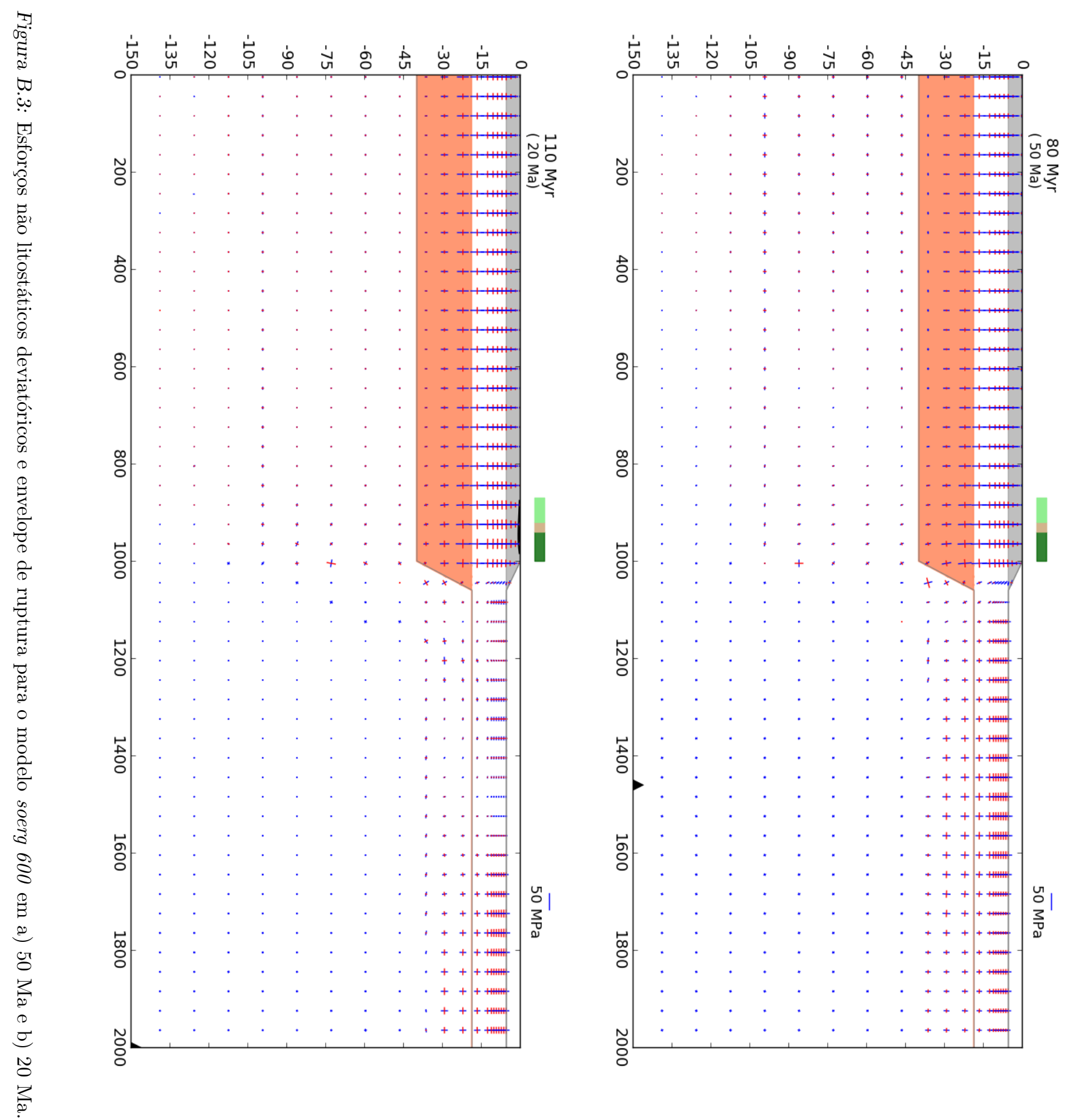


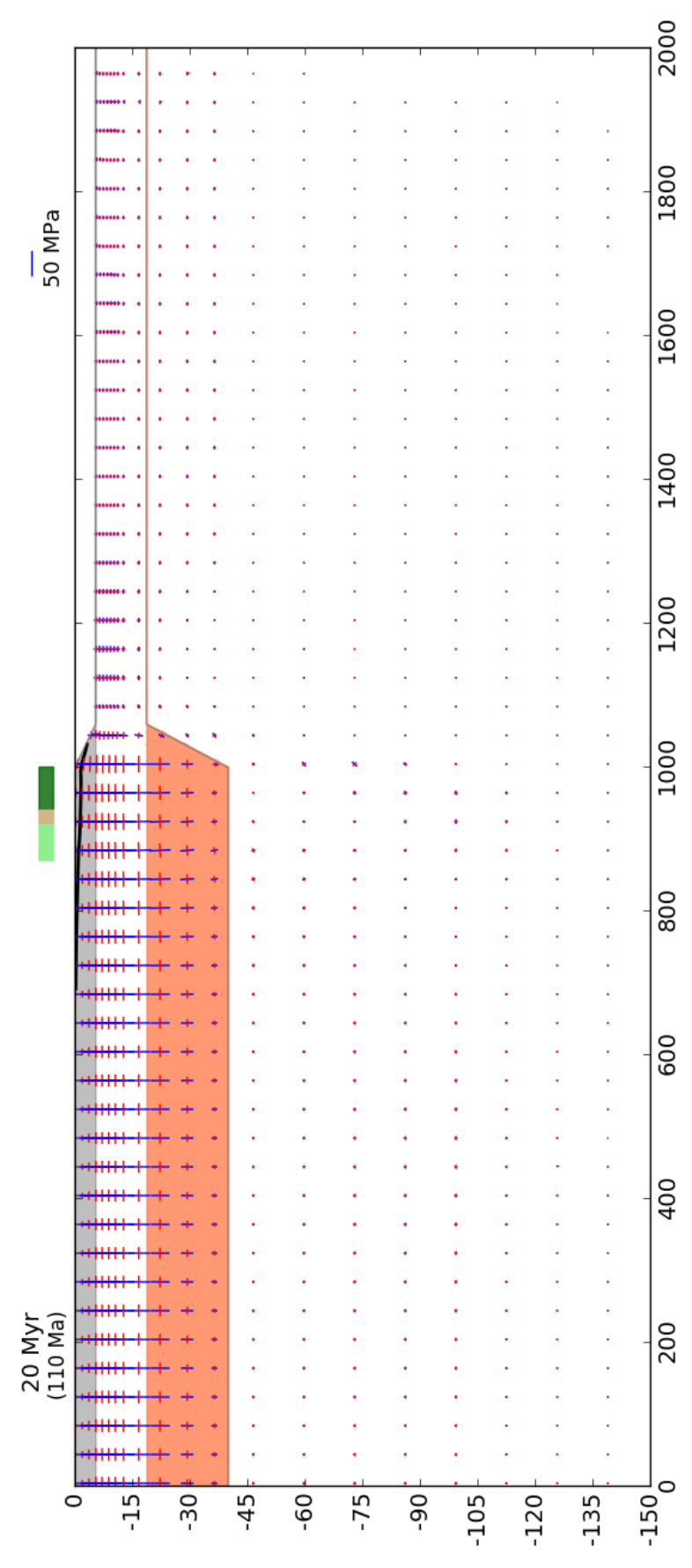

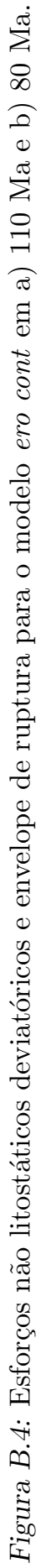



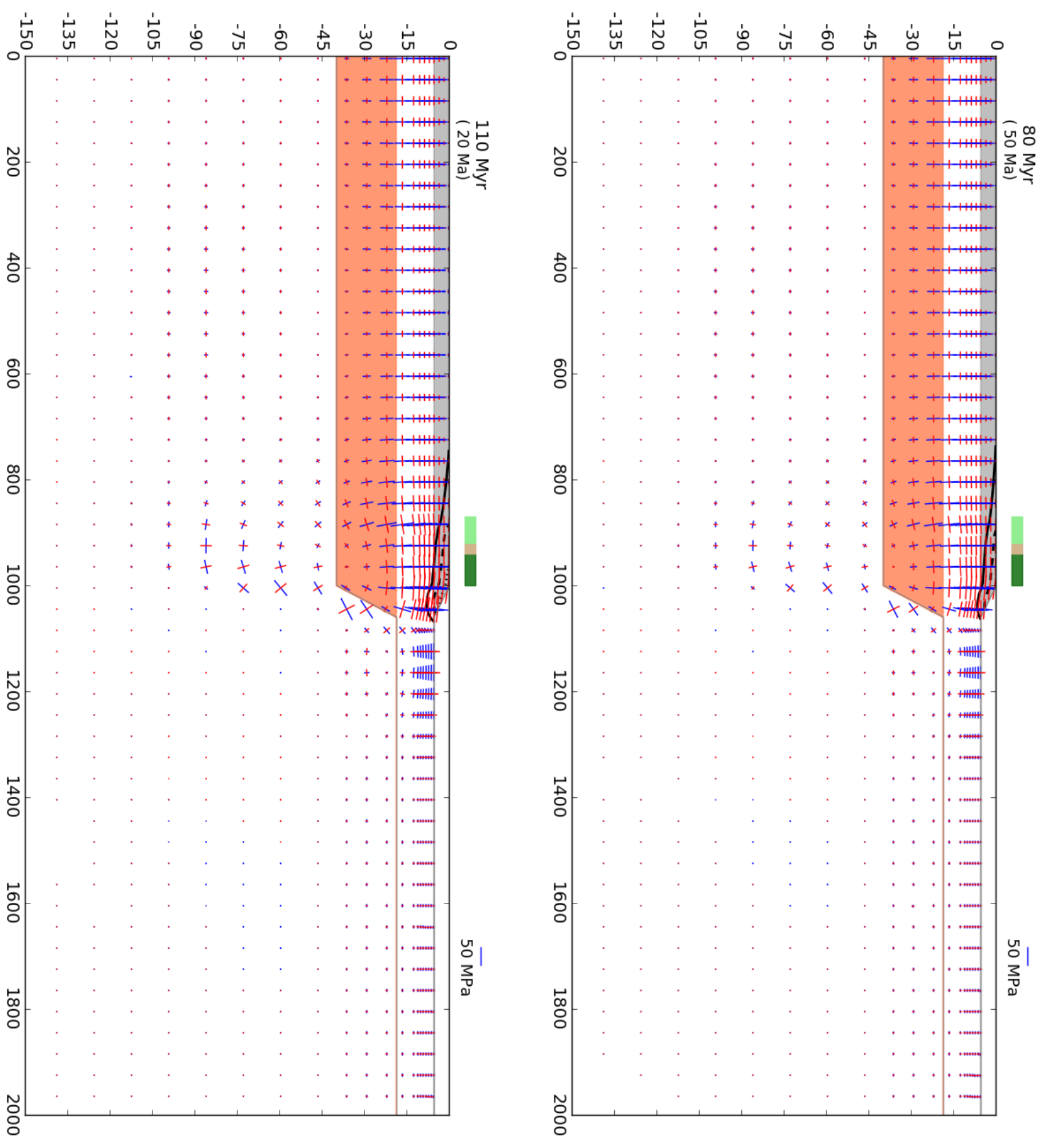

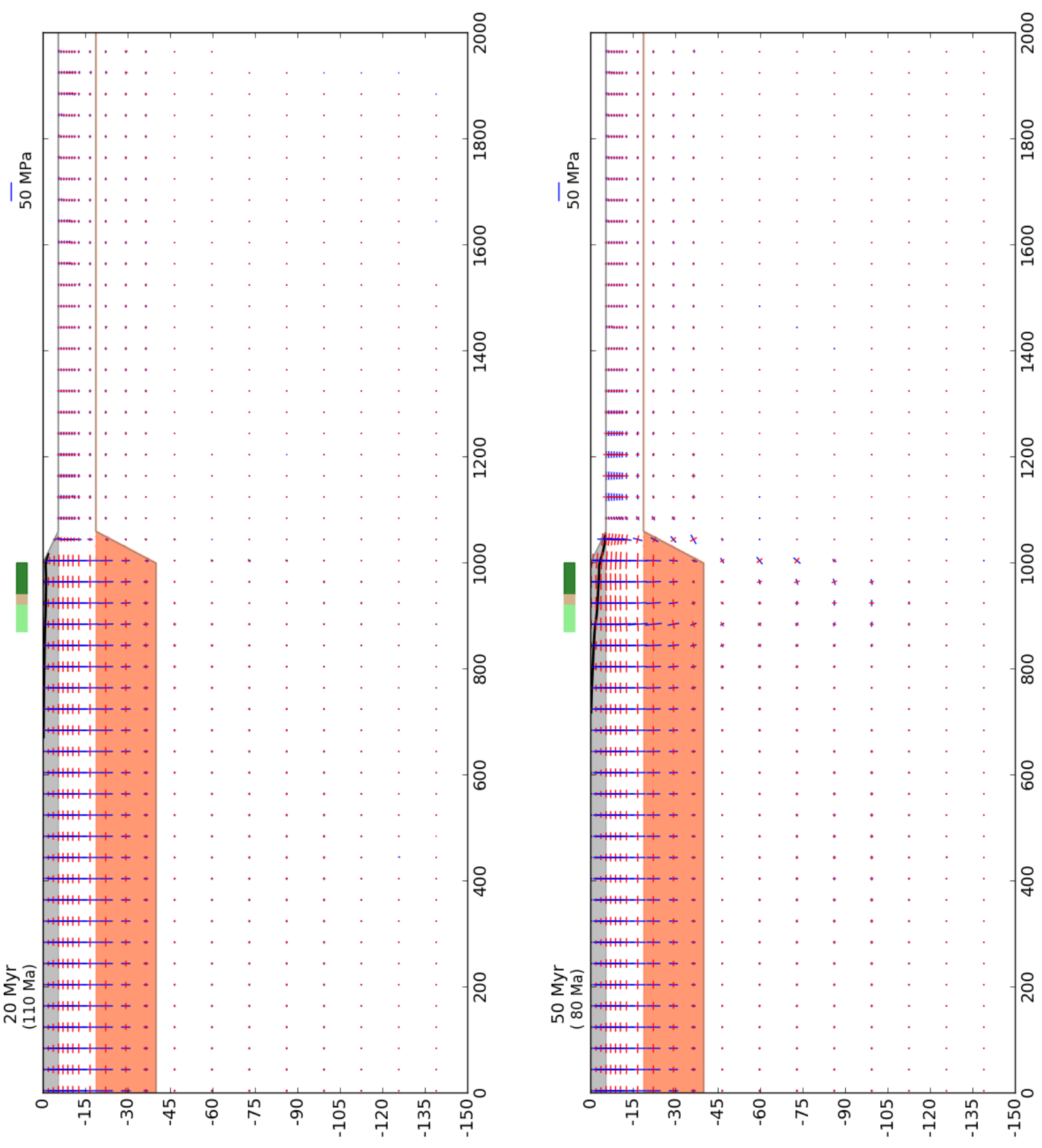

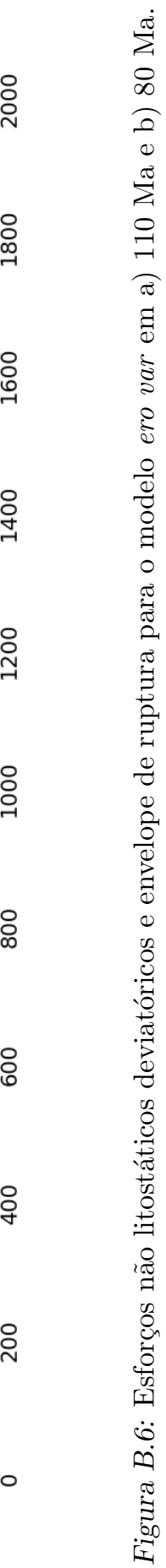



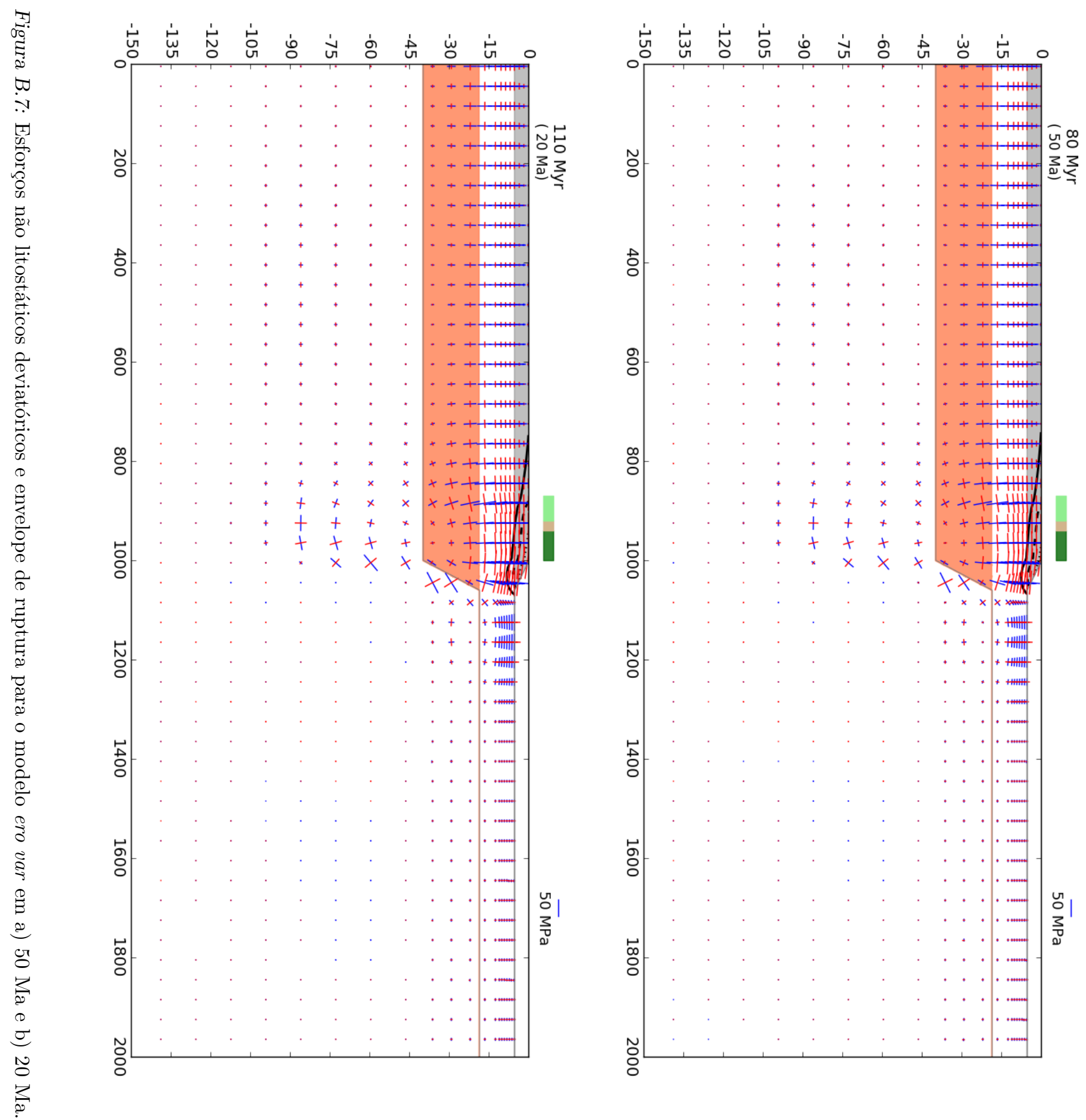


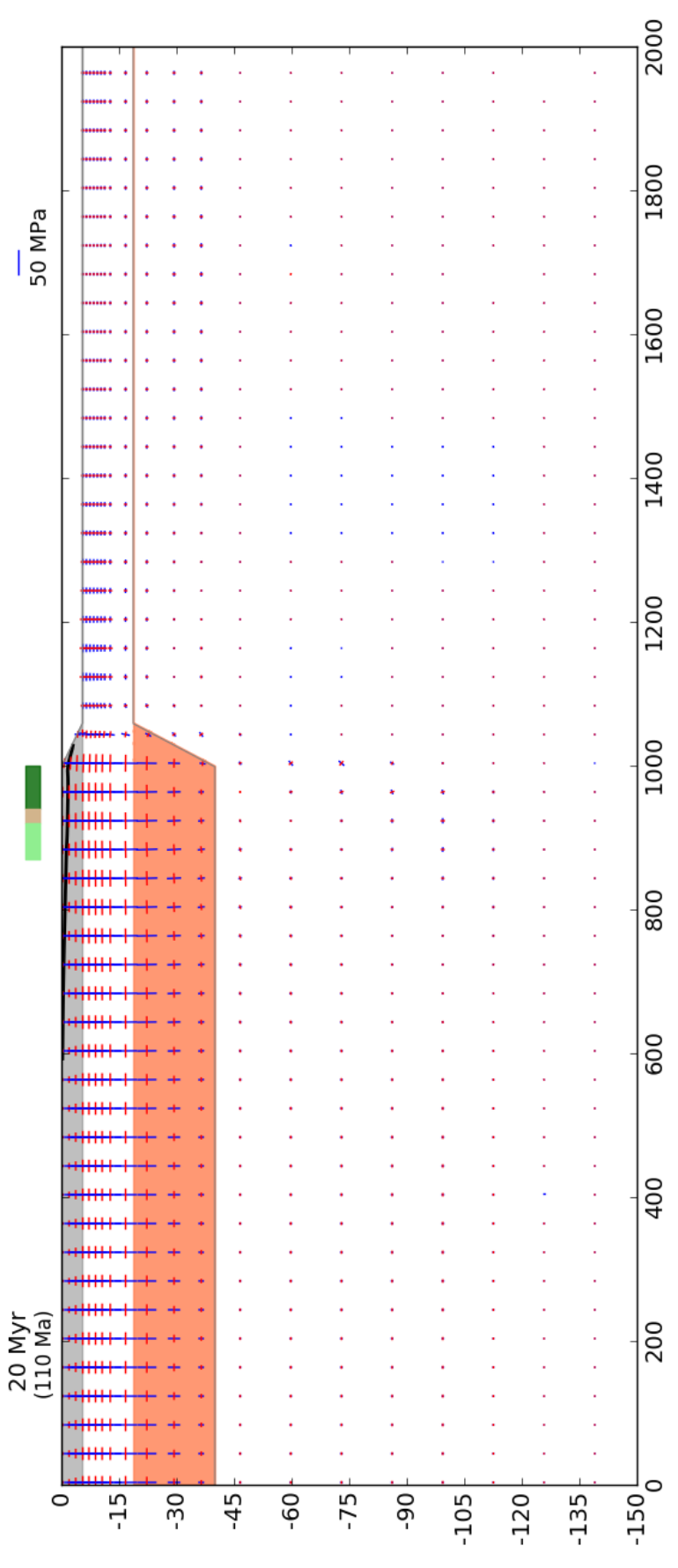

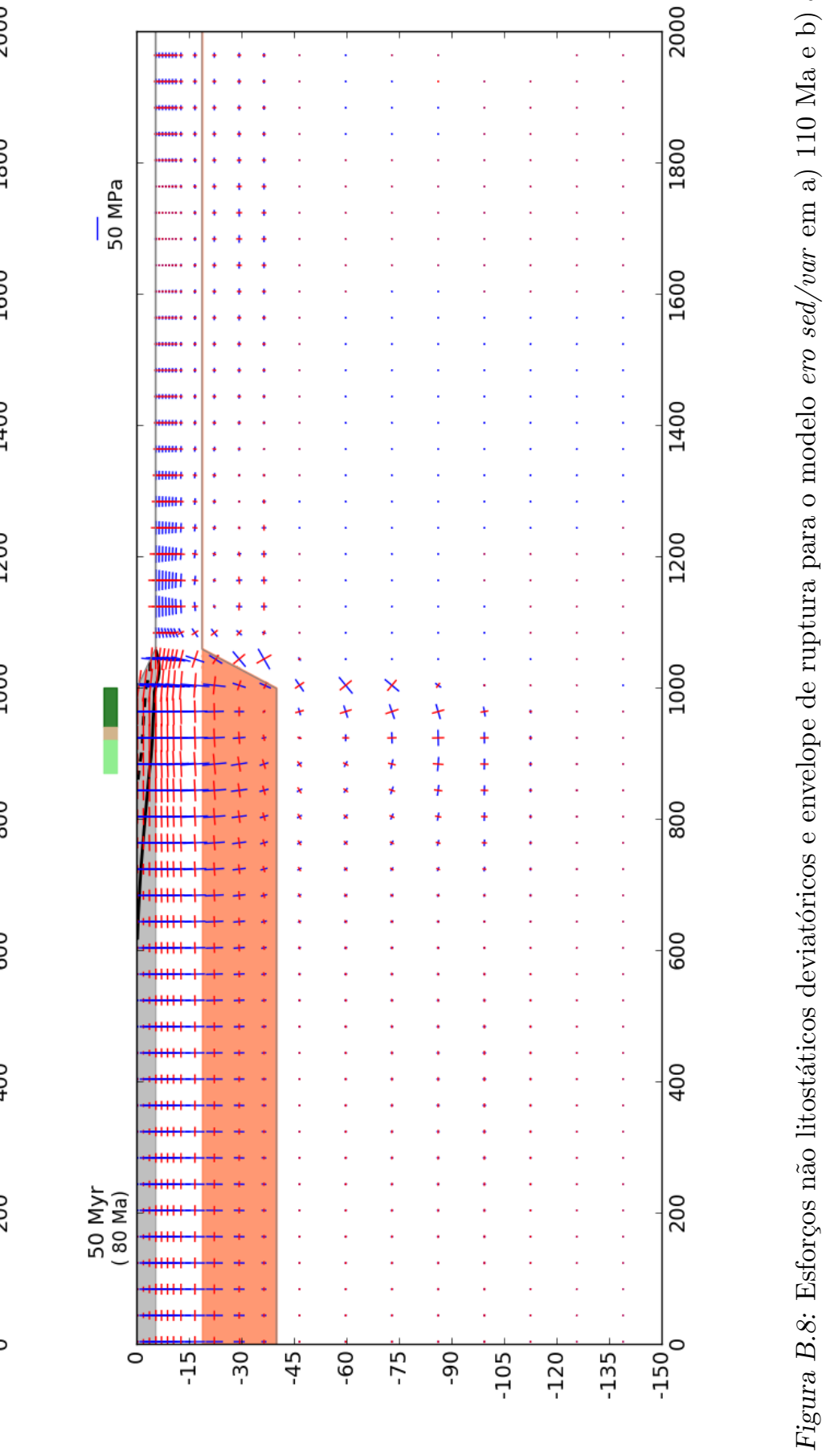



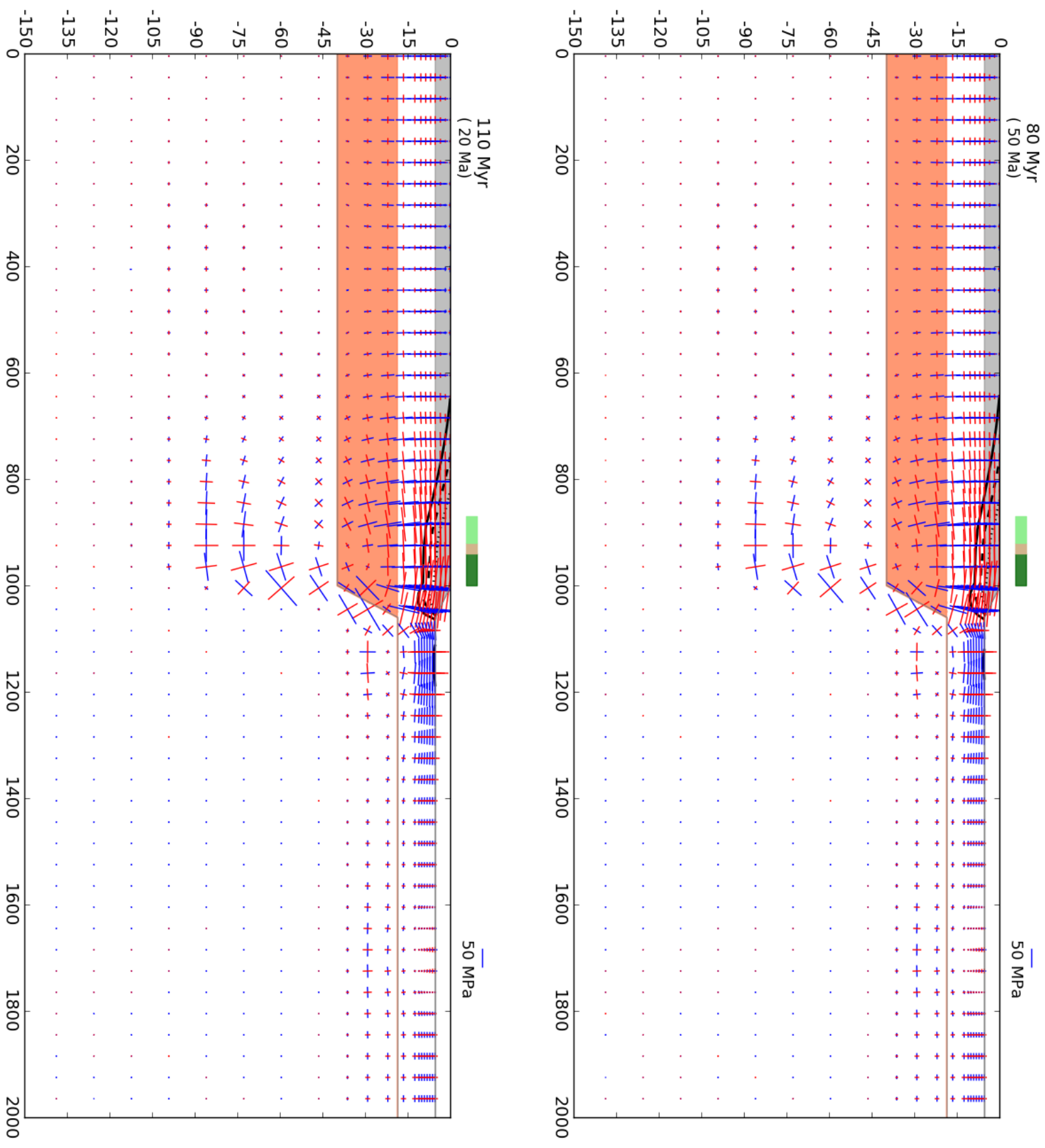


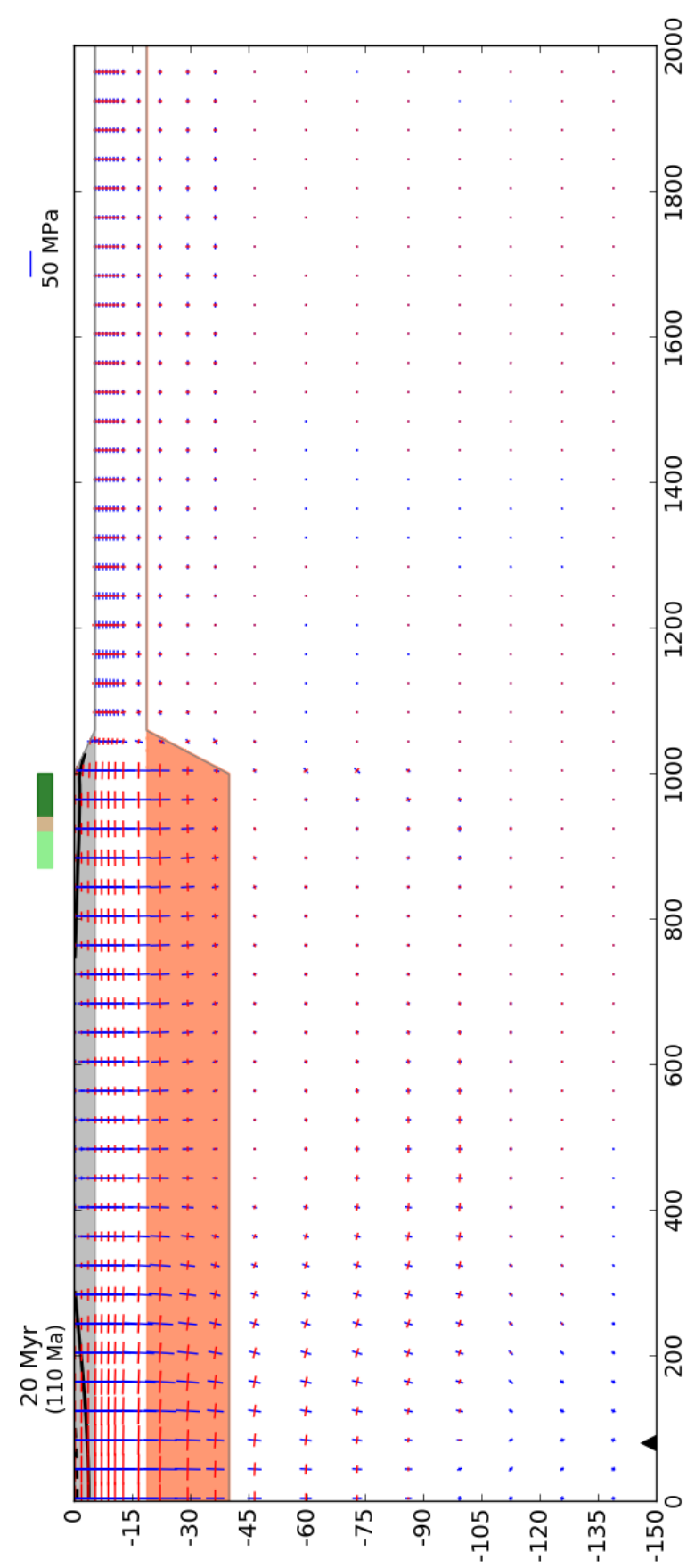

ส

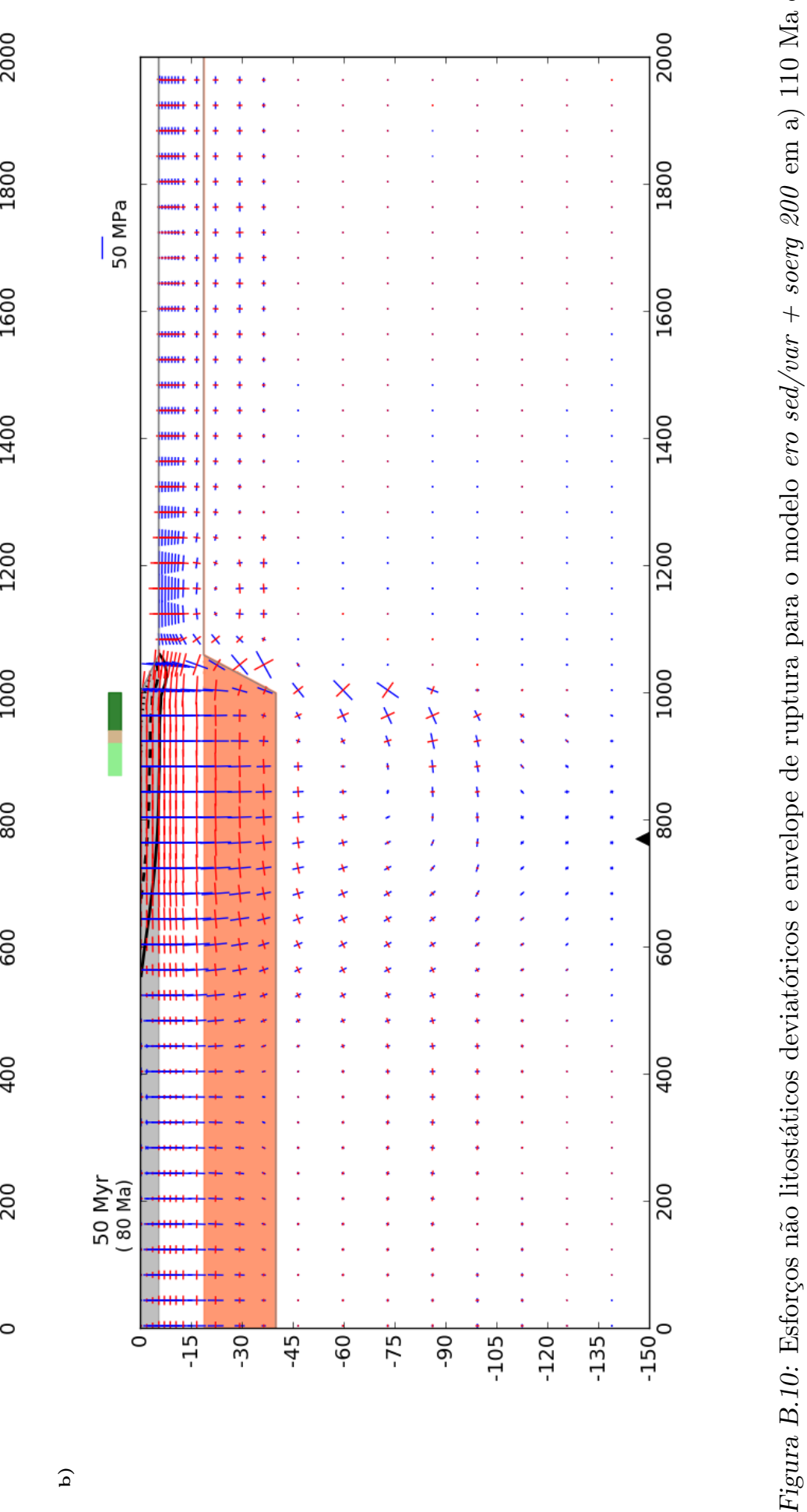


它岕灾 它

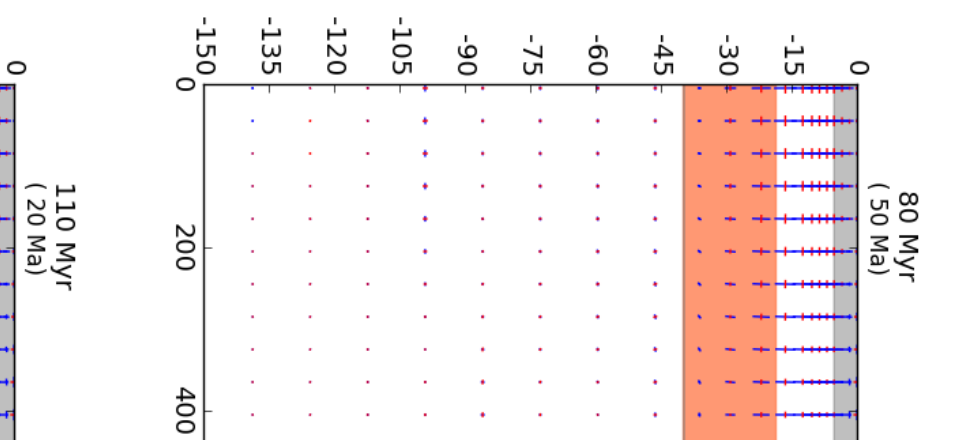

0
3
0
0
0
0
0
0
0
0
0
0
0
0
0
0
0
0
0
0
0
0
0
0

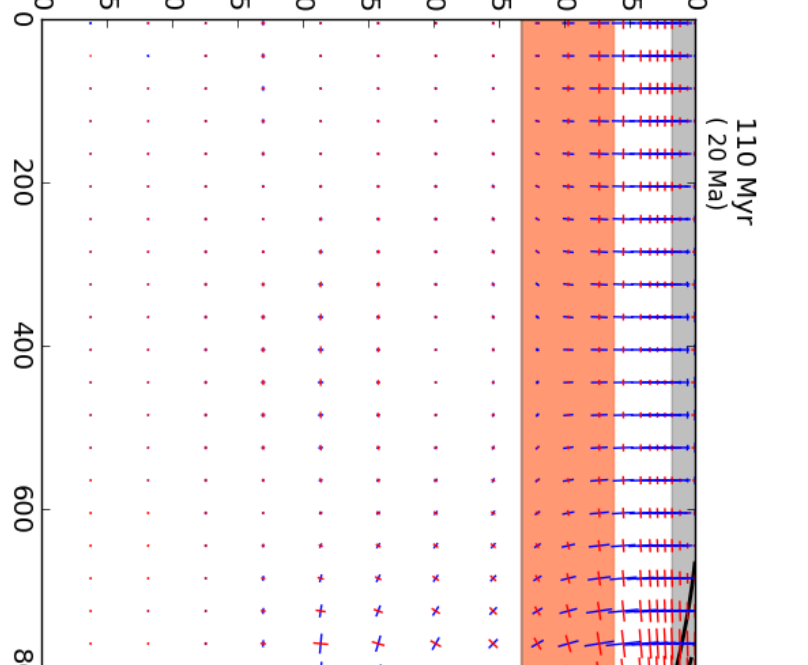

ㅇ

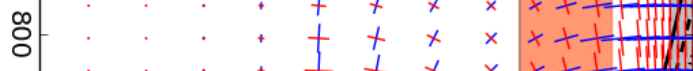

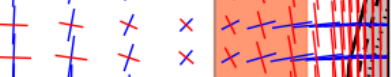

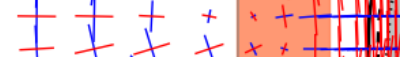
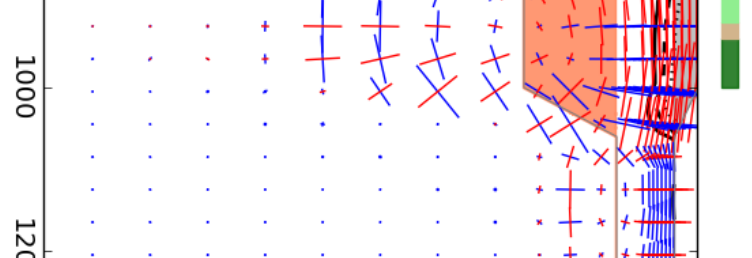

․ㅏㅇ.

+ + +mm

· + +mIntm

. . + +mm

萜

...

. + + + +

$+++$,

$\ldots++$,

ㅎํ요

$++\cdots$

$+++\ldots$

$+++\cdots$

。ั

$+++\cdots \cdot \cdots$

ज़
0
3
3
0

$\stackrel{\circ}{\circ}$

$\cdot+++$ m

- +++ +m!m

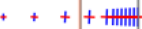

++++ mmm

เั

ㅇํㅇ

옹

$+x+$

t冊的

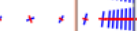

, $x \times$, tmm

, + + +m

$t,+++$ minl

$t+++$ 冊

เั.

- + + + m!n

응 


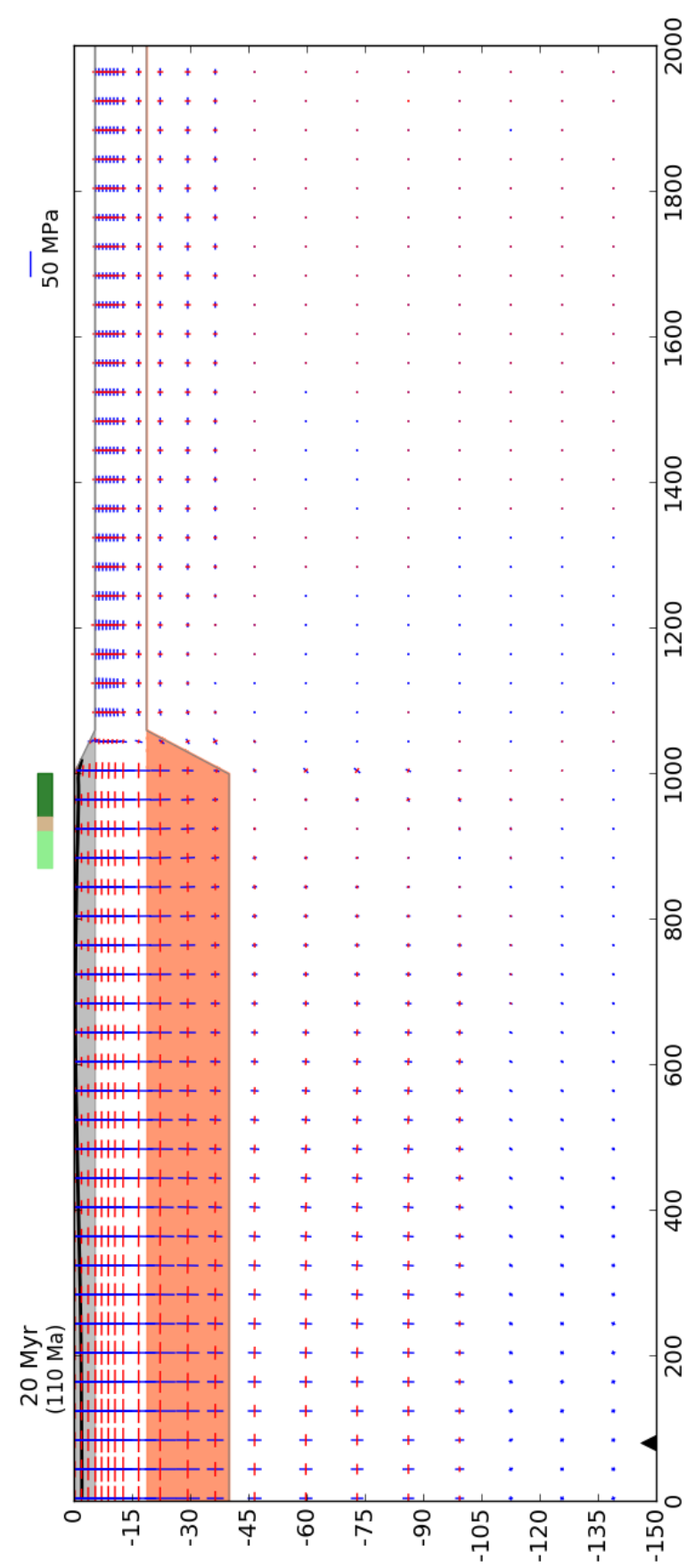

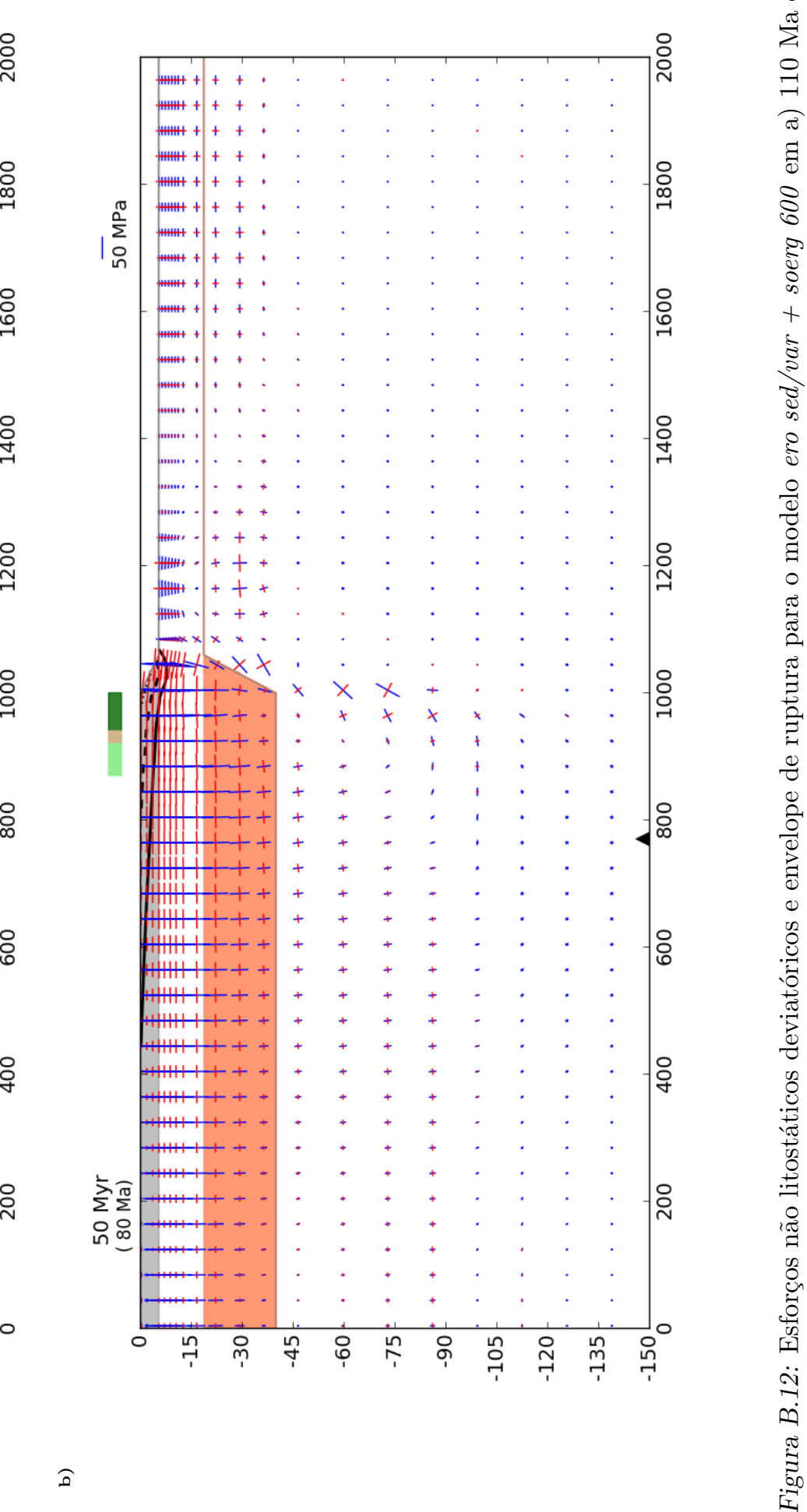




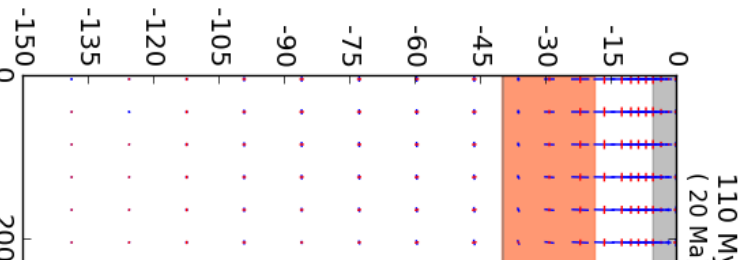

ธิ
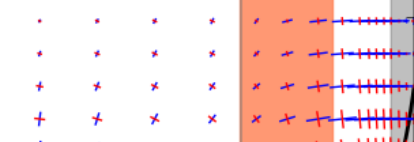
닌

암

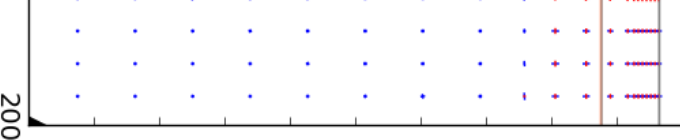



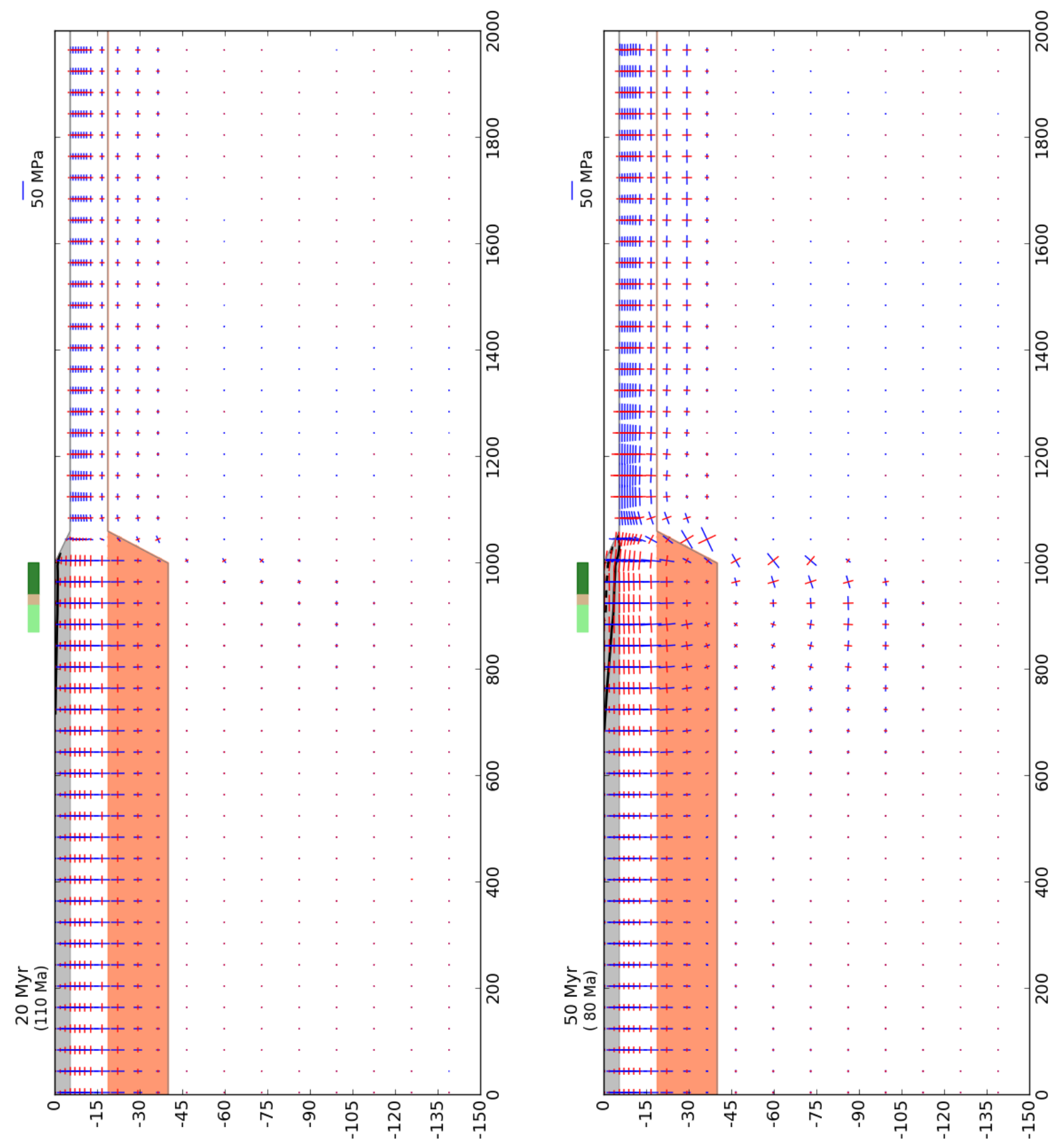

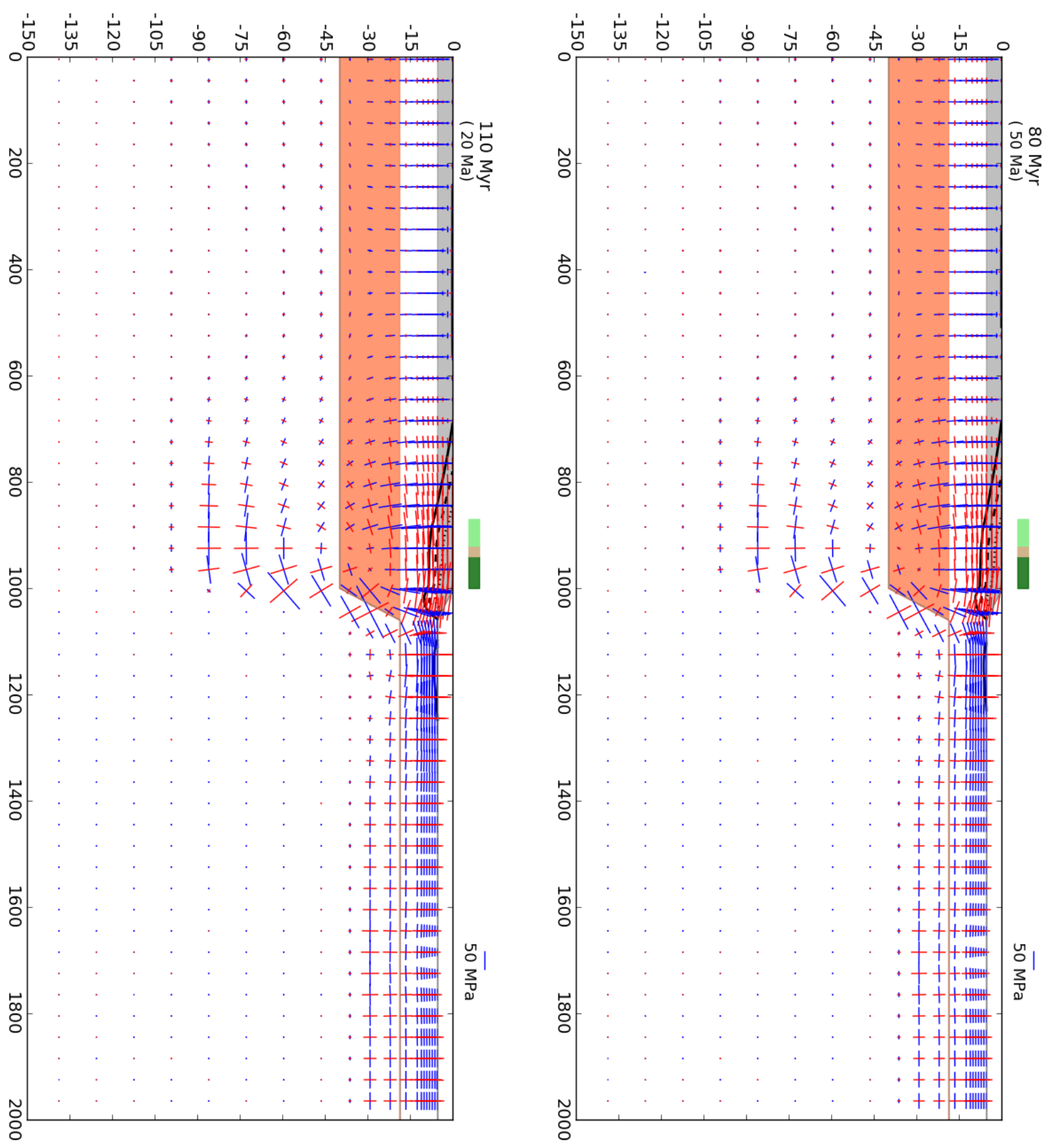

닌

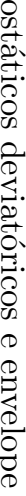

8
0
0
8
8
0
8
0
0
0

نี

앙

\&े 


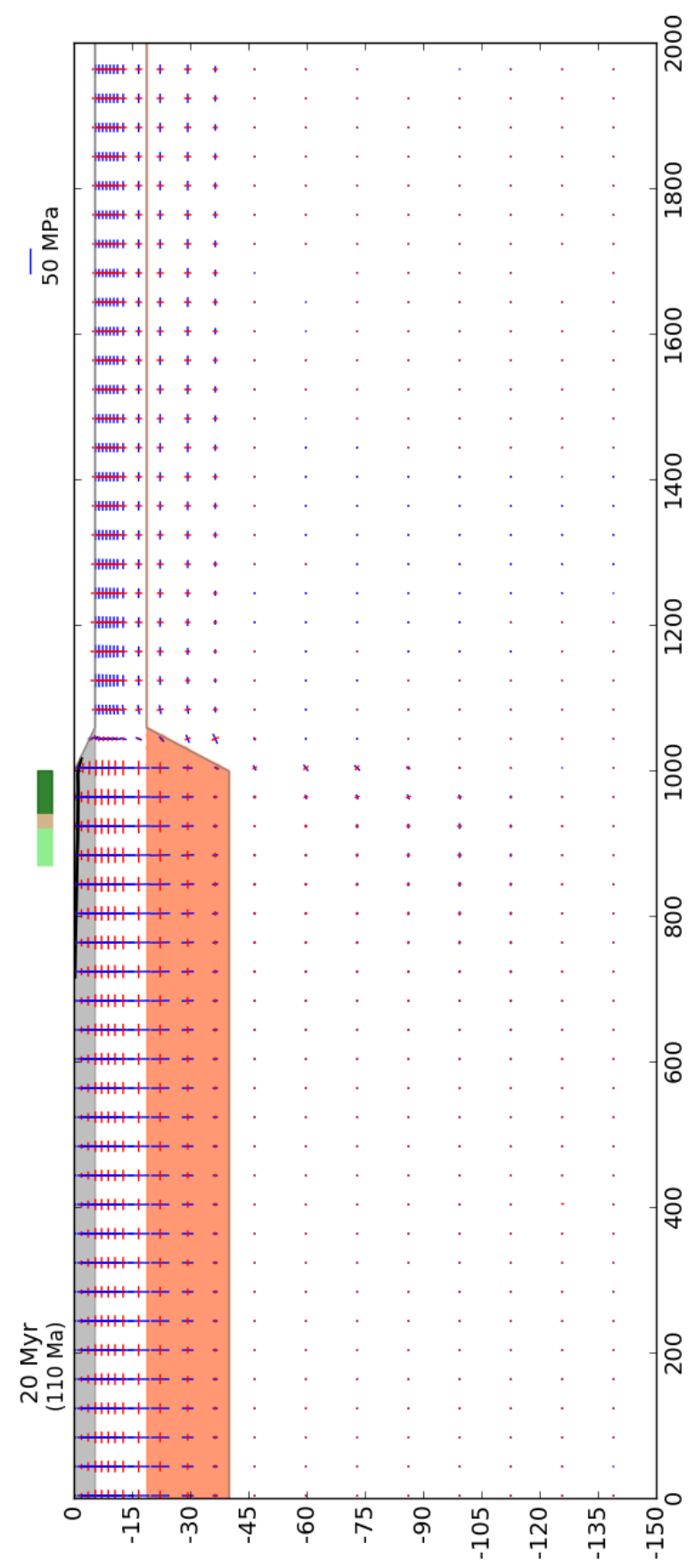

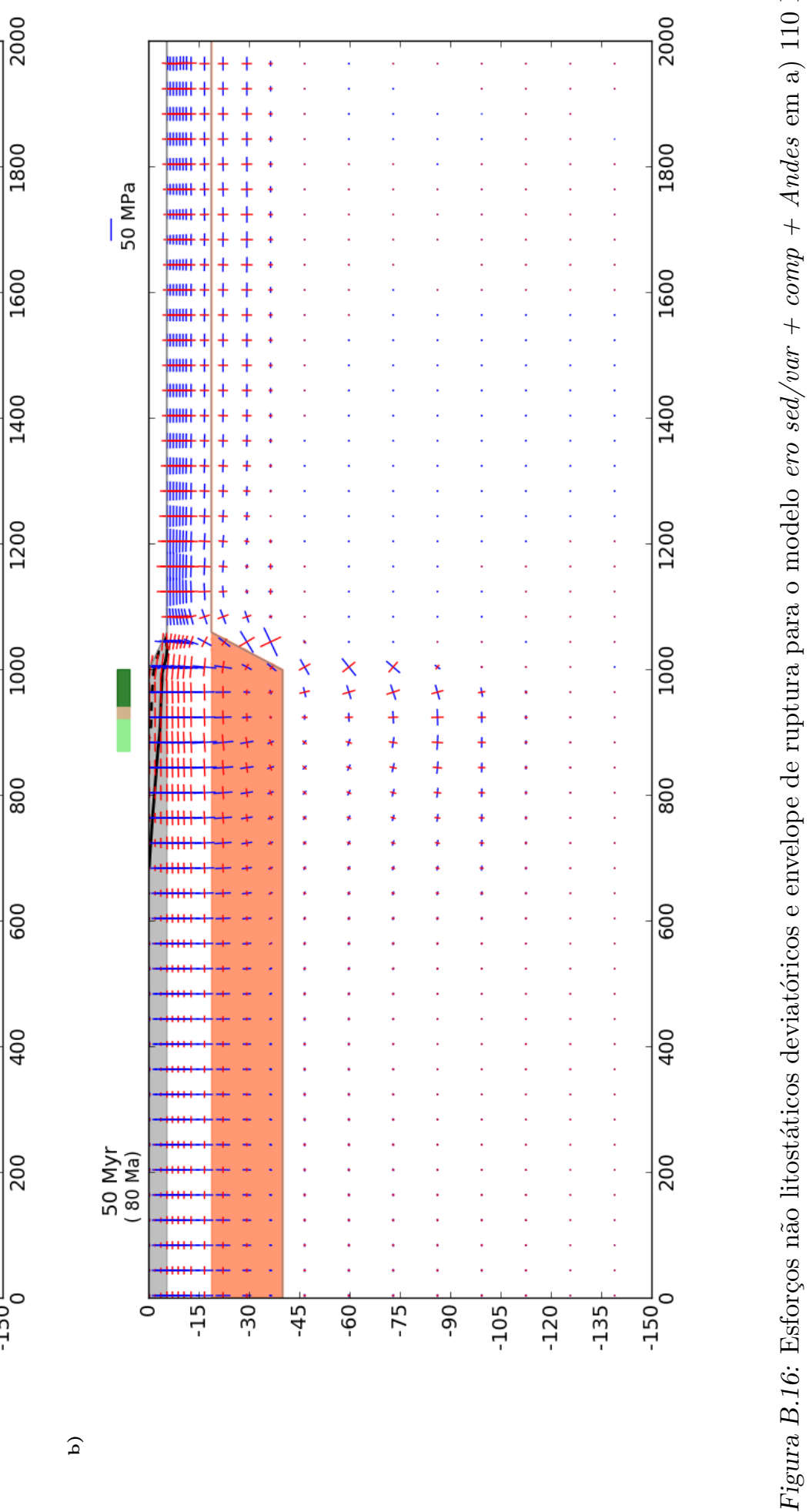



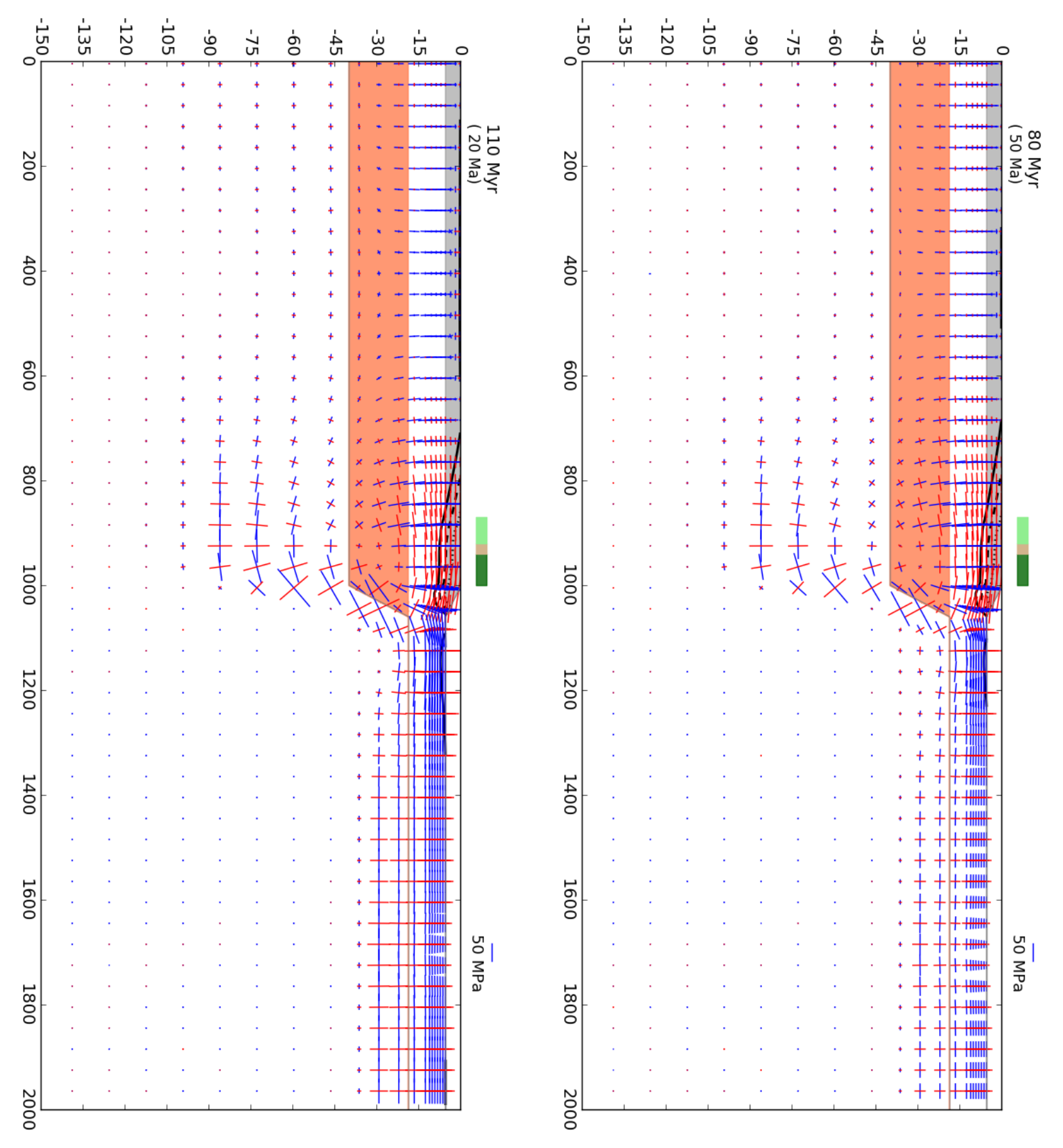

ธิ

하

아.

아.

๖े

층

$+++$

苑

-

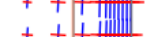

++ +曲组

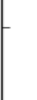

t + 十圇

- + + + 册少

홍-

. +++ +mm

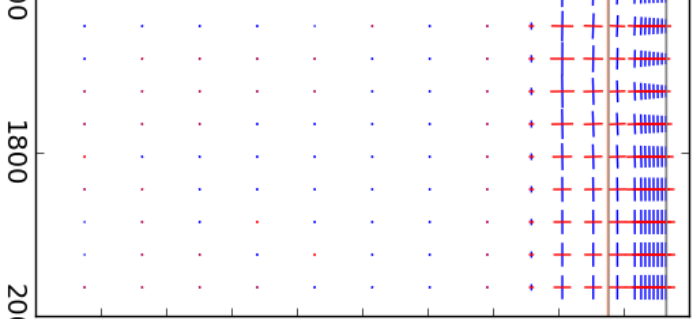

